\author{
Universidade de São Paulo \\ Instituto de Física
}

\title{
Modelo Atomístico para Transporte Eletrônico em Sistemas Orgânicos Desordenados
}

\author{
Járlesson Gama Amazonas
}

Orientadora: $\operatorname{Prof}^{a} \cdot \operatorname{Dr}^{a}$. Marília Junqueira Caldas

Tese de doutorado apresentada ao Instituto de Física para a obtenção do título de Doutor em Ciências.

Comissão examinadora:

$\operatorname{Prof}^{a}$. Dr ${ }^{a}$. Marília Junqueira Caldas (IFUSP)

$\operatorname{Prof}^{a}$. $\operatorname{Dr}^{a}$. Marcia Carvalho de Abreu Fantini (IFUSP)

$\operatorname{Prof}^{a}$. Dr ${ }^{a}$. Kaline Rabelo Coutinho (IFUSP)

Prof. Dr. José Arruda Freire (UFPR)

Prof. Dr. Osvaldo Novais de Oliveira Júnior (IFSC/USP)

São Paulo 
FICHA CATALOGRÁFICA

Preparada pelo Serviço de Biblioteca e Informação do Instituto de Física da Universidade de São Paulo

Amazonas, Járlesson Gama

Modelo atomístico para transporte eletrônico em

sistemas orgânicos desordenados - São Paulo, 2012.

Tese (Doutorado) - Universidade de São Paulo. Instituto de Física - Depto. de Física dos Materiais e Mecânica

Orientador: Profa. Dra. Marília Junqueira Caldas

Área de Concentração:

Polímeros Orgânicos Conjugados

Unitermos:

1. Polímeros Conjugados;

2. Estrutura Eletrônica;

3. Física Computacional;

4. Transporte Eletrônico em Sistemas Orgânicos.

USP/IF/SBI-047/2012 


\section{Agradecimentos}

À minha Orientadora, Professora $\mathrm{Dr}^{a}$. Marília Caldas pela oportunidade de sempre aprender e pelo valioso estímulo a pesquisa científica.

Aos amigos do grupo Nanomol, sempre alegres e ao mesmo tempo muito comprometidos com a pesquisa: Dr. Marcelo dos Santos, $\operatorname{Dr}^{a}$. Regina Lélis, Dr. Ronaldo Giro, Filipe Dalmatti, Francisco Nogueira, José Maximiano, Leonardo Jorge, Dr. Marcos Brown, Dr. Ney Sodré, Philipe Petersen, Rafael Rodrigues, Ricardo Igarashi, Dr. Sergio Urahata.

Pela parceria e valoroza colaboração, sou muito grato aos amigos $\operatorname{Dr}^{a}$. Melissa Pinto, Rodrigo Ramos e Dr. Tales da Silva que estiveram envolvidos mais diretamente neste trabalho.

Pela amizade "de outros tempos", mas que segue firme: Jeconias Rocha, Fábio Alex, Charles Rocha, Dr. Damião Meira, Dr. Joelson Cott, Dr. Rodrigo Amorim, Dr. Ferenc Kiss e Dr. Rolando Larico.

Pelas novas amizades: Samuel Silva, Evandro Tadeu e Michel Lacerda.

À Sandra Ribeiro pelo auxílio nas horas mais difíceis.

Pelo apoio incondicional dos meus familiares, em especial minha esposa Elcineide e meu filho Júnior, pela paciência e companheirismo.

Esta tese foi financiada pelas agências CAPES, INCT-INEO, FAPESP e contou com o apoio computacional do LCCA-USP. 


\section{Resumo}

Polímeros conjugados apresentam muitas propriedades interessantes para utilização como camada ativa em, por exemplo, dispositivos emissores de luz, e transistores de efeito de campo. Os processos na camada ativa são entretanto de difícil modelagem teórica, o que dificulta também o desenho de dispositivos. A dificuldade tem origem na morfologia do material: amorfo, composto de cadeias longas e possivelmente enoveladas, assim uma boa descrição estrutural é necessária para descrever o mecanismo de transporte eletrônico. Nos procedimentos mais comuns o transporte é simulado sem ligação clara com as características atomísticas do material em questão.

Neste trabalho optamos por modelar o transporte eletrônico em filmes poliméricos através de uma Equação Mestre Estocástica (EME) não linear utilizando a formulação de Bässler-MillerAbrahams para a taxa de transição eletrônica. Nossa modelagem porém inclui a simulação de filmes realísticos, a partir de modelos atomísticos construidos por Dinâmica Molecular Clássica (DMC), e a obtenção de todos os parâmetros necessários para escrever a taxa de transição a partir de cálculos quânticos de primeiros princípios. Para cada filme, foram selecionadas "imagens" no decorrer do tempo da DMC e para cada uma dessas, através de cálculos explícitos de ângulos e distâncias inter-sítios, construida a rede topológica de conectividades (com a respectiva taxa de transição). Para isto, foi necessária reparametrização do Campo de Forças Universal com respeito à interação não ligada de energia. Além disso, a partir de cálculos quânticos de primeiros princípios, para todos os parâmetros necessários para a EME: comprimento de conjugação, energias de sítio e integrais de transferência.

Estudamos sistemas oligoméricos de para-fenileno-vinileno (PPV), cristalinos e amorfos. Obtivemos a mobilidade de portadores para diferentes filmes de PV (cristal de $P_{5} V_{4}$, amorfos de $P_{3} V_{2}$ e $P_{26} V_{25}$ ), com várias imagens para um mesmo filme, representando o comportamento a uma determinada temperatura, e ainda com diferentes concentrações de portadores: vemos claramente a necessidade de obtenção de valores médios para todas as quantidades relevantes.

A metodologia proposta se mostrou capaz de incorporar o efeito das características morfológicas do material, e nossos resultados estão em boa concordância, qualitativa e quantitativamente, com resultados experimentais para sistemas símiles. 


\section{Abstract}

Organic conjugated polymers present several interesting properties and can be used as active layers in e.g. light emitting diodes and field effect transistors. The electronic properties in the active layer are however difficult to model theoretically, which makes it also a hard task to engineer the device. The difficulties come from the structural characteristics of the material: amorphous, but composed of long and possibly folded molecular chains, so that a sound description of the structural characteristics is needed for the understanding of the electronic transport. The usual procedures for theoretical simulation bear no clear or direct link with the atomistic characteristics of the given used material.

In this work we model the transport properties of polymer films through a non-linear Stochastic Master Equation, using the Bässler-Miller-Abrahams formulation for the electronic transition rate. Our modeling however includes the simulation of realistic films, from atomistic models built through Classical Molecular Dynamics (CMD), and extracting all the relevant parameters for the SME from ab initio quantum calculations for model systems. For each film, " images" were selected along the CMD time evolution and for each of them a connectivity network (with the corresponding transition rates) was built, from explicit calculations of inter-ring bond distances and bond angles.

To do that, it was needed a re-parametrization of the well-known Universal Force Field, concerning the non-bonded interactions. Furthermore, in parallel with the CMD work, also the values for the application of the SME were obtained from first-principles quantum calculations: conjugation length, site energies and transfer energies.

We studied para-phenylene vinylene PPV oligomeric films, in different situations: crystalline, and amorphous. We calculated hole mobilities for different PV films (crystalline $\mathrm{P}_{5} \mathrm{~V}_{4}$, amorphous $\mathrm{P}_{3} \mathrm{~V}_{2}$ and $\mathrm{P}_{26} \mathrm{~V}_{25}$ ) with several images for the same film, representing a given temperature, and also with different carrier concentrations. We clearly see the need of averaging obtained values for all relevant quantities.

The proposed methodology was shown to incorporate the effects of morphology, and our results are in good accord, qualitatively and quantitavely, with experimental results for similar systems. 


\section{Sumário}

1 Introdução 1

2 Modelamento de Transporte Eletrônico em filmes amorfos de PPV $\quad 8$

2.1 Equação Mestre . . . . . . . . . . . . . . . . . . . . . 9

2.2 Parâmetros Quânticos _. . . . . . . . . . . . . . . . 12

2.2.1 Resultados estruturais: $\mathrm{HF}$ e MP2 . . . . . . . . . . . . . . . . 13

2.2 .2 Resultados estruturais: DFT . . . . . . . . . . . . . . . . . . 19

2.2 .3 Definição de sítio e energia de sítio . . . . . . . . . . . . . . . 22

2.2.4 Conectividade e Integrais de Transferência Eletrônica . . . . . . . . . . 27

2.2.5 Cargas de Hirshfeld . . . . . . . . . . . . . . . . . . 34

3 Parametrização do Campo de Forças Universal 36

3.1 Campo de Forças Universal (UFF) . . . . . . . . . . . . . . . 37

3.2 Otimização de Geometria: Temperatura Nula . . . . . . . . . . . . . . . . 40

3.3 Evolução Temporal: Temperatura Não Nula . . . . . . . . . . . . . . . . . . . . 41

3.4 Verificação estrutural segundo o UFF . . . . . . . . . . . . . . . . . . . . . 42

3.5 Cristal de PPV $\pi$-stack . . . . . . . . . . . . . . . . . . . . 44

3.6 Cristal de PPV Herringbone . . . . . . . . . . . . . . . . . . . . . . 49

3.7 Reparametrização das energias não ligadas do UFF a partir de cálculos ab initio 53

4 Resultados: transporte em sistemas de fenileno-vinileno $\quad 60$

4.1 Sistema cristalino de $P_{5} V_{4} \ldots \ldots \ldots \ldots \ldots$. . . . . . . . . . . . . 60

4.2 Filme amorfo de $P_{3} V_{2} \ldots \ldots \ldots \ldots \ldots \ldots$ 
4.3 Sistema desordenado de $P_{26} V_{25} \ldots \ldots \ldots \ldots$. . . . . . . . . . . 68

5 Sumário e Conclusões $\quad 80$

Apêndices

A Detalhes de Cálculos Quânticos $\quad 83$

A.1 Bases locais . . . . . . . . . . . . . . . . . . . . . . . . 83

A.2 Ondas Planas . . . . . . . . . . . . . . . . . . . . . 84

A.3 Pseudopotencial . . . . . . . . . . . . . . . . . . . . . . . . 84

$\begin{array}{ll}\text { Referências } & 85\end{array}$ 


\section{Capítulo 1}

\section{Introdução}

Polímeros orgânicos conjugados têm várias propriedades interessantes, pois diferentemente dos polímeros saturados demonstram propriedades eletrônicas semicondutoras. Normalmente polímeros são usados como plásticos isolantes, mas a partir dos anos 70, com a descoberta da condução eletrônica em compostos específicos [1], ocorre uma crescente produção de sistemas poliméricos para integrar dispositivos, tornando a síntese, a caracterização e o estudo em geral de polímeros conjugados uma área de pesquisa de grande interesse. Alguns desses polímeros podem também apresentar a propriedade de emissão de luz [2], da injeção de carga por aplicação de campo elétrico externo, em estruturas do tipo diodo, ou a absorção de luz em faixas do visível. Assim, dentre as aplicações previstas para esses compostos estão o desenvolvimento de visores ativos de áreas grandes e flexíveis, além de materiais leves para conversão de energia solar. Estudos recentes mostram por exemplo a construção de células solares baseadas em compósitos de poli-para-fenileno de vinila (PPV, apresentado na Figura 1.1) e óxido de titânio como camada ativa. Para obter alta eficiência o ideal é ter uma rede bicontínua de componen-

tes doadores e aceitadores de elétrons e neste caso o PPV foi usado como doador de elétrons e transportador de buracos [3].

Sistemas como o PPV e derivados têm sido também usados em dispositivos eletroluminescentes, como elemento de camada ativa em diodo emissor de luz (Light Emitting Diode, LED) $[2,4,5]$ e em transistores de efeito de campo (Field Effect Transistor, FET) [6]. O modelamento e entendimento destes dispositvos está diretamente relacionado ao conhecimento do mecanismo de transporte de portadores de carga no interior do sistema orgânico [7], ou ainda, a funciona- 
lidade do dispositivo orgânico está altamente relacionada às particularidades da morfologia [8] e uma boa descrição é necessária para o bom conhecimento das propriedades de transporte.

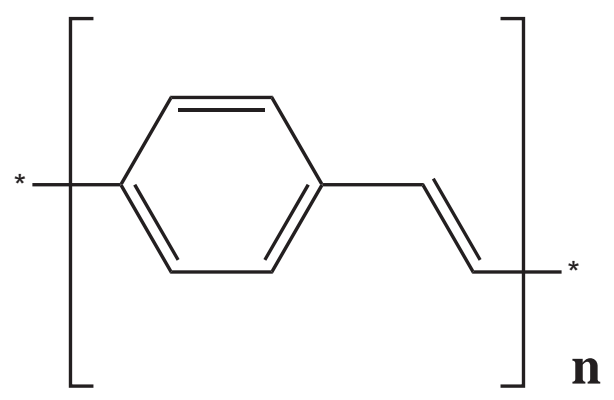

Figura 1.1: Representação de uma cadeia isolada de poli-para-fenileno vinileno (PPV).

O entendimento do transporte de cargas em polímeros é entretanto bastante mais complexo em relação a semicondutores convencionais. Filmes de polímeros são intrinsicamente desordenados, consistindo de nanoregiões cristalinas imersas em regiões amorfas. Nas regiões periódicas perfeitamente cristalinas podemos definir um vetor de onda $\vec{k}$ e neste caso, os elétrons são descritos por ondas caracterizadas por uma energia $E_{k}$. Esta função de onda representa uma função periódica com amplitude modulada por uma onda plana que reflete o efeito do potencial cristalino chamada função de Bloch [9]: o elétron é totalmente deslocalizado, ou seja, pode percorrer todo o material sem perder sua coerência quântica.

O conceito de funções de Bloch vem do tratamento quântico de sólidos convencionais, metais, isolantes ou semicondutores, nos quais as redes de ligações químicas conectam no limite todos os átomos do material. No caso dos cristais poliméricos temos um sistema intrinsicamente diferente, com duas ordens distintas de ligação - intracadeia e intercadeias - mas podemos começar a discussão de efeito de desordem a partir de trabalhos $[10,11]$ seminais sobre materias convencionais.

Em cristais convencionais sabemos que defeitos, impurezas e/ou fônons podem causar o espalhamento dos elétrons, limitando o "livre caminho médio" $L$ e gerando uma situação de desordem. Se o elétron for espalhado fortemente o vetor $\vec{k}$ não é um bom número quântico para descrever os autoestados e a densidade de estados (DOS) é muito diferente daquela obtida quando o material é cristalino. Um espalhamento ainda mais intenso acarreta em um menor livre caminho médio $L$ e uma grande mudança na DOS. Um novo fenômeno pode ocorrer com 

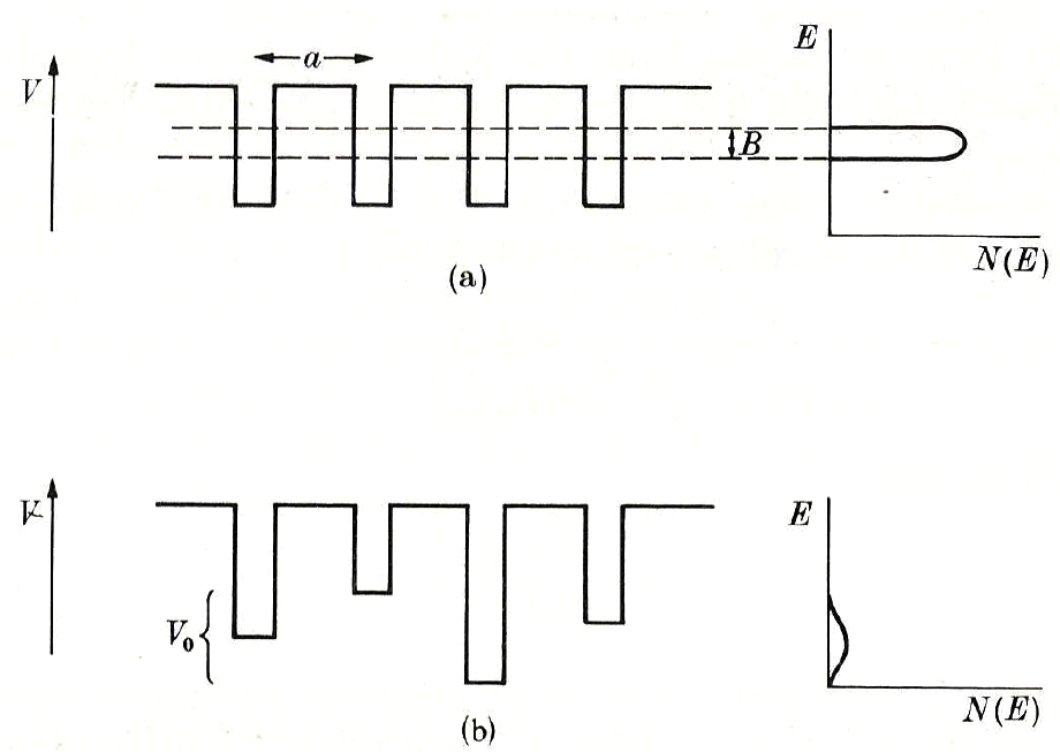

Figura 1.2: Potencial e DOS para sitemas cristalino e amorfo. Em um sistema cristalino (a) a profundidade e o espaçamento entre os poços é fixa devido ao arranjo periódico dos sítios, enquanto num sistema desordenado (b) tanto o espaçamento quanto a profundidade entre os poços é irregular. Figura extraída da referência [10].

a ausência das regiões cristalinas, de forma que cada autofunção é dita localizada, confinada a uma pequena região do espaço, caindo exponencialmente com a distância e com valores de energia quantizados. Este comportamento que resulta em uma DOS com todos os estados localizados é chamado de localização de Anderson [11].

Esse fenômeno é ilustrado na Figura 1.2, retirada da referência [10], que é muito interessante para o nosso caso particular de filme poliméricos. Nesta figura, a cada "sítio cristalino" (que pode no caso convencional representar um ou mais átomos) é assinalado um "poço de potencial" e a passagem entre eles é realizada por tunelamento.

Como veremos mais adiante, no caso de cadeias poliméricas o "sítio" será definido pela deslocalização eletrônica ao longo da cadeia, ou conjugação do segmento polimérico e a profundidade do poço é também definida pela mesma conjugação. Cada cadeia estará interagindo com outras em uma região amorfa e no interior destas regiões podem existir cadeias de diferentes comprimentos de conjugação.

No caso de polímeros aromáticos como o PPV, um dos fatores limitantes ao comprimento de conjugação é a torção entre anéis de fenil por influência, por exemplo, da agitação térmica 
[12] ou do método de crescimento/deposição do filme. Já a conexão ou tunelamento entre os poços pode ser visto em nosso caso como a deslocalização entre cadeias, uma vez que, como será visto também adiante, a transferência eletrônica dentro de uma mesma cadeia é, no mínimo, uma ordem de grandeza maior que aquela entre dois segmentos ou entre cadeias vizinhas. Em resumo, no nosso caso cada poço representa um segmento conjugado e a DOS pode também ser entendida como na Figura 1.2.

Assim, o mecanismo de transporte de portadores em sistemas orgânicos será entendido através de bandas de energia se o meio for cristalino, mas mesmo em um cristal a deslocalização eletrônica é menor e a largura de banda é pequena em comparação com semicondutores inorgânicos (em geral, alguns $k_{B} T$ à temperatura ambiente somente). Portanto, esperam-se valores de mobilidade em cristais moleculares no intervalo de $1-10 \mathrm{~cm}^{2} / V s$ [7], enquanto em materiais amorfos orgânicos são encontrados em geral valores de $10^{-5} \mathrm{~cm}^{2} / V s$.
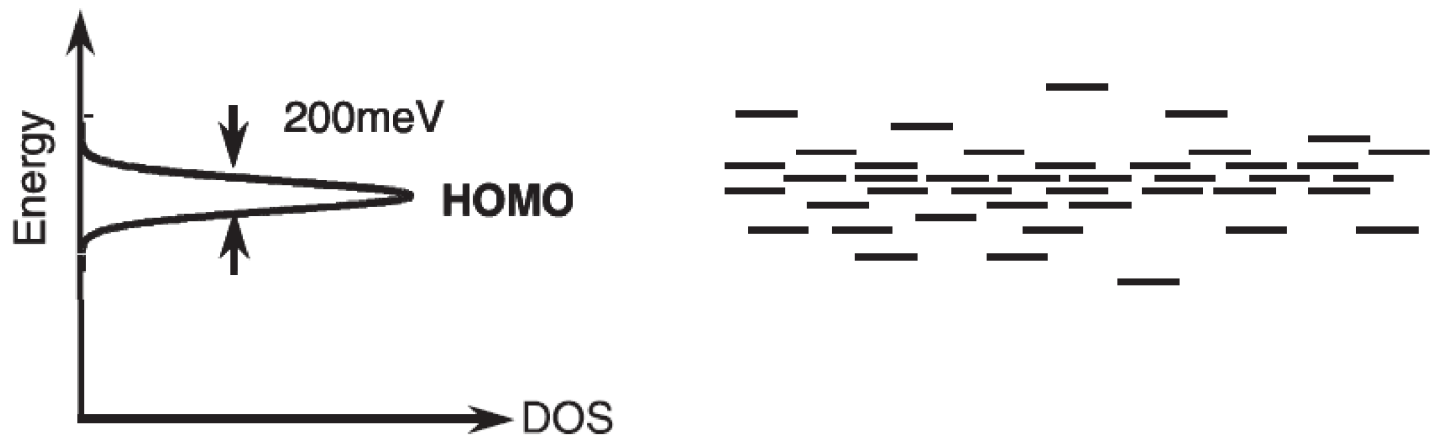

Figura 1.3: Representação da Densidade de Estados (DOS) gaussiana dos níveis ocupados para um filme amorfo. Figura adaptada da referência [7].

Sendo o meio desordenado, o transporte pode ser modelado por salto (hopping) entre sítios e na literatura teórica usualmente o sistema é descrito por uma desordem gaussiana (GDM) da energia de sítio e desordem aleatória de conectividade entre sítios, como proposto por Bässler [13]. Nesse caso, a densidade de estados (DOS) gaussiana tenta representar a distribuição energética dos sítios resultante da flutuação do comprimento de conjugação local [7, 13]. Os segmentos de uma cadeia do polímero, separados por defeitos topológicos, são identificados como sítios cujas energias estão sujeitas a uma distribuição gaussiana de energias, implicando que todos os estados são localizados. Para os níveis HOMO (highest occupied molecular orbital) 
a DOS gaussiana está representada na figura 1.3.

Juntamente com modelo GDM, Bässler [13] usou a taxa de hopping assimétrica na qual a probabilidade de salto de um sítio a outro pode depender do sentido do salto e evolução temporal para os portadores obtida através do método Monte Carlo. Diferentemente, Yu e colaboradores $[14,15]$ usaram um modelo de desordem correlacionada (CDM), taxa de hopping simétrica [16] e evolução temporal de portadores realizada através de uma Equação Mestre.

É interessante notar que para a descrição da mobilidade para LEDs, com baixa densidade de portadores de carga, pode-se muitas vezes usar uma DOS gaussiana, enquanto para a descrição da mobilidade em FETs, com alta densidade de portadores, pode ser usada uma DOS exponencial [7]. Em particular, aqui no grupo Nanomol, a estrutura eletrônica de longas cadeias isoladas de para-fenilenos foi investigada e, neste caso, o efeito da desordem da torção dos anéis sob ação da temperatura reflete uma DOS não gaussiana [12].

Trabalhos mais recentes têm usado metodologias atomísticas que combinam Dinâmica Molecular para gerar as estruturas, enquanto a dinâmica de cargas é obtida através de Métodos Monte Carlo [17] ou usando a Equação Mestre [18]. Segundo estudo de Yu e colaboradores [14], a Equação Mestre apresenta diversas vantagens quando comparada ao método Monte Carlo por garantir solução estacionária, considerar efeitos dependentes da densidade e ser numericamente mais eficiente. Essa foi também a conclusão do trabalho de Mestrado de Marcelo Garcia [19] no nosso grupo.

Como anteriormente discutido, a mobilidade depende fortemente do grau de ordem e pureza em semicondutores orgânicos e, portanto, em grande parte da preparação e condições de crescimento. Desse modo, o estudo da morfologia do filme é de extrema importância e de fato nos servirá como base para aplicações de métodos estatísticos de transporte de carga no filme orgânico.

Neste tabalho, propomos um procedimento para estudo de transporte eletrônico em filmes de polímeros conjugados, partindo de um enfoque atomístico e utilizando parâmetros extraídos de cálculos quânticos específicos para o composto a ser estudado. Uma visão geral do procedimento é ilustrada na figura 1.4. O estudo inicia pela simulação atomística da morfologia do filme, realizada através de Dinâmica Molecular Clássica, da qual retiramos uma série de configurações (imagens) representativas de uma dada temperatura. Para cada imagem realizamos a análise 


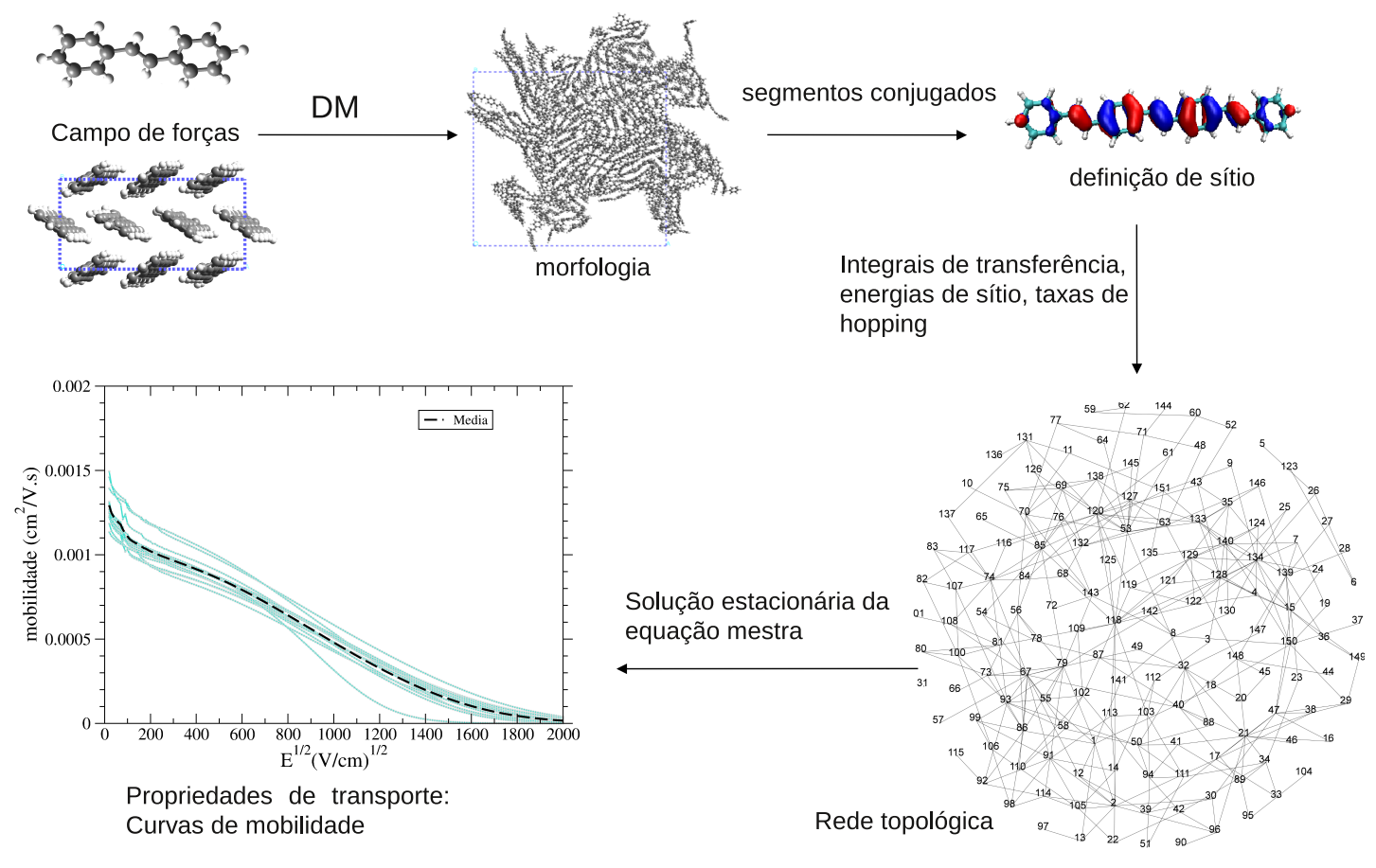

Figura 1.4: Modelamento Atomístico para transporte eletrônico.

morfológica, com a identificação dos sítios eletrônicos e a resultante rede de conectividade entre sítios (topológica). Com essa rede em mãos passamos à solução da Equação Mestre correspondente, para diversos valores de campo e de concentração de portadores, e obtemos o comportamento da mobilidade. Finalmente, obtemos o resultado como a média de várias imagens. Nossa proposta tem de especial o fato de termos escolhido todos os parâmetros envolvidos a partir de cálculos quânticos, realizados em formalismos Hartree-Fock ou, na maior parte, de Teoria do Funcional da Densidade, para sistemas modelo de PPV ou de oligômeros de PV.

Nossa definição de "comprimento de sítio", ou conjugação, tem caráter atomístico, e está relacionada a cálculos quânticos de delocalização orbital em função da torção entre anéis primeiros vizinhos. De modo a aproximar os valores a cada comprimento de conjugação, que chamaremos de energias de sítio, focalizamos aqui proriedades eletrônicas de oligômeros de fenileno-vinileno com cadeias de diferentes tamanhos. As energias de sítio a serem usadas na taxa de hopping 
foram calculadas usando teoria de perturbação de muitos corpos $(G W)$ para pequenas cadeias isoladas de fenileno vinileno [20], enquanto as taxas de hopping são obtidas através do cálculo de integrais de transferência [21, 22] entre sítios, obtidas usando cálculos ab initio DFT em cristais de PPV.

No capítulo 2 descrevemos a metodologia utilizada, a partir da Equação Mestre, e brevemente as metodologias quânticas. Apresentamos os resultados quânticos obtidos para oligômeros isolados e cristais, considerados para definição do comprimento de sítio, da energia e da transferência eletrônica entre sítios que serão usados para o cálculo de transporte de portadores nos filmes desordenados, e, ainda, da carga atômica e interação de dispersão, parâmetros para descrição da interação entre cadeias na DMC.

Cálculos de Mecânica e Dinâmica Molecular Clássica (MMC/DMC) têm exercido um papel fundamental na determinação da estrutura polimérica e na estimativa e explicação de suas propriedades. No caso específico de filmes amorfos, é muito importante que a descrição de interações intermoleculares sejam bem descritas, em especial propriedades elásticas. Descrevemos no capítulo 3 o procedimento de obtenção de parâmetros geométricos, e a formação de filmes amorfos de PVs por DMC para sistemas com milhares de átomos. Verificamos que o campo de forças padrão Universal Force Field (UFF) [23] é muito conveniente para a descrição de sistemas isolados, mas apresenta problemas quanto à descrição dos sistemas cristalinos 3D de fenil-vinil e fenil-fenil. Como os parâmetros de cadeia isolada são bem descritos, a má descrição para os filmes deve estar relacionada à parametrização da interação não-ligada $\left(E_{N L}\right)$ entre cadeias, descritas em termos de interações de van der Waals e de Coulomb: Nossa escolha, como mencionamos acima, foi trazer de cálculos quânticos ab initio DFT os parâmetros necessários. Descrevemos assim os procedimentos para obtenção de uma melhor descrição dos sistemas ordenados, PPV e oligômeros, que nos permitirá obter também uma melhor descrição dos filmes amorfos.

Finalmente, no capítulo 4 apresentamos nossos resultados para filmes de PPV, simulados a partir de cadeias longas (26 anéis de fenil). Os valores e o comportamento obtidos para a mobilidade de buracos apresentam boa concordância, em termos qualitativos e quantitativos, com resultados experimentais relevantes, e demonstram a validade do procedimento proposto. 


\section{Capítulo 2}

\section{Modelamento de Transporte Eletrônico em filmes amorfos de PPV}

A mobilidade $\mu$ dos portadores em um meio material é definida pela razão entre o campo elétrico externo aplicado $(E)$ e a velocidade resultante média $(v)$ dos portadores que participam da corrente elétrica, conforme mostra a equação 2.1 .

$$
\mu=\frac{v}{E}
$$

O grau de desordem estrutural pode alterar significativamente a mobilidade dos portadores no polímero [7], assim é comum encontrar na literatura valores muito diferentes de mobilidade para um mesmo polímero, na medida em que a desordem afeta o campo elétrico local devido ao arranjo supramolecular, influencia diretamente a quebra de conjugação dos estados eletrônicos, bem como induz à ocorrência da localização de carga e dá origem aos chamados 'traps' - que atuam como armadilhas de carga.

O modelo teórico para o tratamento da condução de portadores nestes sistemas é o transporte do tipo hopping, em que os portadores tunelam entre estados localizados, sendo ajudados no processo pela energia térmica e por meio da atuação, por exemplo, de campo elétrico externo.

Como dito na Introdução, aqui simularemos o transporte de portadores através de Equação Mestre, que detalharemos a seguir; na sequência, descrevemos a metodologia utilizada para a obtenção dos parâmetros que entram na sua resolução. 


\subsection{Equação Mestre}

A Equação Mestre Não Linear $2.2[24,25]$ é utilizada para determinar a evolução temporal da probabilidade, $P_{i}$, de ocupação de cada sítio $i$, entre os quais transitam os portadores de carga. Cada sítio tem sua posição no espaço bem definida, de modo que, determinada que a taxa com que ocorrem os saltos dos portadores, seja diretamente determinado o fluxo de portadores no interior do material.

A taxa de variação temporal $\frac{d}{d t} P_{i}(t)$ da probabilidade de ocupação do sítio $i$ é dada em termos das taxas: de chegada de portadores (positiva) vindos dos demais sítios $j$ conectados ao sítio $i$, modelada por $\left\{\sum_{j}^{N} w_{i j} P_{j}\left(1-P_{i}\right)\right\}$, e de saída de portadores (negativa) para os sítios $j$ conectados ao sítio $i$. Assim:

$$
\frac{d}{d t} P_{i}(t)=\sum_{j}^{N}\left[w_{i j} P_{j}\left(1-P_{i}\right)-w_{j i} P_{i}\left(1-P_{j}\right)\right]
$$

onde $w_{i j}$ é a taxa (temporal) de transição para o salto (hopping) do sítio $j$ para o sítio $i$, e será discutida mais adiante (depende de características eletrônicas locais, do campo elétrico externo aplicado, e da temperatura); os termos $\left(1-P_{j(i)}\right)$ inserem no modelo o princípio da exclusão de Pauli. A solução estacionária da Equação Mestra é obtida com a condição:

$$
\frac{d P_{i}(t)}{d t}=0
$$

Dessa forma, reagrupando os termos e resolvendo para $P_{i}$, vem

$$
\begin{gathered}
\sum_{j} w_{i j} P_{j}=P_{i}\left\{\sum_{j} w_{j i}+\sum_{j}\left(w_{i j}-w_{j i}\right) P_{j}\right\} \\
P_{i}=\frac{\sum_{j} w_{i j} P_{j}}{\sum_{k} w_{k i}}\left\{1-\frac{\sum_{j}\left(w_{j i}-w_{i j}\right) P_{j}}{\sum_{k} w_{k i}}\right\}^{-1}
\end{gathered}
$$

Assim, com a eq. 2.5, a probabilidade de ocupação para cada sítio $i, P_{i}$ pode ser calculada autoconsistentemente sobre toda a rede, para cada valor de campo elétrico aplicado $\vec{E}$, a partir de uma ocupação inicial qua se admite uniforme e definida a partir de uma concentração de portadores desejada. Após convergida a probabilidade de ocupação de cada sítio, a velocidade 
dos portadores em relação ao campo pode ser calculada por meio da equação 2.6 , onde $\hat{E}$ é o versor do campo elétrico

$$
v=\frac{1}{N} \sum_{i}\left[\sum_{j} w_{i j} P_{i}\left(1-P_{j}\right)\left(\hat{E} \cdot R \hat{r}_{i j}\right)\right]
$$

onde se inclui, portanto, o movimento contra e a favor ao campo de modo a constituir a velocidade efetiva dos portadores na rede.

Dentre os modelos para $w_{i j}$ mais conhecidos estão os de Marcus [26], de Miller-Abrahams [27] e a taxa de hopping simétrica [16]. Neste trabalho utilizamos o modelo de Miller-Abrahams segundo a proposta de Bässler [13], descrita a seguir.

Seja $\Delta E_{i j}$ a energia da transição do portador do sítio $j$ para o sítio $i$, dada por:

$$
\Delta E_{i j}=\left(\epsilon_{i}-\epsilon j\right)-e \mathbf{E} \cdot \mathbf{R}_{i j}
$$

onde $\epsilon_{i(j)}$ consiste da energia do estado localizado no sítio $i(j)$ (energia de sítio), e é a carga do portador (buraco), E é o campo elétrico local e $\mathbf{R}_{i j}$ o vetor distância que vai do sítio $j$ ao sítio $i$. Desta forma, a barreira a campo nulo a ser superada pelo portador é dada pelas energias de sítio, enquanto $-e \mathbf{E} \cdot \mathbf{R}_{i j}<0$ se o campo aponta na direção que vai de $j$ para $i$, reduzindo a barreira (caso $\left.\epsilon_{i}>\epsilon j\right)$.

$\mathrm{Na}$ proposta de Bässler-Miller-Abrahams $w_{i j}$ assume a forma:

$$
\omega_{j i}=w_{0} e^{-\Gamma_{i j} \mathbf{R}_{i j} / a}\left\{\begin{array}{l}
\exp \left(-\beta \Delta E_{i j}\right), \text { se } \Delta E_{i j}>0 \\
1, \text { se } \Delta E_{i j}<0
\end{array}\right.
$$

sendo $\beta=1 / k_{B} T$. Nessa equação, $w_{0}$ é um "pré-fator" e a exponencial em $\Gamma_{i j} R_{i j} / a$ representa a sobreposição de funções de onda entre estados de portador nos sítios $i$ e $j$. Fazemos notar que nessa proposta está implícita a escolha de modelo de transporte por hopping contra o modelo de "small-polaron". Entre um modelo e outro, conforme discutido por Bässler, está a importância relativa entre a energia de deformação intracadeia e a energia de interação cadeia-cadeia. Na forma Bässler-Miller-Abrahams a energia de ativação térmica está totalmente contida no termo assimétrico, enquanto no primeiro termo temos a interação eletrônica.

Essa escolha (muito diferente da presente no modelo de Marcus [26]) é justificada [13] pela magnitude muito pequena da energia de ligação polarônica em cristais de naftaleno - onde 
poderíamos ter uma contribuição significativa. Conforme discutido por Ferretti e colaboradores [21] em cristais de PPV essa contribuição também pode ser, em primeira ordem, desprezada dada a diferença muito grande entre a mobilidade inter e intracadeia. No nosso caso, tratando de um sistema amorfo com cadeias finitas, a aproximação poderia ser mais grave: entretanto ainda neste caso cada "sítio" é preso ao restante da cadeia, como veremos a seguir, e novamente o efeito polarônico não tem a mesma magnitude que para oligômeros curtos livres. Portanto, nossa definição da taxa de transferência seguirá estritamente a proposta Bässler-Miller-Abrahams, e discutiremos na seção 2.2.4 como quantificar o termo de transferência eletrônica entre sítios.

Neste ponto, destacamos apenas que podemos associar essa taxa a um sistema de dois estados $(i, j)$, ou dois níveis, acoplados por um hamiltoniano de interação, que escrevemos através do termo não diagonal $H_{i j}$. Nesse hamiltoniano em princípio está incluído todo efeito do ambiente. Podemos agora utilizar a equação de Schroedinger na sua forma dependente do tempo $\mathscr{H} \Psi(t)=i \hbar \delta \Psi(t) / \delta t$ e chegaremos a forma final para a taxa de transferência, com substituição

$$
w_{0} e^{-\Gamma_{i j} R_{i j} / a} \longrightarrow \hbar^{-1} E_{i j}
$$

em que $E_{i j}$ é a integal de transferência que será descrita na seção 2.2.4.

Continuando, com relação ao termo assimétrico (desordem energética), é interessante comentar (como na referência [13]) que admite-se um acoplamento elétron-fônon fraco o suficiente para que possamos desprezar os efeitos polarônicos, mas forte o suficiente para garantir o acoplamento no banho térmico.

Uma vez que tenhamos a morfologia de um filme-modelo, gerado como comentaremos adiante, podemos em primeiro lugar, com o cálculo de ângulos entre anéis para cada cadeia, determinar o tamanho do segmento conjugado (sítio) e a posição média de cada sítio e definir a energia de sítio; devemos a seguir dada a distância vetorial entre cada dois sítios e a orientação relativa dos segmentos conjugados, obter o valor da correspondente interação eletrônica. A partir daí, teremos o filme descrito por uma rede de conectividade entre sítios.

Ainda com respeito à rede de conectividades, a interação eletrônica é calculada para cada dois "meros" ou anéis de cada sítio. Tomamos como sendo o canal de transporte entre dois sítios aquele que tem o maior valor do acoplamento entre anéis, do sítio $i$, e do sítio $j$, assumindo, 
então, o vetor da conexão como sendo aquele que une os anéis escolhidos.

As simulações são, desta forma, dependentes dos parâmetros: rede de conectividade (número e conexões entre sítios) concentração de portadores, temperatura $(T)$ e campo elétrico $(\mathbf{E})$ aplicado sobre o sistema. As propriedades morfológicas locais do filme afetam os parâmetros intrínsecos do material: taxas de hopping, energias de sítio, conectividade (topologia), posições relativas entre os sítios $\left(\mathbf{R}_{i j}\right)$.

O modelamento atomístico de transporte eletrônico, em sistemas complexos e desordenados como filmes de polímeros, envolveu o desenvolvimento do tratamento a ser adotado, uma vez que não existe até esta data um procedimento padrão. Como descrito acima, necessitamos parâmetros estruturais para a definição do comprimento de conjugação, e portanto definição do "sítio" em si - uma vez que o filme tenha sido gerado, por cálculo de DMC; entretanto, necessitamos também de parâmetros confiáveis para a geração do filme, ou seja, obtenção de energias não-ligadas de Coulomb e dispersão (ou van der Waals). Além disso, também o processo de migração de cargas ou hopping depende de parametrização. No nosso modelamento, todos esses dados são retirados de cálculos quânticos. Descrevemos aqui a metodologia que utilizamos para obtenção destes parâmetros, sempre a partir de cálculos quânticos de primeiros princípios. No caso da formulação de DMC descrevemos no próximo capítulo o campo de forças sobre o qual apoiamos nosso modelamento, o campo de forças Universal, e detalhamos como é feita a inserção de parâmetros nesse campo.

\subsection{Parâmetros Quânticos}

No interior de filmes orgânicos podem existir cadeias de polímeros em diferentes configurações, afetando principalmente a torção dos anéis de fenil [28] que atua como limitante para a delocalização eletrônica ao longo da cadeia, o comprimento de conjugação. Além disso, particularmente para o PPV existem estudos, tanto experimentais [29, 30, 31] quanto teóricos $[32,33,34,35,36,37]$ apresentando diferentes resultados relacionados à planaridade das cadeias. Segundo Chen et al. [31] os anéis de fenil vizinhos do trans-PPV estão no mesmo plano, entretanto, o ângulo diedral entre o anel de fenil e o segmento vinil fica em torno de $10^{\circ}$. Cálculos teóricos para uma cadeia infinita e isolada de PPV foram realizados com ângulos de 
torção fixos para se obter as energias de diferentes conformações e os resultados sugerem que o estado fundamental do PPV tem uma configuração planar [35, 36]. De fato, o desvio observado da planaridade é para um cristal e não para uma cadeia isolada e como a diferença de energia entre as conformações planar e não planar para a cadeia isolada já é muito pequena torna-se difícil confirmar uma torção para o PPV [35].

Trabalharemos aqui com cadeias finitas pequenas, uma vez que nosso objetivo é modelamento para uso em DMC. Ainda, como discutido em vários trabalhos [35, 36] a conformação das cadeias, tanto isoladas como no meio cristalino ou amorfo, depende em parte da estabilização energética adquirida por conjugação $\pi$, e em parte de atração/repulsão eletrostática entre segmentos não diretamente ligados: por exemplo, repulsão entre átomos de hidrogênio. Nesse caso, é interessante o conceito de "carga do átomo na molécula", de definição fexível e controversa, mas indispensável para o modelamento por DMC. Assim, descrevemos também o modelo de Hirshfeld aqui adotado.

Uma vez definidos os sítios passamos ao modelamento da transferência eletrônica entre dois sítios vizinhos através da integral transferência $E_{i j}$ relacionada à facilidade com que um portador de carga pode tunelar entre duas moléculas vizinhas. No caso de filmes de aromáticos em que temos interesse, uma das propriedades estruturais mais importantes para o transporte por "hopping" entre duas cadeias orgânicas está relacionada à distância entre os eixos das cadeias, e o ângulo intermolecular. Como veremos podemos calcular as integrais de transferência entre cadeias usando o formalismo tight binding (TB) a partir de cálculos ab initio de estrutura de bandas. Para o cálculo das $E_{i j}$ seguiremos a metodologia adotada por Ferretti et al. [21, 22], descrita na seção 2.2.4.

\subsubsection{Resultados estruturais: HF e MP2}

Iniciamos descrevemos o procedimento de Campo Auto Consistente de Hartree-Fock (HF). Neste caso, considerando uma função de onda total descrita pelo determinate de Slater, determinamos o mínimo de energia usando o princípio variacional. Assim podemos derivar as equações de Hartree-Fock HF (equação 2.10) na qual o primeiro termo é o hamiltoniano monoeletrônico, o segundo a energia de Coulomb e o terceiro o operador de Troca. Nesta equação, $\epsilon_{i}$ é o autovalor de energia relacionado orbital molecular $\varphi_{i}$ do $i$-ésimo estado eletrônico. 


$$
\hat{F} \varphi_{i}=\left\{h(i)+\sum_{l=1}^{N}\left[J_{l}(i)-K_{l}(i)\right]\right\} \varphi_{i}=\epsilon_{i} \varphi_{i}
$$

Em geral, os obitais moleculares $\varphi_{i}$ são escritos como uma combinação linear de orbitais atômicos:

$$
\varphi_{i}=\sum_{p} \chi_{p} C_{p i}
$$

onde $\chi_{p}$ representa o p-ésimo orbital atômico. Entretanto, resultados contraditórios relacionados à planaridade de cadeias isoladas de PV têm mostrado que, a nível teórico, a energia de correlação eletrônica pode ser necessária para uma correta descrição estrutural. Como a energia total calculada através do método HF não leva em conta a energia de correlação dos elétrons, partimos para formas alternativas de inclusão de correlação como o método perturbativo descrito a seguir.

Segundo a Teoria de Perturbação de Møller-Plesset de segunda ordem (MP2), conhecido autovalor não perturbado $E_{0}^{(0)}$ podemos obter a correção de segunda ordem para energia $E^{(2)}$, em termos dos autoestados não perturbados $\varphi_{0}^{(0)}$ por influência da perturbação $\hat{V}$.

$$
E^{(2)}=\sum_{n \neq 0} \frac{\left|\left\langle\varphi_{0}^{(0)}|V| \varphi_{n}^{(0)}\right\rangle\right|^{2}}{E_{0}^{(0)}-E_{n}^{(0)}}
$$

É comum encontrarmos na literatura resultados diversos que parecem depender do tipo de conjunto de base utilizado. Assim, descrevemos a seguir as bases locais 6-31G(d,p) e a aug-cc-pVDZ que utilizamos neste trabalho.

O conjunto base mais simples ocorre quando cada orbital atômico é representado por um único orbital do tipo de Slater (STO), com um único expoente zeta. A fim de melhorar o conjunto base mínima, podemos usar duas funções para cada orbital atômico - conjunto de base zeta duplicada.

Além disso, pode-se duplicar apenas as orbitais de valência e manter uma única função para cada função de camada interna. Portanto, 6-31G conjunto de base implica que cada camada interna representado por uma função de base única é uma contração de 6 gaussianas primitivas, enquanto que a orbital de valência é dividido em função interna contraída de 3 gaussianas primitivas e função externa contraída de 1 gaussiana primitiva. Ao adicionar funções 
de polarização para conjunto de base 6-31G, a adição de funções tipo $p$ para hidrogênio e tipo $d$ para o carbono para formar a base $6-31 \mathrm{G}(\mathrm{d}, \mathrm{p})[38,39,40,41]$.

Como vimos a correção energia de correlação pode ser obtida através de diferentes métodos teóricos, como MP2 ou através das melhorias do conjunto de base. Este erro pode ser reduzido pela inclusão de funções com alto momento angular, $(\mathrm{d}, \mathrm{f}, \mathrm{g}, \ldots)$, tais como o conjunto de base zeta duplicada polarizada de correlação consistente (cc-pVDZ) [42]. Os cálculos correlacionados são baseados na interação de configuração (CI), incluindo cálculos excitações simples e duplas de configuração Hartree-Fock dos átomos. Os conjuntos $s p$ são obtidos a partir de cálculos atômicos otimizados enquanto os conjuntos de polarização $(p, d, f, \ldots)$ são construídos utilizando funções gaussianas simples com expoentes otimizadas para cada novo conjunto. O conjunto de base zeta duplicada polarizada de correlação consistente aumentado (aug-cc-pVDZ) é proposto para descrever o caráter mais difuso dos elétrons. Neste caso, um conjunto de funções primitivas otimizadas $s$ e $p$ foi adicionado ao grupo $s p$ de cada um dos conjuntos de base cc-pVDZ do átomo neutro e os expoentes otimizados usando o cálculo de interação de configuração com o orbital $1 s$ núcleo congelado.

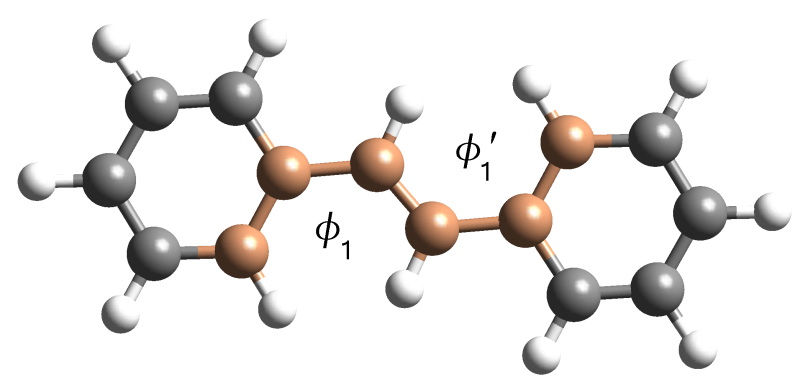

Figura 2.1: Oligômero de PPV com dois anéis $P_{2} V_{1}$. Os ângulos diedrais assumem o mesmo módulo em sentidos opostos, $\phi_{1}=-\phi_{1}^{\prime}$.

Mostramos a seguir o efeito da torção dos anéis mais internos de pequenas cadeias isoladas de PV obtidos através de cálculos HF e MP2. Trabalhamos sempre com cadeias terminadas em fenil (phenyl-capped) que desiguinamos por $P_{n} V_{n-1}$. Nossos resultados foram obtidos através de cálculos ab initio de estrutura eletrônica com diferentes conjuntos de bases locais, e de onda planas quando possível. De forma comparativa, obtemos as geometrias do estado fundamental dos oligômeros com 2 anéis $\left(P_{2} V_{1}\right.$, trans-estilbeno) e 4 anéis $\left(P_{4} V_{3}\right)$ de fenil, variando os ângulos 
diedrais $\phi_{1}$ and $\phi_{1}^{\prime}$, como mostram as figuras 2.1 e 2.2 , respectivamente.

A torção na cadeia $P_{2} V_{1}$ acontece entre anéis que já representam as bordas da molécula, já o oligômero $P_{4} V_{3}$ apresenta pelo menos seis ângulos diedrais de interesse destacados na figura 2.2a e 2.2b. Neste trabalho, os diedrais externos $\phi_{3}$ e $\phi_{3}^{\prime}$ são mantidos fixos em $0^{\circ}$, os diedrais $\phi_{2}, \phi_{2}^{\prime}$ e os diedrais internos $\phi_{1}$ e $\phi_{1}^{\prime}$ variam em sentidos opostos em passos de $15^{\circ}$. Em todos os casos os valores de energia com $\phi_{1}=\phi_{1}^{\prime}=0^{\circ}$ foram tomados como referência.

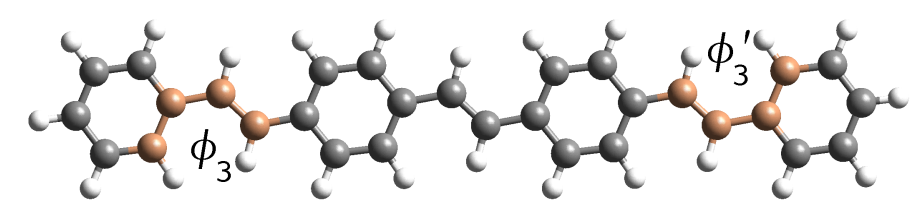

(a)

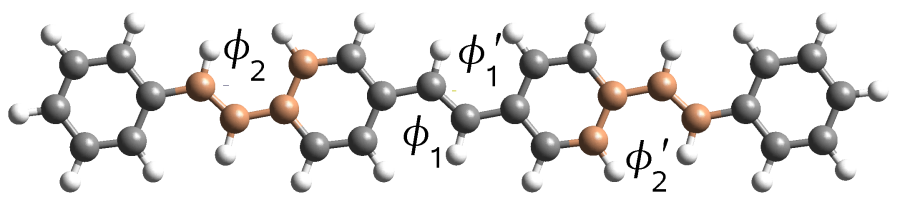

(b)

Figura 2.2: Ângulos diedrais de interesse para o cáculo da barreira de torção do oligômero $P_{4} V_{3}$. Os diedrais externos são fixos em zero, $\phi_{3}=\phi_{3}^{\prime}=0^{\circ}$. Os diedrais são variados em sentidos opostos em intervalos de $15^{\circ}, \phi_{2}=-\phi_{2}^{\prime}$ e $\phi_{1}=-\phi_{1}^{\prime}$.

Para cada valor fixo de $\phi_{1}$ e $\phi_{1}^{\prime}$, realizamos uma otimização completa da geometria dos sistemas $P_{2} V_{1}$ e $P_{4} V_{3}$ usando os métodos ab initio HF e MP2 com a base 6-31G(d,p). No caso do oligômero $P_{4} V_{3}$, os diedrais $\phi_{2}$ e $\phi_{2}^{\prime}$ também estão livres para otimizar, impondo a simetria $C_{2 h}$ para o sistema planar e $C_{2}$ para os demais sistemas. Partindo das geometrias MP2/6-31G(d,p), calculamos a energia total de cada configuração usando o conjunto de base aug-cc-pVDZ (desenvolvida por Dunning [43] para corrigir a energia de correlação de valência, com uma série de funções difusas $s, p$ e $d$ ). A energia potencial relativa em função do ângulo diedral mais interno $\left(\phi_{1}\right)$ de oligômeros isolados, $P_{2} V_{1}$ e $P_{4} V_{3}$, são mostrados nas Figuras 2.3 e 2.4, respectivamente. Os pontos representam os dados calculados e as linhas são curvas de ajuste.

Os resultados RHF (HF para camada fechada, "Restricted HF") e RMP2 (MP2 para camada fechada, "Restricted MP2") para o $P_{2} V_{1}$ com a base 6-31G(d,p) indica para a estrutura do estado 


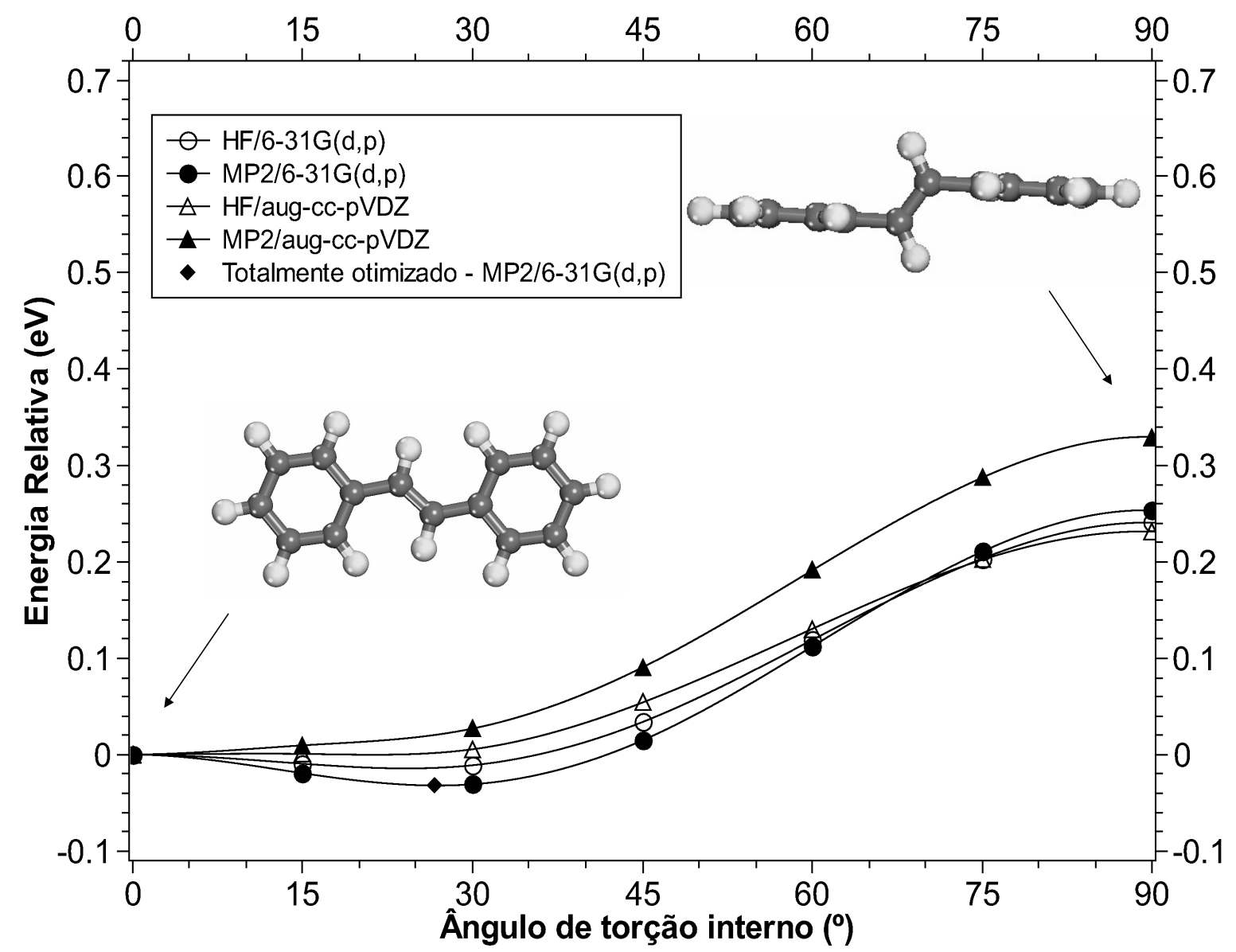

Figura 2.3: Potencial de torção para o oligômero de dois anéis de fenil, $P_{2} V_{1}$. As energias foram calculadas usando métodos dependentes da função de onda com os conjuntos de bases locais 6-31G(d,p) e aug-cc-pVDZ. Os resultados mostram que a estrutura do estado fundamental do $P_{2} V_{1}$ isolado pode ser planar ou não, dependendo somente do conjunto de base utilizado.

fundamental de trans-estilbeno uma configuração não-planar com ângulo diedral $\phi_{1}=26,75^{\circ}$. A diferença em energia potencial entre o mínimo $\left(\phi_{1}=26,75^{\circ}\right)$ e máximo de energia $\left(\phi_{1}=90^{\circ}\right)$ são 0,254 eV com o método RHF/6-31G(d,p) e 0,282 eV se usamos o método perturbativo RMP2/6-31G(d,p). Notamos, neste caso, a influência muito baixa da energia de correlação eletrônica vinda do cálculo RMP2 sobre as curvas de energia de torção. Estes resultados, com o mínimo absoluto $\phi_{1}=26.75^{\circ}$, estão em boa concordância com não-planaridade de $30^{\circ}$ observada para trans-estilbeno pela referência [44] e em excelente acordo com cálculos ab initio (HF e MP2) com diferentes conjuntos de base (6-31G, 6-31Gd e 6-31Gdp) em que os ângulos 
diedrais variam entre 21.6 e $26.7^{\circ}[34,45]$. Em contraste, mais recentemente, cálculos MP2 com a aproximação de caroço congelado usando conjunto de base aug-cc-pVDZ indica que o trans-estilbeno isolado é uma molécula planar [32]. Conseqüentemente, usamos as geometrias otimizadas com RMP2/6-31G(d,p) para calcular as energias com o conjunto de base aug-ccpVDZ ainda considerando os métodos RHF e RMP2: nossos resultados com esse conjunto de base mais completo mostram agora o mínimo de energia absoluto para conformações planares $\left(\phi_{1}=0^{\circ}\right)$.

As curvas de torção têm formas semelhantes, mas apresentam uma diferença energética em torno de $0,1 \mathrm{eV}$ para $\phi_{1}=90^{\circ}$, mostrando que os efeitos de correlação eletrônica não podem ser simplesmente desprezados, ao contrário do afirmado na referência [46]. Assim, nossos resultados confirmam as discrepâncias entre vários artigos citados para o trans-estilbeno e, portanto, cálculos análogos para o oligômero de quatro anéis também foram realizados a fim de investigar uma possível influência nos resultados devido ao tamanho de molécula (figura 2.4).

Para geometrias otimizadas de $P_{4} V_{3}$, as energias de torção RHF/6-31G(d,p) e RMP2/6$31 \mathrm{G}(\mathrm{d}, \mathrm{p})$ apontam para uma estrutura não planar de simetria $C_{2}$, exibindo um ângulo de torção interno $\phi_{1}=23,9^{\circ}$, mostrando que, relativamente ao oligômero de 2 anéis, os efeitos produzidos pelo aumento do tamanho da molécula são pequenos, mas levam a uma cadeia "mais planar". Os efeitos de correlação usando essa base reduzida sobre a barreira de torção $\phi_{1}=90^{\circ}$ não ultrapassam $\sim 0.06 \mathrm{eV}$. Na sequência passamos ao estudo da influência da escolha de base, usando a base aug-cc-pVDZ. Neste caso, novamente as curvas de potencial usando RHF e RMP2 mostram que o oligômero $P_{4} V_{3}$ tem um mínimo absoluto em $\phi_{1}=0^{\circ}$, correspondente a uma cadeia de simetria planar $C_{2 h}$, em boa concordância com nossos resultados calculados para o $P_{2} V_{1}$ e relatados pelas referências $[32,34]$. Em particular, notamos que os cálculos RMP2/aug-cc-pVDZ apresentam um mínimo de energia local em $\phi_{1}=30^{\circ}$. Mais uma vez, em acordo com os resultados obtidos para o $P_{2} V_{1}$, a principal influência sobre as curvas de energia de torção devido a influência da energia de correlação vinda do cálculo RMP2 é elevar a energia da barreira de torção em $\phi_{1}=90^{\circ}$, neste caso de $\sim 0.1 \mathrm{eV}$.

Em resumo, nosso estudo mostra que os métodos baseados na função de onda são fortemente influenciados pelo conjunto de base selecionado. 


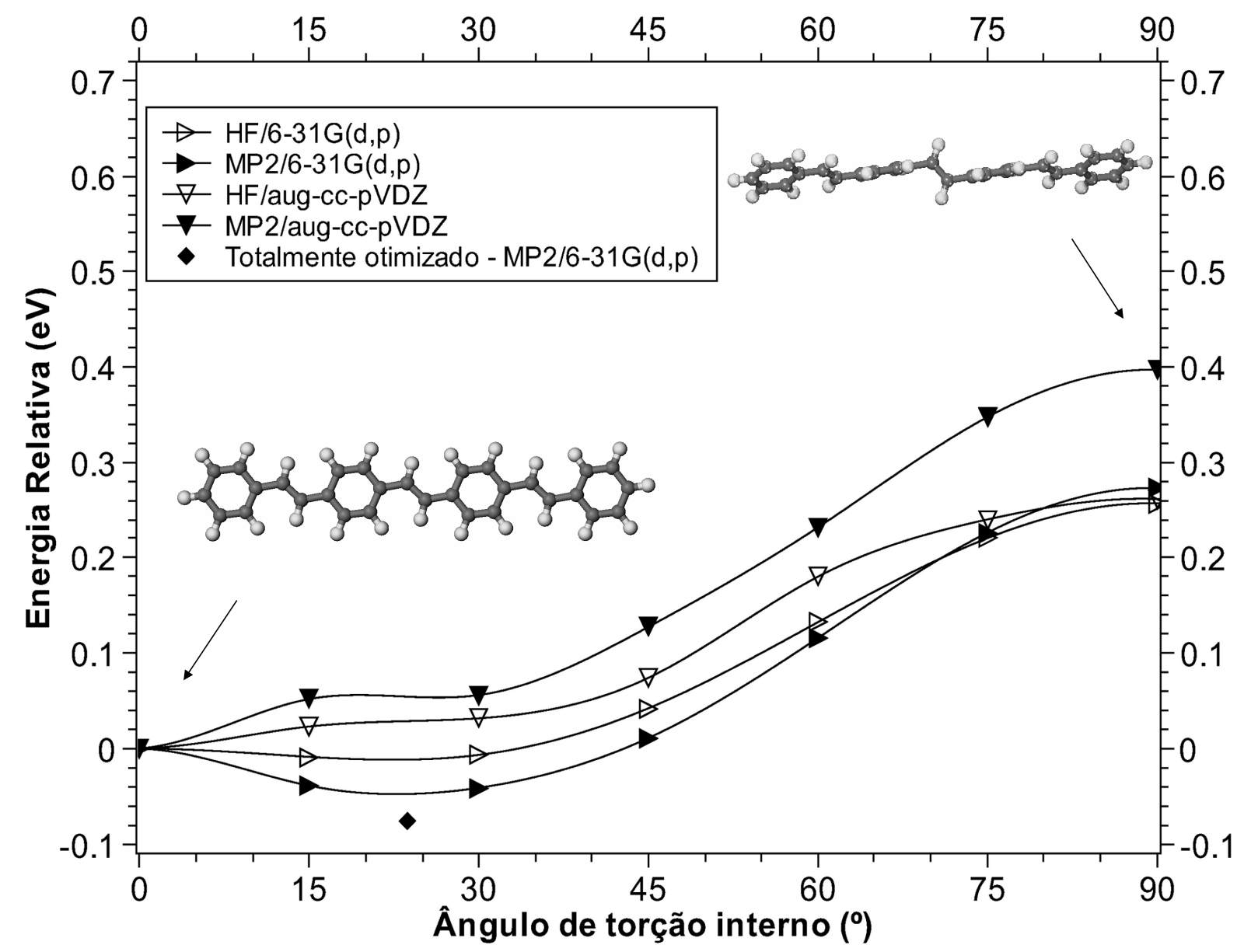

Figura 2.4: Potencial de torção para o oligômero de quatro anéis de fenil, $P_{4} V_{3}$. As energias foram calculadas usando métodos dependentes da função de onda com os conjuntos de bases locais 6-31G(d,p) e aug-cc-pVDZ. Os resultados para a estrutura do estado fundamental (planar ou não planar) dependem fortemente do conjunto de base utilizado.

\subsubsection{Resultados estruturais: DFT}

Outro formalismo muito útil na descrição da estrutura eletrônica é a Teoria do Funcional da Densidade (Density Functional Theory DFT). Consideramos uma série de equações de partículas individuais dependentes da densidade total de carga eletrônica do sistema $\rho(r)$. A DFT é baseada na teoria Hohenberg-Kohn [47] em que a densidade de carga eletrônica de um gás elétrons é analisada em um potencial externo. Os efeitos de troca e correlação são englobados em um funcional único e podemos chegar a equações auto-consistentes semelhantes às equações 
de HF, mas com todos os operadores substituídos por funcionais de $\rho(r)$. As chamadas equações de Kohn-Sham [48]. Além disso, já consideram uma expressão de campo médio em termos de orbitais de Slater.

$$
\left\{-\frac{1}{2} \nabla^{2}+\left[\varphi(r)+\mu_{x c}(\rho(r))\right]\right\} \psi_{i}(r)=\epsilon_{i} \psi_{i}(r)
$$

Calculamos para ambos oligômeros $P_{2} V_{1}$ e $P_{4} V_{3}$ a energia potencial como uma função de $\phi_{1}$ usando aproximações da Densidade Local (LDA, ajusta as soluções de Ceperley-Alder para o gás de eletrons uniforme) [49, 50] e Gradiente Generalizado (GGA) [51] , através do funcionais SVWN5 que é conhecido como LSDA (Local Spin Density Approximation) e PBE (funcional of Perdew, Burke and Ernzerhof). Para investigar um possível efeito dos conjuntos de base usamos novamente bases locais 6-31G(d,p), aug-cc-pVDZ e estendemos a comparação à base de ondas planas (PW) usando a aproximação GGA-PBE e LDA-PZ, com pseudo-potenciais ultra-suaves [52]. Neste caso, as funções de onda eletrônicas foram expandidas até a energia cinética de corte de 25 Ryd, e (para simular a cadeia isolada) construimos uma caixa com 20 A de vácuo em todas as direções. Os cálculos com base de ondas planas foram realizados no código quantum espresso [53].

Passamos agora aos resultados obtidos através de cálculos baseados na DFT. Todos os resultados foram agora obtidos usando a geometria otimizada RMP2/6-31G(d,p). O potencial de torção em função do ângulo diedral mais interno $\left(\phi_{1}\right)$ para $P_{2} V_{1}$ e $P_{4} V_{3}$ é graficado nas figuras 2.5 e 2.6 , respectivamente.

Todos os cálculos DFT, LDA e GGA, para a molécula isolada de trans-estilbeno, independentemente do conjunto de base adotado, apresentam energias de mínimo absoluto em $\phi_{1}=0^{\circ}$, i. e., geometrias de estado fundamental com conformações planares (simetria $C_{2 h}$ ). A forma das curvas DFT, usando aproximação LDA ou GGA, com conjuntos de bases locais ou de ondas planas são muito semelhantes. A principal diferença entre estas curvas reside na barreira de torção $\left(\phi_{1}=90^{\circ}\right)$ com as energias relativas variando de $0,44 \mathrm{eV}$ (GGA/aug-cc-pVDZ) a 0,61 eV (LDA/PW). No geral, os resultados estão de acordo com aqueles encontrados para o $P_{2} V_{1}$ isolado usando o método B3LYP/aug-cc-pVDZ [32].

Nossos resultados para o oligômero $P_{4} V_{3}$ são mostrados na Fig. 2.6. De forma análoga aos resultados LDA e GGA para o $P_{2} V_{1}$, todos os cálculos realizados para o $P_{4} V_{3}$ indicam 


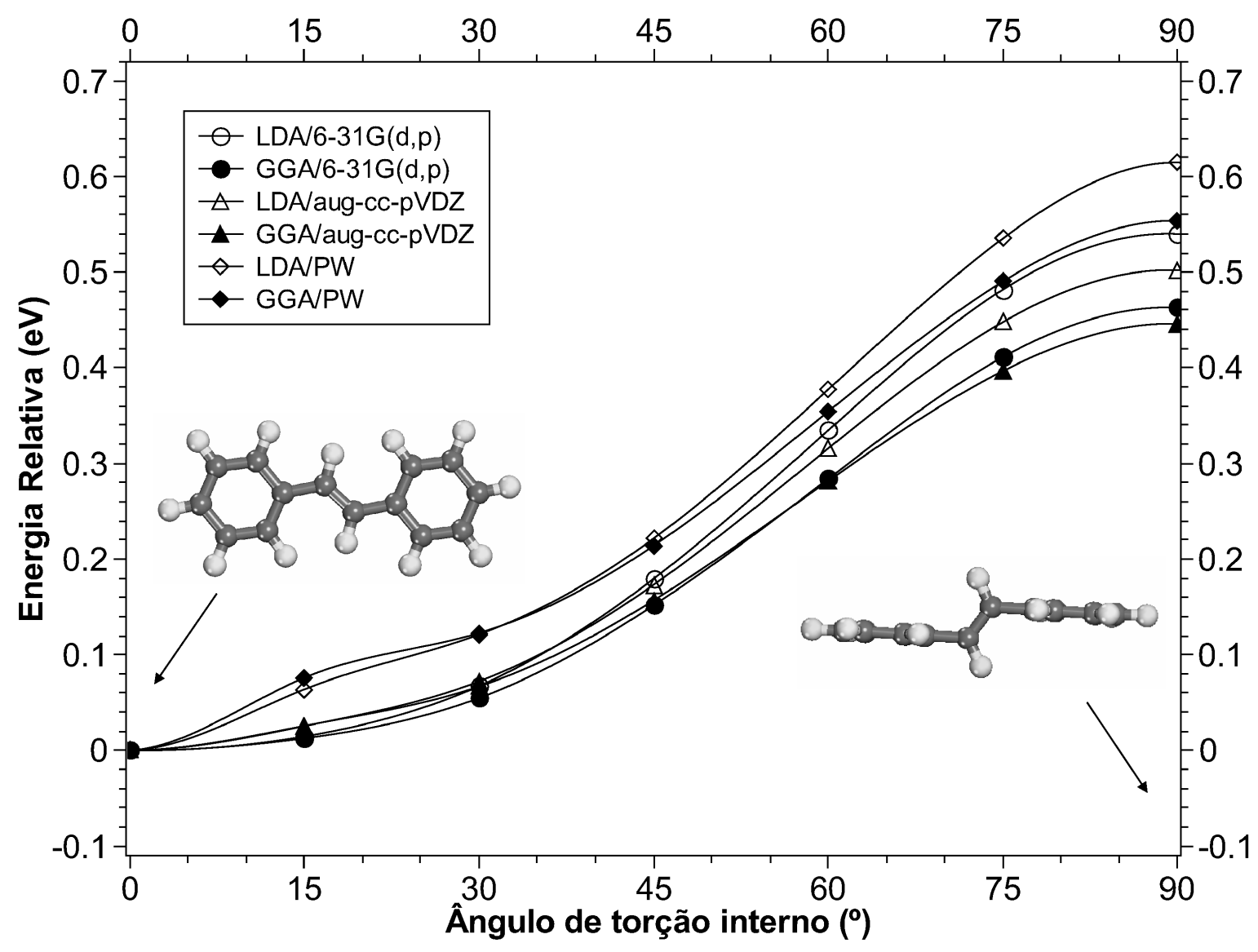

Figura 2.5: Potencial de torção para o oligômero de dois anéis de fenil, $P_{2} V_{1}$. As energias foram calculadas usando métodos dependentes da densidade eletrônica com conjuntos de bases locais 6-31G(d,p), aug-cc-pVDZ e de ondas planas (PW). O resultado para a estrutura de estado fundamental é sempre planar, independentemente do conjunto de base utilizado.

que a estrutura mais estável corresponde à configuração planar. A forma das curvas DFT são ligeiramente diferentes no tocante à presença de um mínimo local $\left(\phi_{1}=30^{\circ}\right)$. A altura da barreira de torção varia de 0,553 eV para GGA/PW a 0,659 eV para LDA/6-31G(d,p). Estes resultados estão em concordância com os cálculos DFT/LDA da literatura, para uma cadeia unidimensional infinita isolada com barreiras de toção em torno de $\sim 0,78 \mathrm{eV}[35] \mathrm{e}$ 0,56 eV $[36,37]$.

Concluindo, nossos cálculos com funcionais dependentes da densidade eletrônica apontam para a planaridade do trans-estilbeno isolado, $P_{2} V_{1}$ e confirmam o mesmo resultado para o oligômero maior, $P_{4} V_{3}$ independentemente do conjunto de base adotado, locais ou de ondas 


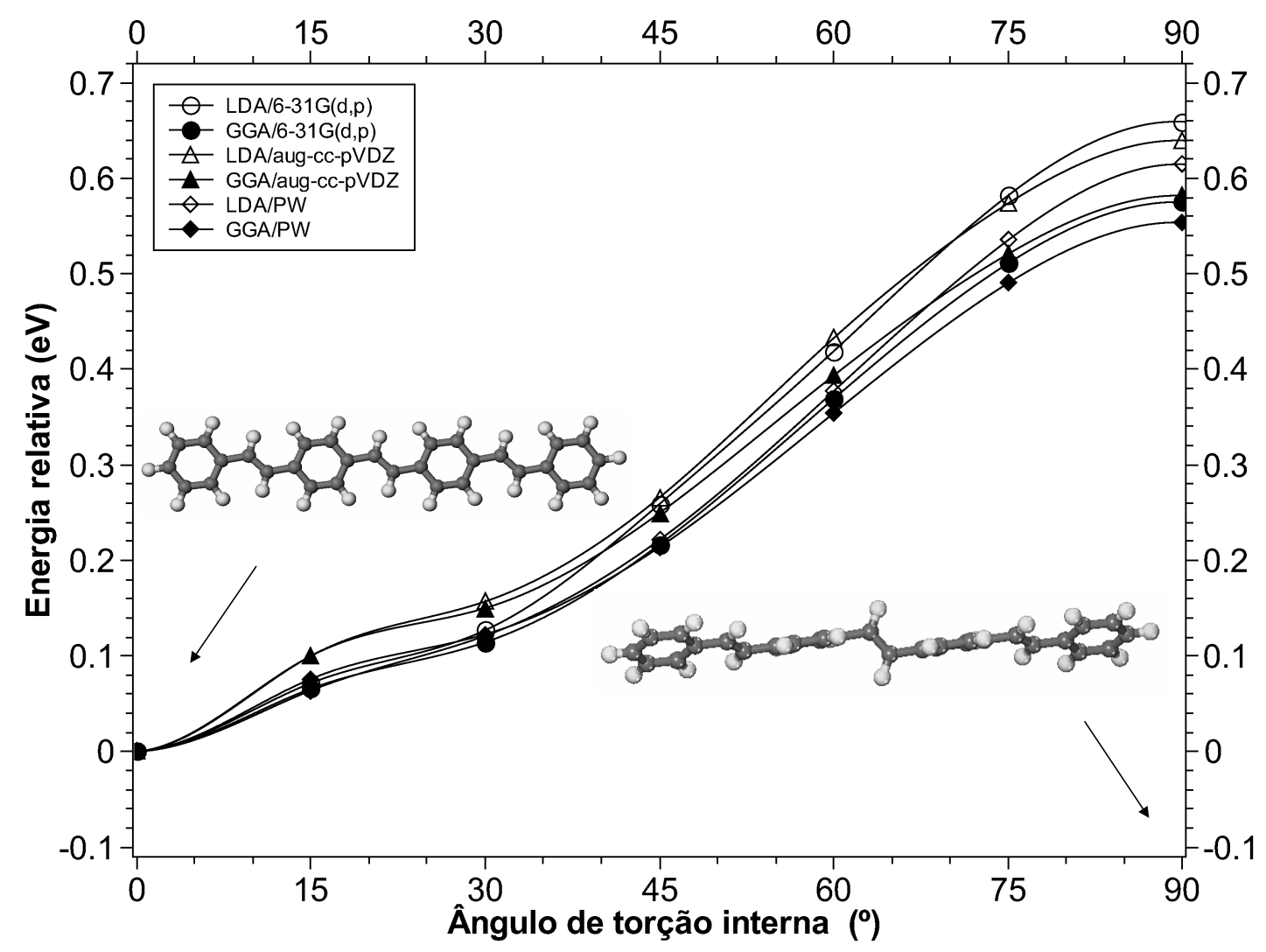

Figura 2.6: Potencial de torção para o oligômero de quatro anéis de fenil, $P_{4} V_{3}$. As energias foram calculadas usando métodos dependentes da densidade eletrônica com conjuntos de bases locais 6-31G(d,p), aug-cc-pVDZ e de ondas planas (PW). Os resultados mostram que a estrutura de estado fundamental do $P_{4} V_{3}$ isolado é sempre planar, independente do conjunto de base utilizado.

planas. Além disso, os valores de barreira para o maior $P_{4} V_{3}$ e menor oligômero $P_{2} V_{1}$, mostram que a energia de torção entre anéis primeiros vizinhos é sempre muito semelhante.

\subsubsection{Definição de sítio e energia de sítio}

A configuração planar detetada acima facilita a delocalização dos orbitais de fronteira HOMO (Highest Occupied Molecular Orbital) e LUMO (Lowest Unoccupied Molecular Orbital) e contribui para a maior conjugação do sistema. É interessante então, investigar o efeito da torção 
entre anéis primeiro vizinhos sobre a delocalização orbital.

Partimos dos resultados ab initio de geometria otimizada com RMP2/6-31G(d,p) e calculamos os orbitais LUMO e HOMO em função do ângulo de torção para os valores $\phi_{1}=\left(0^{\circ}\right.$, $15^{\circ}, 30^{\circ}$ e $90^{\circ}$ ). A extensão espacial, os sinais e formas do LUMO (L) e HOMO (H) para os oligômeros $P_{2} V_{1}$ e $P_{4} V_{3}$ estão ilustrados nas Figuras 2.7 e 2.8, nesta ordem.

Analisando a distribuição eletrônica para o $P_{2} V_{1}$ da Figura 2.7a, tanto para o HOMO quanto para o LUMO, confirmamos que a delocalização orbital é estendida sobre toda molécula para a situação de cadeia planar, quando $\phi_{1}=0^{\circ}$. A distribuição orbital a forma dos orbitais é tipicamente do tipo $\pi$ favorecendo a conjugação do sistema. Nas Figuras 2.7b e 2.7c, quando $\phi_{1}=0^{\circ}, 15^{\circ}, 30^{\circ}$, respectivamente, ainda podemos ver a delocalização orbital dos elétrons $\pi$ mesmo para grandes ângulos entre anéis $\phi_{1}=60^{\circ}$. Já na Figura $2.7 \mathrm{~d}$, quando a torção vale $\phi_{1}=90^{\circ}$ o LUMO não chega a ser significativamente afetado, mas percebemos a quebra de conjugação do HOMO: como não existe mais a participação do vinil, o trans-estilbeno agora se comporta como dois anéis de fenileno, dois "sítios" conjugados. Dada a perfeita simetria admitida, os orbitais têm contribuição idêntica de ambos anéis de fenil.

A comparação do efeito da torção sobre a distribuição eletrônica com o aumento do tamanho da cadeia é interessante. Assim, para o $P_{4} V_{3}$, vemos o LUMO (L) e o HOMO (H) para a situação de conformação planar, $\phi_{1}=0^{\circ}$ (na Figura 2.8a) e não-planares com torções para os anéis mais internos de $\phi_{1}=15^{\circ}$ (Figura 2.8b) e $\phi_{1}=30^{\circ}$ (Figura 2.8c). Seguindo a tendência do transestilbeno, vemos que estes orbitais também são do tipo $\pi$ e que a delocalização praticamente não é afetada para grandes valores de torção, ou equivalentemente, ângulos entre anéis de até $60^{\circ}$.

Os estados LUMO e HOMO são mostrados na Figura 2.8d para o valor de ângulo diedral $\phi_{1}$ $=90^{\circ}$. Neste caso, a torção leva à quebra de conjugação para ambos os orbitais de fronteira. A contribuição devida ao grupo vinileno central é muito pequena tanto para HOMO quanto para LUMO e, conseqüentemente, como sistemas conjugados são limitados a átomos de carbono insaturados, o oligômero $P_{4} V_{3}$ apresenta agora duas regiões conjugadas separadas, equivalente a dois oligômeros de $P_{2} V_{1}$, ou ainda, a influência da torção entre anéis de fenileno altera de forma significativa a conjugação do sistema, e podemos considerar, para efeito de modelamento de transporte, a presença de dois sítios. 

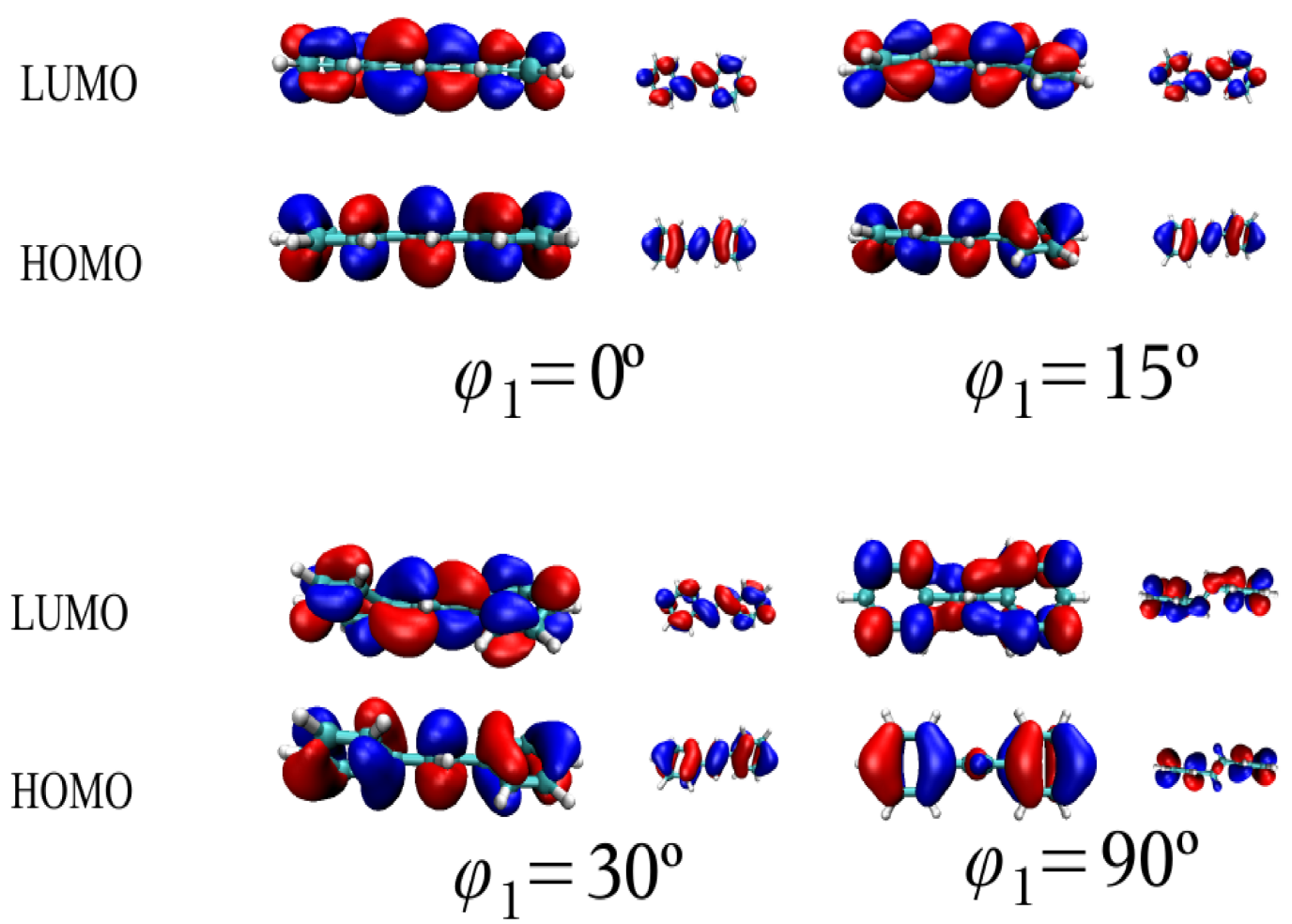

Figura 2.7: Duas visões dos Orbitais moleculares HOMO e LUMO em função dos ângulos diedrais internos $\phi_{1}$ para o $P_{2} V_{1}$. A delocalização orbital é mantida mesmo para grandes ângulos entre anéis $2 \phi_{1}=60^{\circ}$.

Para analizar a delocalização do orbital HOMO, coletamos os coeficientes devidos aos átomos de carbono do vinil central e posteriormente, somamos os quadrados destes coeficientes. Para o HOMO, na situação de cadeia planar a contribuição dos carbonos do vinil é máxima 17\%, enquanto para ângulos de torção de $30^{\circ}$ e $60^{\circ}$ as contribuições valem 15 e 8\%, respectivamente. Quando o ângulo de torção vale $90^{\circ}$ somente $2 \%$ do orbital HOMO está sobre os átomos do vinil central.

Desta maneira, consideraremos com o objetivo de desenvolver uma teoria simplificada mas baseada em resultados atomísticos, que para ângulos superiores a $60^{\circ}$ ocorre a quebra de conjugação, podendo o elétron transitar de um lado a outro da molécula apenas mediante o acoplamento por hopping. Consideraremos que vale este mesmo valor de ângulo limite para distorções frontais da ligação entre fenil (que chamaremos como é usual de 'kink', ou 'tilt').

À medida em que se aumenta o tamanho dos oligômeros, sem torções, observa-se as maiores 


\section{LUM0}

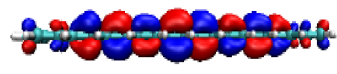

posogos
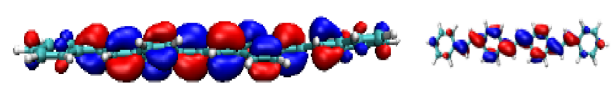

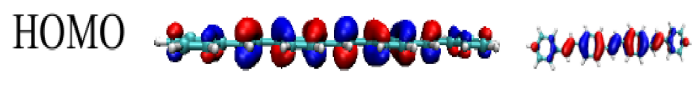

$$
\varphi_{1}=0^{\circ}
$$

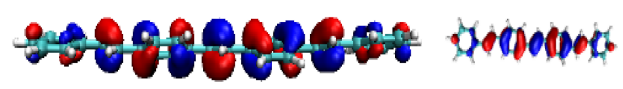

$$
\varphi_{1}=15^{\circ}
$$

LUMO
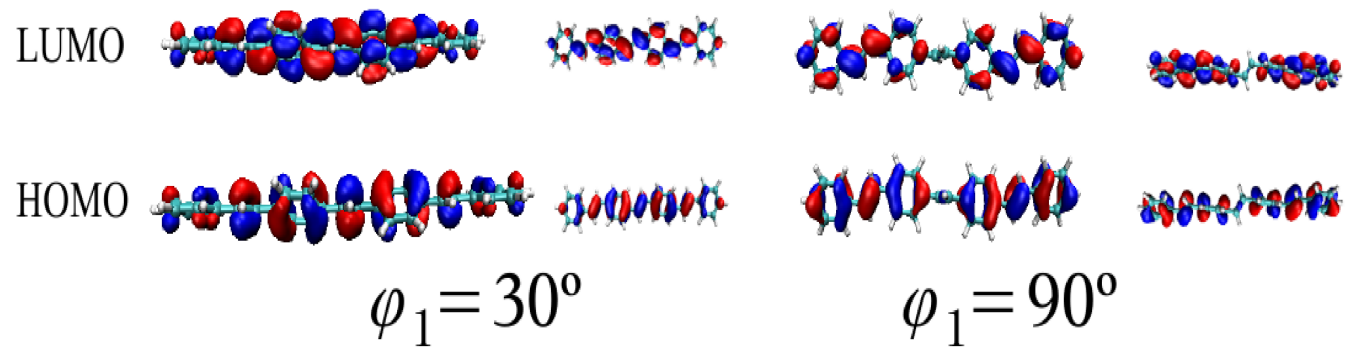

Figura 2.8: Duas visões dos Orbitais moleculares HOMO e LUMO em função dos ângulos diedrais internos $\phi_{1}$ para o $P_{4} V_{3}$. A delocalização orbital é mantida mesmo para grandes ângulos entre anéis $2 \phi_{1}=60^{\circ}$.

delocalizações dos estados eletrônicos. O gap entre o HOMO e o LUMO diminui, sendo a energia do HOMO elevada e do LUMO reduzida.

Passando agora ao transporte entre sítios, a energia para fazer transitar um buraco de um determinado estado eletrônico $i$ para outro estado $f$, é igual àquela consumida para promover um elétron do estado $f$ ao $i$. Este mecanismo é representado no esquema pictórico da figura 2.9. Assim, a migração do buraco do estado (sítio) de maior deslocalização para o de menor localização se dá por meio da absorção do respectivo quantum de energia. Desta maneira, o ordenamento correto das energias associadas às transições dos buracos é obtido tomando-os pela diferença entre sua energia e uma energia de referência como se define usualmente pela "banda de buracos" em semicondutores convencionais.

Uma energia de referência particularmente boa será a do estado de vácuo, que, portanto, independe de efeitos internos à estrutura eletrônica do sistema considerado. Para o cálculo das energias de sítio dos buracos utilizamos como modelo o cálculo dos potenciais de ionização (ionization potential IP) sobre oligômeros isolados de PPV de diferentes tamanhos. Desta 
maneira garantimos o alinhamento relativo dos níveis eletrônicos em relação a promoção de elétrons ao vácuo, estando as diferenças das energias de sítio asseguradas.
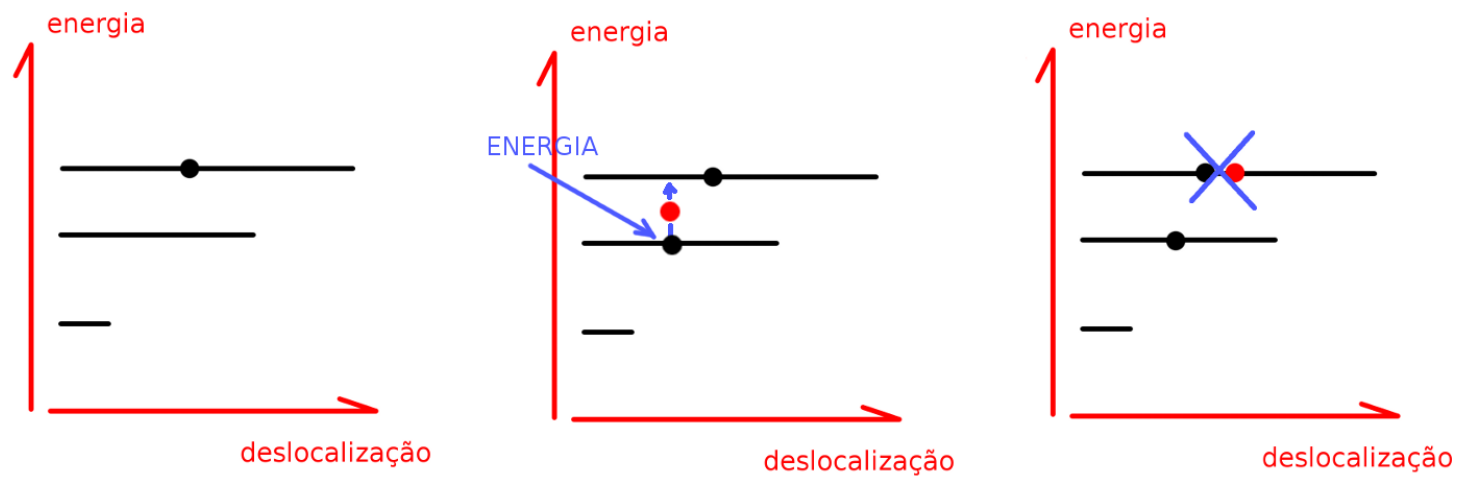

Figura 2.9: Representação diagramática da migração de um buraco de um nível mais deslocalizado para um nível menos deslocalizado.

O IP é definido como sendo a energia necessária para remover um elétron de um átomo ou molécula. Ele pode ser calculado por meio de metodologias ab initio como o método HartreeFock (utilizando o teorema de Koopmans [54]), ou aproximado dentro do esquema de energia total da DFT por meio da diferença da energia total do sistema neutro e carregado (ausência de 1 elétron), método conhecido como $\triangle \mathrm{SCF}$.

Modelos mais sofisticados utilizando teoria de perturbação de muitos corpos como o $G_{0} W_{0}$ podem também ser aplicados de modo a incluir efeitos de correlação nas energias de criação do buraco. Assim, nesta etapa do trabalho utilizamos dados de cálculos $G_{0} W_{0}$ para oligômeros de PPV de diferentes tamanhos [20].

O comportamento do IP tem dependência linear com o inverso do comprimento da cadeia de PPV (ou, ainda, do número de unidades fenil, como é preferível parametrizar para nosso problema). O potencial para a cadeia infinita corresponde ao ponto onde $1 / N \rightarrow 0$. Pelo ajuste visto na Figura 2.10 obtemos o valor de $5.5 \mathrm{eV}$, o valor experimental é de $5.6 \mathrm{eV}$, mostrando a adequação da metodologia. 


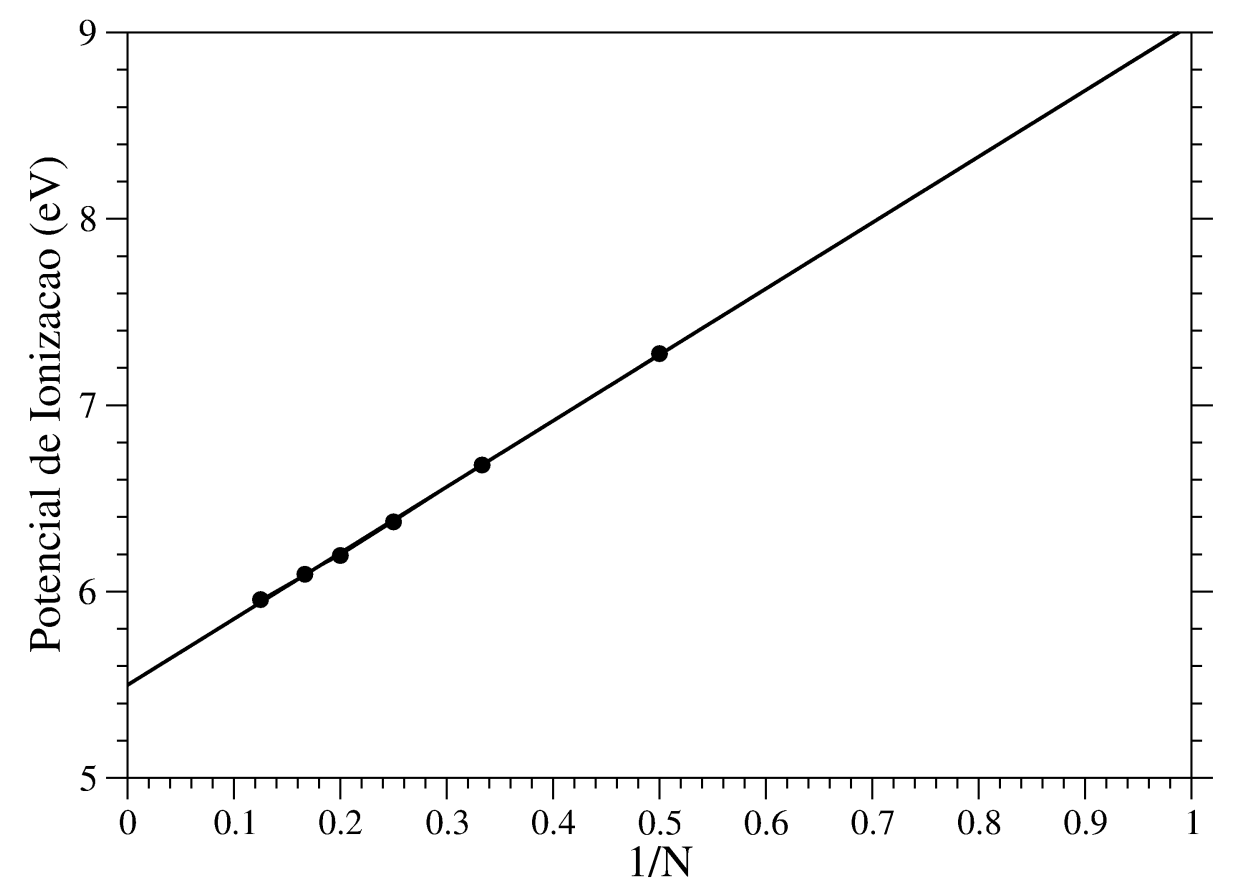

Figura 2.10: Ajuste do potencial de ionização versus o inverso do comprimento (em número de unidades de fenil) para cadeias isoladas de PPV sobre valores calculados [20] usando metodologia $G_{0} W_{0}$. A curva ajustada é dada por $I P=3.5440 \times N^{-1}+5.4982(\mathrm{eV})$. A incerteza do ajuste dos parâmetros é menor que $1 \%$.

\subsubsection{Conectividade e Integrais de Transferência Eletrônica}

Repetimos a seguir o método descrito nas referências [21, 22] para obtenção das integrais de transferência. Definidos os sítios, devemos associar a cada par um termo de conectividade. Nos modelos usuais, o pré-fator $w_{0}$ é utilizado para ajuste de dados experimentais, enquanto no nosso modelo utilizaremos o cálculo quântico de integrais de transferência eletrônica e um modelo simplificado de tunelamento entre dois estados (níveis). A integral de transferência eletrônica é

$$
E_{i j}=\left\langle\phi^{i}|H| \phi^{j}\right\rangle
$$

em que H é o hamiltoniano do sistema (filme amorfo), e $\phi^{i}, \phi^{j}$ são os autoestados de portador referente aos sítios $i, j$. Muitas vezes, o cálculo de $E_{i j}$ é realizado para um sistema extremamente 
simplificado que não incorpora o efeito do filme, ou seja, para um par de oligômeros ("dímero") no vácuo. Aqui traremos o valor de $E_{i j}$ de cálculos realizados em sistemas condensados homogêneos (cristais) que reflitam a densidade e orientação local do par de sítios considerado, conforme descrito abaixo. Dessa forma, incorporamos o efeito do ambiente.

Para um sistema cristalino tridimensional podemos associar dois diferentes tipos de periodicidades, uma unidimensional ocorrendo ao longo do eixo da cadeia descrito pelo vetor de rede $\vec{c}$, e outra bidimensional associada aos parâmetros de rede laterais, que denotaremos por $\{\overrightarrow{\mathcal{P}}\}$. O arranjo cristalino pode ter $q$ cadeias não-equivalentes, localizadas nas posições $\{\vec{\tau}\}$, conforme visto na célula cristalina do PPV nas figuras 2.11 e 2.12.

A idéia fundamental para o cálculo da transferência inter-cadeias vem de escrever o problema cristalino em termos das autofunções para o problema de cadeia isolada unidimensional. O autoestado correspondendo à ith cadeia não-equivalente no sth sítio da rede é representado como:

$$
\phi_{m k_{z}}^{i}\left(\vec{r}-\vec{\tau}_{i}-\overrightarrow{\mathcal{P}}_{s}\right)
$$

em que $\vec{k}$ representa o vetor de onda e $m$ o indice de banda. Dessa forma, o autoestado cristalino $\psi_{l \vec{k}}(\vec{r})$ pode ser expandido em termos dos estados de cadeia isolada,

$$
\psi_{l \vec{k}}(\vec{r})=\sum_{s, m, i} C_{m, i}^{l} e^{i \vec{k} . \overrightarrow{\mathcal{P}}_{s}} \phi_{m k_{z}}^{i}\left(\vec{r}-\vec{\tau}_{i}-\overrightarrow{\mathcal{P}}_{s}\right)
$$

A solução para cristal será dada por

$$
\sum_{m, i} C_{m, i}^{l} \sum_{s} e^{i \vec{k} \cdot \overrightarrow{\mathcal{P}}_{s}} E_{n j, m i}^{k_{z}}\left(\overrightarrow{\mathcal{P}}_{s}\right)=\epsilon_{l}(k) \sum_{m, i} C_{m, i}^{l} \sum_{s} e^{i \vec{k} \cdot \overrightarrow{\mathcal{P}}_{s}} \alpha_{n j, m i}^{k_{z}}\left(\overrightarrow{\mathcal{P}}_{s}\right)
$$

nas quais foram usadas as definições para as integrais de transferência $E_{n j, m i}^{k_{z}}\left(\overrightarrow{\mathcal{P}}_{s}\right)$ e de "overlap" $\alpha_{n j, m i}^{k_{z}}\left(\overrightarrow{\mathcal{P}}_{s}\right)$ :

$$
\begin{aligned}
E_{n j, m i}^{k_{z}}\left(\overrightarrow{\mathcal{P}}_{s}\right) & =\int d^{3} r \phi_{n k_{z}}^{j^{*}}\left(\vec{r}-\vec{\tau}_{j}\right) H \phi_{m k_{z}}^{i}\left(\vec{r}-\vec{\tau}_{i}-\overrightarrow{\mathcal{P}}_{s}\right) \\
\alpha_{n j, m i}^{k_{z}}\left(\overrightarrow{\mathcal{P}}_{s}\right) & =\int d^{3} r \phi_{n k_{z}}^{j^{*}}\left(\vec{r}-\vec{\tau}_{j}\right) \phi_{m k_{z}}^{i}\left(\vec{r}-\vec{\tau}_{i}-\overrightarrow{\mathcal{P}}_{s}\right)
\end{aligned}
$$


O cristal de PPV em disposição $\pi$-stack apresenta apenas uma cadeia $(q=1)$ por célula unitária , conforme mostra a Figura 2.11. Como estamos interessados em transporte por buracos, ficaremos restritos à "banda HOMO" considerando somente um nível por cadeia.

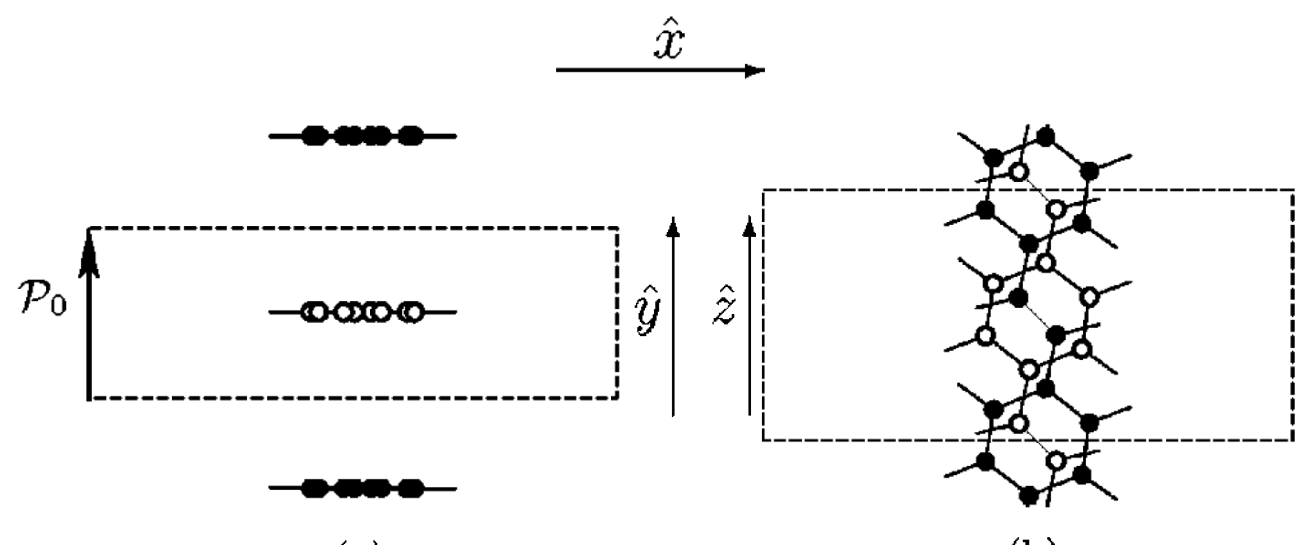

(a)

(b)

Figura 2.11: Arranjo cristalino para o PPV $\pi$-stack indicando em (a) que a célula unitária apresenta apenas uma cadeia e em (b) o empilhamento de stack, fenil-vinil. Figura extraída das referências [21, 22].

Resolvendo a equação de autovalores chegamos à seguinte expressão para $E_{i j}$ :

$$
E_{m 1, m 1}^{k z}\left(\overrightarrow{\mathcal{P}}_{s}\right)=\frac{1}{N_{\vec{k}}} \sum_{\vec{k}} e^{-i \vec{k} \cdot \overrightarrow{\mathcal{P}}_{s}} \epsilon_{m}(\vec{k})
$$

na qual $\epsilon(\vec{k})$ representa a energia da banda HOMO em termos do vetor de onda $\vec{k}$.

Para a célula do PPV herringbone (HB) temos a simetria cristalina com duas cadeias não equivalentes por célula. Neste caso, temos dois sítios na célula, com um estado eletrônico por sítio.

A integral de transferência $E_{i j}$ agora á dada por:

$$
E_{m 1, m 2}^{k_{z}}(0)=\frac{1}{8}\left[\epsilon^{+}(k)-\epsilon^{-}(k)\right]
$$

na qual $\epsilon^{+}(k)$ e $\epsilon^{-}(k)$ representam a separação (desdobramento) da banda HOMO devido à interação entre as cadeias.

Nossa estratégia foi então variar os parâmetros estruturais para cristais em simetrias HB e $\pi$-stack e retirar os valores para as integrais de transferência. Partindo de uma célula com 


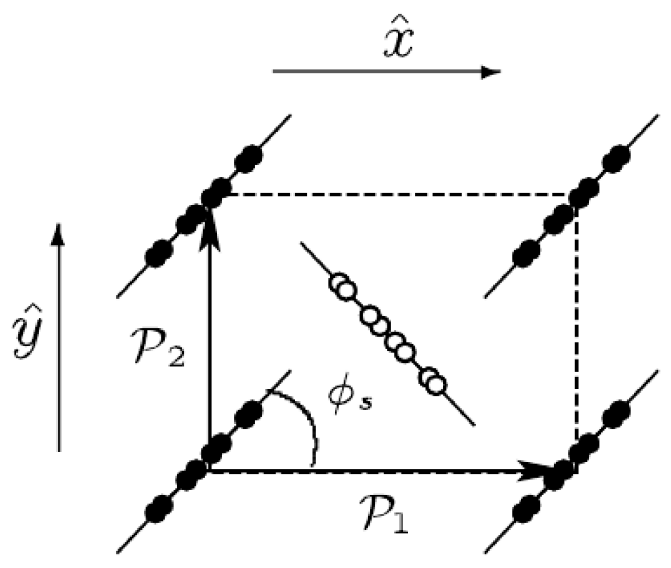

(a)

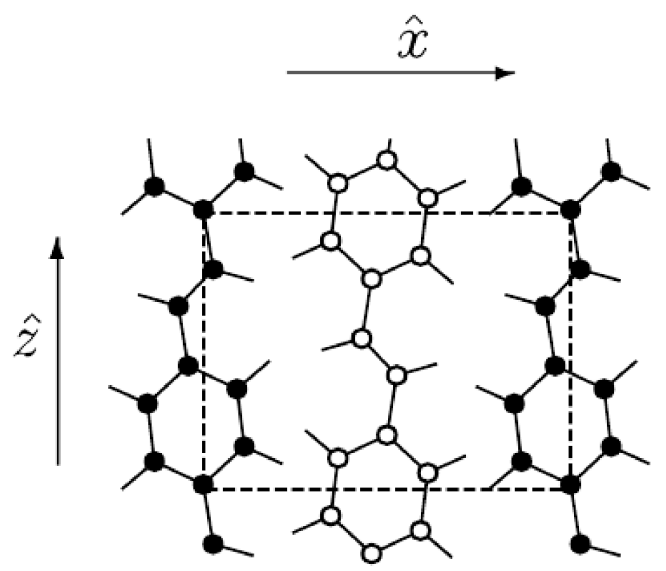

(b)

Figura 2.12: Arranjo cristalino para o PPV herringbone indicando em (a) a periodicidade bidimensional $\{\overrightarrow{\mathcal{P}}\}$ e em (b) a periodicidade uni-dimensional ao longo da cadeia equivalente ao parâmetro $\vec{c}$. Figura extraída das referências [21, 22].

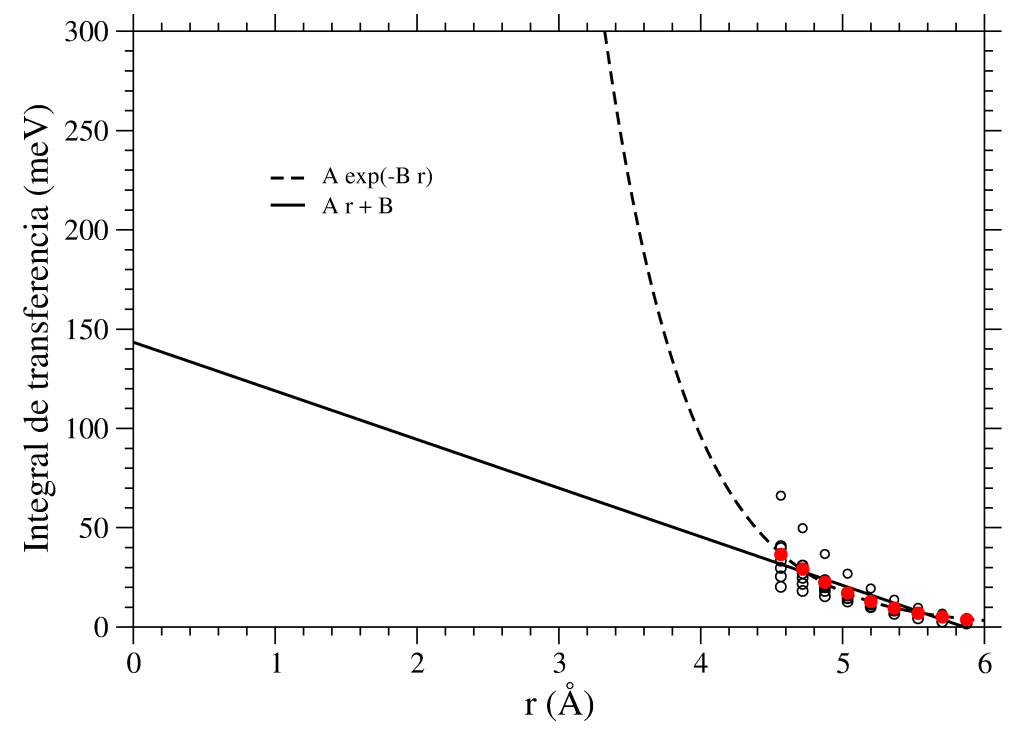

Figura 2.13: Ajuste linear, equação 2.24, sobre os valores ab initio calculados da integral de transferência para a simetria herring-bone dos cristais de $P P V$. Em pontilhado mostramos um ajuste com modelo exponencial que, apesar de representar melhor a região de pontos calculados, leva claramente a inconsistências para distâncias pequenas. 
simetria HB, tomamos como referência os parâmetros de rede experimentais e a partir destes, variamos as distâncias entre cadeias (variando os parâmetros de rede laterais), e para cada nova distância variamos o ângulo de colocação das cadeias de $0^{\circ}$ até $90^{\circ}$. Geramos diferentes configurações e para cada uma, usando o método DFT/LDA com base de ondas planas e corte de energia cinética de 45 Ryd, como implementado no pacote quantum espresso [53], calculamos a estrutura de bandas e obtemos o valor da integral de transferência.

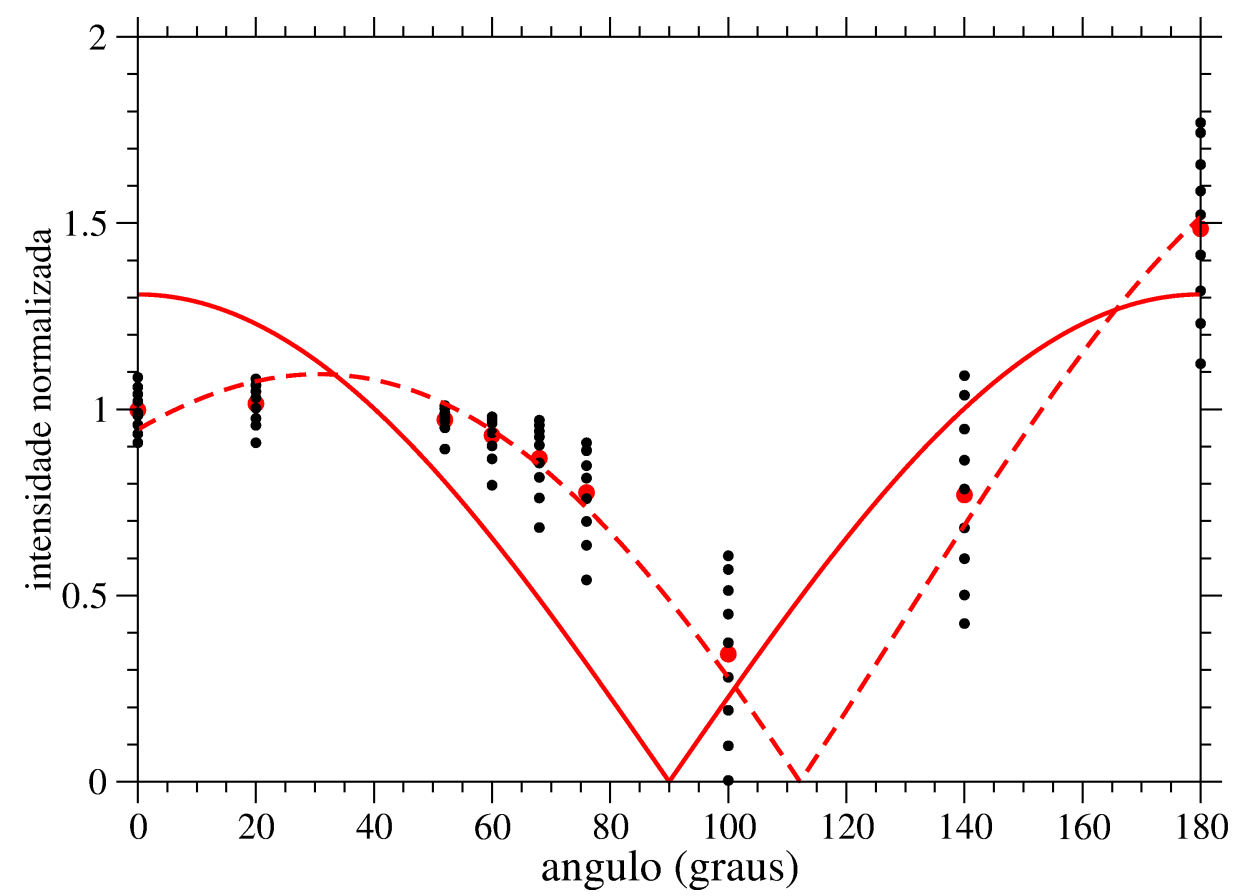

Figura 2.14: Ajuste da dependência angular (equação 2.26) das integrais de transferência $a b$ initio renormalizadas pela equação 2.25, para a simetria herring-bone dos cristais de PPV. Em pontilhado apresentamos um ajuste alternativo com ajuste de fase não nula e um envelope exponencial; esse ajuste incorpora os desvios de simetria observados, mas é apresentado apenas a título de comparação, uma vez que o comportamento médio é suficientemente garantido pelo por esse modelo simplificado.

De forma equivalente, para a célula cristalina de PPV em disposição $\pi$-stack, modificamos os parâmetros $\alpha$ e $b$ de forma que a distância entre anéis variou no intervalo $(4,05-9,20) \AA$. Nossos resultados de $E_{i j}$ em função da distância estão ilustrados nas Figuras 2.13 (herringbone) e 2.15 ( $\pi$-stack) e mostram um comportamento tipicamente exponencial para a integral de 
transferência.

Em linhas gerais podemos diferenciar os empacotamentos herring-bone $(H B)$ e $\pi$-stack $(\pi$-S) por meio do uso de vetores auxiliares para caracterizar a disposição relativa das cadeias de PPV. Quanto à configuração $\pi$-stacking, por se tratar de um empacotamento muito específico, sendo particularmente intenso o acoplamento em virtude do alinhamento paralelo entre as cadeias e do empilhamento fenil-vinil, modelamos separadamente a transferência eletrônica deste caso e usamos como modelo geral aquele do empacotamento herring bone, conforme o esquema abaixo.

$$
I T=H(\theta, r)=\left\{\begin{array}{l}
H^{\pi-S}(r), \text { se } \theta<10 ; \text { e } 36<\theta_{1}, \theta_{2}<50 \\
H^{H B}(\theta, r), \text { demais casos }
\end{array}\right\}
$$

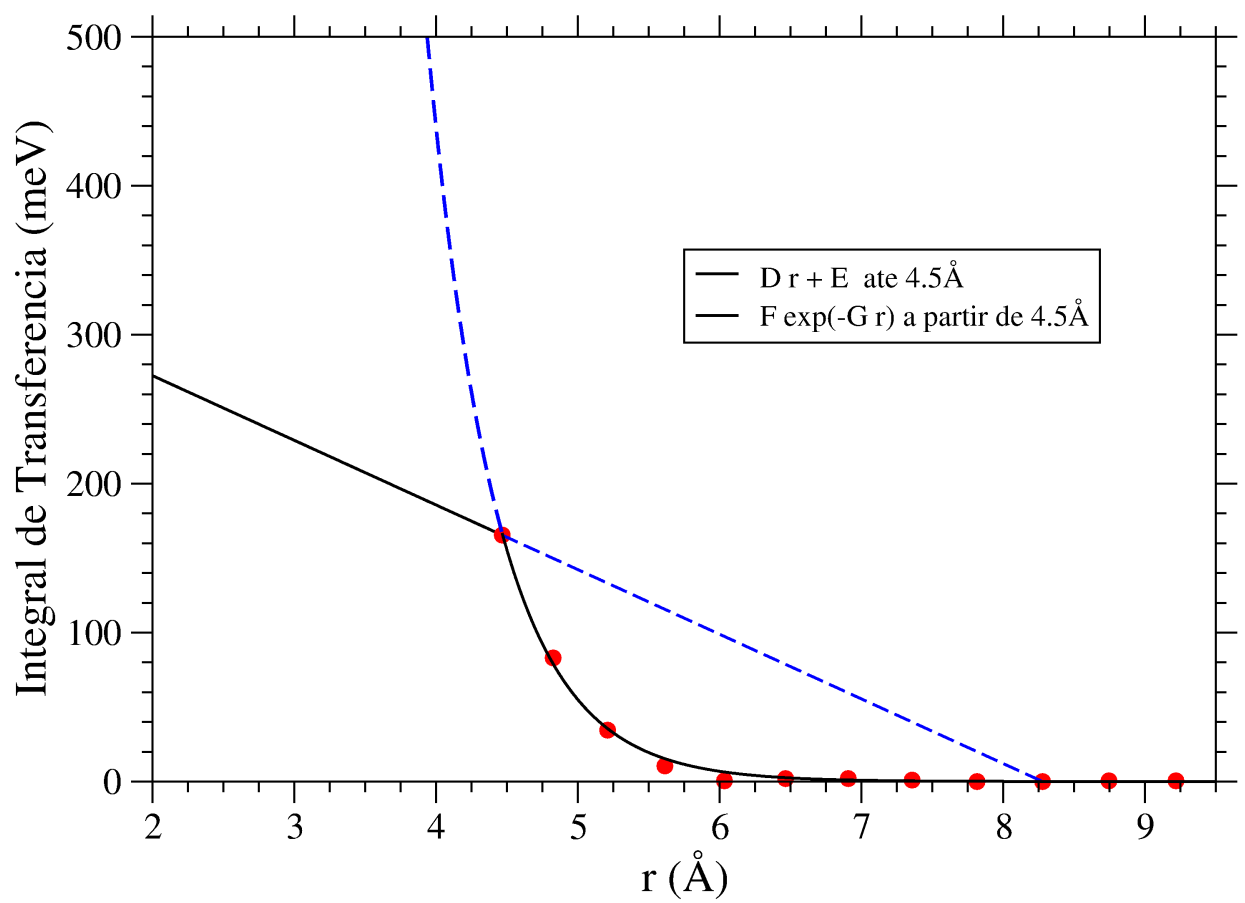

Figura 2.15: Ajuste da dependência das integrais de transferência $a b$ initio para a simetria $\pi$-stacking dos cristais de PPV, $H^{\pi-S}(r)$. 
Além disso, realizamos a parametrização integrais de transferência em termos de um modelo de campo médio, assumindo a simplificação de que são separáveis os efeitos da distância $(r)$ e do ângulo entre anéis $(\theta)$

$$
H^{H B}(\theta, r)=H_{\theta} \times H_{r}
$$

Parametrizamos a curva para $H_{r}$ a partir dos pontos calculados usando as estrutura de bandas, conforme exposto anteriormente, em função da distância entre os anéis da cadeia. Para ajuste escolhemos um modelo linear, que representa de forma razoável a tendência dos pontos calculados, garante boa estabilidade numérica, e preserva a simplicidade do modelo.

$$
H_{r}=A r+B
$$

A parte angular, $H_{\theta}$, da integral de transferência entre duas cadeias foi obtida renormalizando os valores calculados por método ab initio (eq. 2.25), tomados como função do ângulo entre as cadeias, e, assim, aplicamos o ajuste do parâmetro $C$, com a equação-modelo 2.26 (figura 2.14).

$$
\begin{gathered}
H_{\theta}=\frac{H(\theta, r)}{H_{r}} \\
H_{\theta}=C|\cos (\theta)|
\end{gathered}
$$

Partindo da equação 2.26, a forma de $H_{\theta}$ foi escolhida por observação direta da forma das curvas, juntamente com a imposição da simetria em torno do ângulo de $90^{\circ}$.

Como comentado anteriormente existe uma diferença notável para integrais de transferência do empacotamento $\pi$-stacking, em relação ao herring-bone, o que nos conduziu ao ajuste independente da dependência com a distância para esta simetria cristalina, $H^{\pi-S}(r)$, apresentado na figura 2.15. Novamente, tendo em vista a necessidade de conter valores excessivos, realizamos aqui também um ajuste linear mas apenas para distâncias inferiores a $4.5 \AA$, utilizando pontos que levam a valores razoáveis para a IT. Notamos que dificilmente precisamos utilizar tais valores, dada a quase inexistência de distância desta ordem nos filmes simulados, entretanto é uma precaução necessária. 
Tabela 2.1: Parâmetros obtidos por ajustes com mínimos quadrados realizados para as integrais de transferência ab initio utilizando os diferentes modelos de integrais de apresentados no texto, entre parênteses os coeficientes de incerteza do ajuste.

\begin{tabular}{lll|ll}
\hline HB: & $H_{r}=A r+B$ & & $H_{\theta}=C \cos \theta$ & \\
& $\mathrm{A}\left(\AA^{-1}\right)$ & $\mathrm{B}(\mathrm{eV})$ & $\mathrm{C}$ & \\
& $-0.0245(10 \%)$ & $0.1434(9 \%)$ & $1.3082(11 \%)$ & \\
\hline$\pi-\mathrm{S}:$ & $H^{\pi-S}(r)=D r+E ; r<4.5$ & & $H^{\pi-S}(r)=F \exp (-G r) ; r \geq 4.5$ & \\
\hline $\mathrm{D}\left(\AA^{-1}\right)$ & $\mathrm{E}(\mathrm{eV})$ & $\mathrm{F}(\mathrm{eV})$ & $\mathrm{G}\left(\AA^{-1}\right)$ \\
-0.0434 & 0.3593 & $1785.44(26 \%)$ & $2.0774(3 \%)$ \\
\hline
\end{tabular}

A tabela 2.1 resume o conjunto de parâmetros para estas diferentes integrais de transferência, bem como as incertezas nos ajustes.

\subsubsection{Cargas de Hirshfeld}

Finalmente, descrevemos aqui o procedimento adotado para associar cargas aos átomos-namolécula necessário na simulação de DMC. Dentre os mais conhecidos métodos de cálculo de cargas atômicas, estão aqueles em que a Matriz População $P$ compõem a função de densidade eletrônica $\rho(r)$, como os métodos de Mulliken [55] e Löwdin [56]. Hirshfeld [57] propôs uma metodologia totalmente diferente e baseada diretamente nas densidades eletrônicas da molécula (átomos ligados) e dos átomos livres. A participação de cada componente na densidade eletrônica do sistema (uma molécula, por exemplo) é realizada segundo a função de partição definida como:

$$
\omega_{A}(r)=\frac{\rho_{A}(r)}{\sum_{A^{\prime}} \rho_{A}(r)}
$$

em que $\rho_{A}(r)$ é a densidade para o átomo livre A (isolado) no estado fundamental, colocado na posição (molecular) do átomo ligado correspondente, e a soma em A inclui todos os átomos da molécula. A densidade correspondente ao átomo ligado é dada por: 


$$
\rho_{A}^{l i g}(r)=\omega_{A}(r) \rho^{m o l}(r)
$$

em que $\rho^{m o l}(r)$ é a densidade eletrônica real da molécula. A carga de Hirshfeld para o átomo A é obtida usando:

$$
Q_{A}=Z_{A}-\int d r^{3} \rho_{A}^{l i g}(r)
$$

onde $Z_{A}$ é o número atômico do átomo em questão. Essa definição é também chamada de "divisão acionária", dada a característica de participação ou contribuição de cada átomo à densidade eletrônica em cada ponto do espaço. 


\section{Capítulo 3}

\section{Parametrização do Campo de Forças Universal}

A Dinâmica Molecular Clássica (DMC) permite simulações atomísticas de sistemas-modelo com grandes células unitárias que seriam intratáveis em sua totalidade com metodologia $a b$ initio. Assim, nossas simulações de grandes regiões amorfas, importantes na definição das propriedades eletrônicas dos polímeros, foram realizadas aplicando as técnicas de DMC. Nestes cálculos, a energia total de um sistema é escrita a partir da forma funcional e dos parâmetros de um campo de força clássico, de forma que é importante saber qual campo descreve melhor o sistema analisado.

Dentre os diversos campos de força existentes, o campo Universal (UFF) [23] usa tipos atômicos facilmente definidos a partir do elemento atômico, da hibridização e conectividade. Além disso, de modo geral o UFF é conhecido por apresentar boa descrição estrutural para comprimentos de ligação e ângulos simples. A escolha do UFF é devida também à grande vantagem se tratar de um Campo "editável", dentro de vários pacotes computacionais, de domínio público ou comerciais [58] e ainda, apesar deste trabalho tratar somente de sistemas carbono-hidrogênio $(\mathrm{CH})$, é importante enfatizar que todos os átomos da tabela periódica são incluidos. Isto torna o UFF mais interessante se considerarmos uma visão mais ampla, já que o nosso grupo trabalha com heteroátomos de enxofre $(\mathrm{S})$, oxigênio $(\mathrm{O})$ e nitrogênio $(\mathrm{N})$ e já extendeu a análise também à metais como o ouro $(\mathrm{Au})$ e o alumínio $(\mathrm{Al})$. 


\subsection{Campo de Forças Universal (UFF)}

Descrevemos brevemente os termos de enegia ligada e não ligada associados ao campo de forças Universal1.02 (UFF). Como veremos a interação ligada de energia do UFF será mantida devido à boa descrição interna dos nossos sistemas. Entretanto, modificamos as contribuições não ligadas de energia para uma melhor adequação dos sistemas conjugados.

A energia total do UFF leva em conta interações de átomos ligados e não-ligados da seguinte forma:

$$
E=E_{R}+E_{\phi}+E_{\theta}+E_{\omega}+E_{v d w}+E_{e l}
$$

As chamadas interações ligadas representam energia de estiramento de ligações $\left(E_{R}\right)$, de ângulos internos $\left(E_{\theta}\right)$, de torção $\left(E_{\phi}\right)$ e os termos de inversão $\left(E_{\omega}\right)$. As interações entre os átomos não ligados incluem as interações eletrostática $\left(E_{e l}\right)$ e de Van der Waals $\left(E_{v d w}\right)$. Podemos escolher diferentes funcionais para cada termo, assim listamos abaixo os que foram usados neste trabalho.

Energia de Estiramento $\left(E_{R}\right)$ : Harmônica

$$
E_{R}=\frac{1}{2} K_{I J}\left(r-r_{I J}\right)^{2}
$$

Neste caso, $K_{I J}$ e $r_{I J}$ referem-se à constante de força em kcal $/$ mol- $\AA^{2}$ e distância de equilíbrio em $\AA$, respectivamente, entre átomos I e J.

Ângulos internos $\left(E_{\theta}\right)$ : Harmônica

$$
E_{\theta}=\frac{1}{2} K_{I J K}\left(\theta-\theta_{I J K}\right)^{2}
$$

$K_{I J K}$ e $\theta_{I J K}$ referem-se à constante de força angular e ângulo de equilíbrio entre os átomos $I J K$, respectivamente, centrado no átomo $J$.

Ângulos de torção $\left(E_{\phi}\right)$ : Projeção

$$
E_{\phi}=K_{I J K L} \sum_{n=0}^{m} C_{n} \cos (n \phi)
$$

Sendo $K_{I J K L}$ a constante de força, $\phi$ o ângulo de torção e os coeficientes da expansão $C_{n}$ são determinados pela barreira e periodicidade do potencial. 


\section{Inversão $\left(E_{\omega}\right)$ :}

Também conhecida como "umbrela", é tomada como expansão em série de cossenos em $\omega$, e refere-se a $I$ ligados a outros três outros átomos J, K e L, da seguinte forma:

$$
E_{\omega}=K_{I J K L}\left(\cos (\omega)-\cos \left(\omega_{I J K L}\right)\right)
$$

em que $K_{I J K L}$ é a constante de força e $\omega_{I J K L}$ é o ângulo entre o eixo IL e o plano IJK.

Dispersão $\left(E_{v d w}\right)$ : Lennard-Jones

$$
E_{v d w}=D_{I J}\left\{-2\left[\frac{r_{I J}}{r}\right]^{6}+\left[\frac{r_{I J}}{r}\right]^{12}\right\}=-\frac{C_{6}}{r^{6}}+\frac{C_{12}}{r^{12}}
$$

onde

$$
r_{I J}=1 / 2\left(r_{I}+r_{J}\right) \quad \text { e } \quad D_{I J}=\sqrt{D_{I} D_{J}}
$$

O termo $D_{I J}(\mathrm{kcal} / \mathrm{mol})$ é a profundidade do potencial e $r_{I J}$ é a distância $(\AA)$ de equilíbrio entre os átomos $I$ e $J$. A tabela 3.1 apresenta valores de $D_{I J}$ e $r_{I J}$ para os átomos de carbono (C) e hidrogênio $(\mathrm{H})$ adotados como padrão no UFF.

Tabela 3.1: Valores padrão do UFF para profundidade de potencial $D_{I J}$ e distância de equilíbrio $r_{I J}$ para os átomos de carbono $\mathrm{C}$ e hidrogênio $\mathrm{H}$.

\begin{tabular}{c|c|c}
\hline & $r_{I J}$ (angstrons) & $D_{I J}(\mathrm{kcal} / \mathrm{mol})$ \\
\hline $\mathrm{C}$ & 3.851 & 0.105 \\
$\mathrm{H}$ & 2.886 & 0.044 \\
\hline
\end{tabular}

Eletrostática $\left(E_{e l}\right)$ :

$$
E_{e l}=c_{0} \frac{Q_{I} Q_{J}}{\varepsilon r}
$$

Aqui, $c_{0}$ é a constante de dimensionalidade, $Q_{I}$ e $Q_{J}$ são as cargas, $r$ é a distância interatômica, e $\varepsilon$ é a constante dielétrica tomada igual a 1. As cargas sobre cada átomo podem ser calculadas usando o Método de Equilíbrio de Cargas (QEq - Charge Equilibration [59]) descrito abaixo. Neste caso, as cargas dependem da geometria do sistema analisado, do átomo 
em questão e ainda do ambiente externo. Assim, se desejarmos otimizar uma dada geometria e também calcular as cargas sobre os átomos, usamos o UFF seguido do cálculo de cargas atômicas usando o QEq em um ciclo que termina com a energia total convergida. No QEq [59] a energia atômica está relacionada a dados experimentais tais como afinidade eletrônica $(A E)$

$$
A E=E_{A 0}-E_{A}(-1)
$$

e potencial de ionização $(P I)$.

$$
P I=E_{A}(+1)-E_{A 0}
$$

Nas quais $E_{A 0}$ representa a energia de um átomo neutro, $E_{A}(-1)$ e $E_{A}(+1)$ indicam as energias do átomos com falta e excesso de uma carga, nesta ordem. A energia de um átomo como função de carga é aproximada por:

$$
E_{A}(Q)=E_{A 0}+\chi_{A}^{0} Q_{A}+1 / 2 J_{A A}^{0} Q_{A}^{2}
$$

em que $\chi_{A}^{0}$ e $J_{A A}^{0}$ são derivados de dados experimentais através das relações

$$
\chi_{A}^{0}=\frac{1}{2}(P I+A E) \quad J_{A A}^{0}=P I-A E
$$

Podemos obter a condição de equilíbrio a partir do potencial químico (uma função das cargas sobre todos os átomos):

$$
\chi_{A}\left(Q_{1}, \ldots, Q_{N}\right)=\frac{\delta E}{\delta Q_{A}}=\chi_{A}^{0}+J_{A A}^{0} Q_{A}+\sum_{B \neq A} J_{A B} Q_{A}
$$

O cálculo de energias entre átomos não ligados envolvendo as interações eletrostática e de van der Waals é incluído para pares de átomos a partir de terceiros-vizinhos, e limitado por uma distância de corte. No caso de simulação de cristais, utilizamos para as interações de longo alcance entre um átomo e suas imagens periódicas o método de somas de Ewald. Neste caso, o potencial pode ser escrito como a soma [60]:

$$
E_{Q Q}=\frac{1}{2} \sum_{\vec{n}}\left(\sum_{i=1}^{N} \sum_{j=1}^{N} Q_{i} Q_{j}\left|\vec{r}_{i j}+\vec{n}\right|^{-1}\right)
$$




\subsection{Otimização de Geometria: Temperatura Nula}

A estrutura otimizada de um sistema seria aquela em que todas as forças existentes foram balanceadas, e o sistema está então em equilíbrio estático. Tomando o exemplo mais simples possível de um oscilador harmônico unidimensional onde a energia E é expressa em termos de uma variável $x$, e duas constantes $k$ e $x_{0}$, temos:

$$
E=\frac{1}{2} k\left(x-x_{0}\right)^{2}
$$

A solução é obtida partindo de uma estrutura inicial (ou tentativa), $x_{1}$, e é perseguida a estrutura que esteja cada vez mais próxima do valor de $x$ que minimiza $E$. Tomando a primeira e segunda derivadas da equação 3.15 em relação a $x$ chegamos às relações

$$
\begin{gathered}
\frac{d E}{d x}=k\left(x-x_{0}\right) \\
\frac{d^{2} E}{d x^{2}}=k
\end{gathered}
$$

A partir do ponto da superfície correspondente a uma estrutura inicial o processo de minimização de energia ocorre de forma iterativa. Em cada iteração, determina-se a direção de mudança das coordenadas a partir do gradiente de energia potencial $\frac{d E}{d x}$.

$$
x_{0}-x_{1}=-\frac{1}{\frac{d^{2} E}{d x^{2}}} \frac{d E}{d x}
$$

Numa situação mais geral, para um potencial qualquer (não-harmônico) são necessários vários passos para se chegar a condição de mínimo. Existem várias técnicas para se obter a estrutura de menor energia, aqui utilizamos sempre o método do Gradiente Conjugado, em que, sendo a constante de força $\frac{d^{2} E}{d \vec{r}^{2}}$ escrita como uma constante $\gamma$ :

$$
\vec{r}_{0}-\vec{r}_{1}=-\gamma \frac{d E}{d \vec{r}}
$$

o método inicialmente assume a direção do gradiente $\frac{d E}{d \vec{r}}$ e continua até obter um mínimo nesta direção. Uma vez que a direção corrente foi minimizada qualquer melhoramento ocorrerá em direções ortogonais, assim o algoritmo passa a seguir numa direção normal (ou conjugada) da direção corrente. O procedimento é repetido até que se consiga a menor energia para o sistema [61]. 


\subsection{Evolução Temporal: Temperatura Não Nula}

Em dinâmica molecular admitimos que o sistema está em movimento associado a uma dada temperatura não nula. A posição $\vec{r}$ das partículas de um sistema, a velocidade $\vec{v}$ e ainda a aceleração $\vec{a}$ são obtidas novamente usando a mecânica newtoniana. As forças são dadas pelo negativo do gradiente da energia potencial para a $i$-ésima partícula:

$$
\vec{F}_{i}=-\frac{\delta V}{\delta \vec{r}_{i}}
$$

Considerando por simplicidade de notação o movimento unidimensional, se conhecemos a posição $x$ no tempo $t, x(t)$, então é possível obter uma equação de movimento para pequenos intervalos de tempo (conhecida como equação de Verlet):

$$
x(t+\delta t)=2 x(t)-x(t-\delta t)+a(t) \delta t^{2}
$$

Para um sistema de $3 n$ coordenadas pode-se mostrar que a posição $\vec{r}$ e a velocidade $\vec{v}$ de uma partícula podem ser calculadas usando o algoritmo de Verlet de velocidade:

$$
\begin{gathered}
\vec{r}(t+\delta t)=\vec{r}(t)+v(t) \delta t+\frac{1}{2} \vec{a}(t) \delta t^{2} \\
\vec{v}(t+\delta t)=\vec{v}(t)+\frac{1}{2}[\vec{a}(t)+\vec{a}(t+\delta t)] \delta t
\end{gathered}
$$

onde o passo de tempo $\delta t$ deve ser pequeno o suficiente para que a aproximação descrita anteriormente seja válida.

A relação com a temperatura é calculada a partir das velocidades atômicas:

$$
3 n k_{B} T=\sum_{i=1}^{n} m_{i} v_{i}^{2}
$$

Além disso, nos cálculos Dinâmica Molecular precisamos ainda definir o "ensemble". Um sistema cujas paredes são diatérmicas, móveis e que não permite troca de partículas ( $N$ fixo) é descrito pelo ensemble NPT, temperatura T e pressão P fixas. Escolhemos para implementar este ensemble o método de Andersen [62].

Já no ensemble NVT, o número de partículas, o volume V e a temperatura são mantidos constantes. Neste caso, usamos o método de Nosé-Hoover [63]. 


\subsection{Verificação estrutural segundo o UFF}

A boa representação de um sistema complexo passa pela boa descrição do sistema mais simples possível, de forma que nossa primeira verificação estrutural para o $P P V$ como forma de validação do Campo Universal se deu para o oligômero isolado $P_{4} V_{3}$.

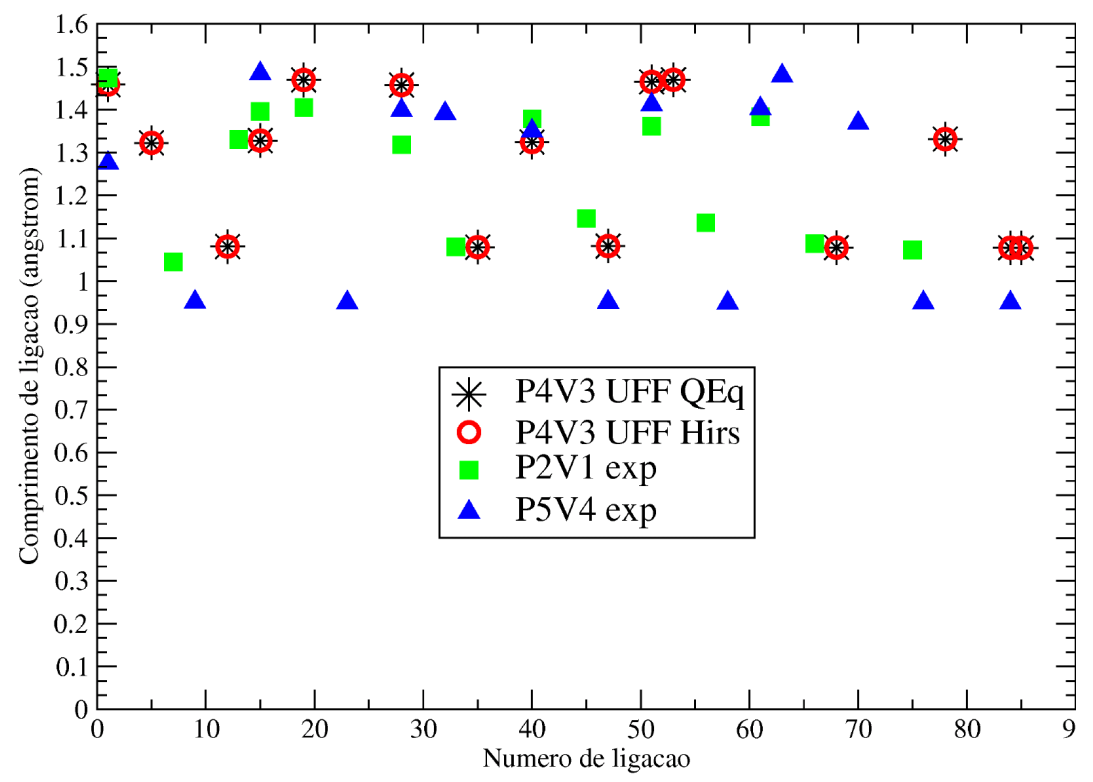

Figura 3.1: Comprimentos de ligação para o $P_{4} V_{3}$. A maior diferença ocorre para ligação $C-H$ com valores para o $P_{4} V_{3}$ até $13 \%$ maiores em relação aos observados em cristais de $P_{5} V_{4}$.

Como dito anteriormente, uma das vantagens associadas ao Campo Universal é o fato deste ser parametrizável. Dessa forma, partindo do cálculo de cargas e usando o pacote OFF (Open Force Field) do Cerius2 [58], fixamos cargas atômicas não-nulas no UFF. Analisamos a interação ligada de energia do campo de forças UFF com cargas fixas vindas do QEq e do método de Hirshfeld. A Figura 3.1 mostra que as diferentes cargas fixas não afetam a conjugação do sistema, apresentando comprimentos de ligação muito similares. Comparativamente a Figura 3.1 mostra também que nossos resultados calculados para o $P_{4} V_{3}$ apresentam boa concordância com os valores observados em sistemas cristalinos de $P_{2} V_{1}$ e $P_{5} V_{4}$. A maior diferença ocorre nas ligações $C-H$ em relação as cadeias de $P_{5} V_{4}$, neste caso, as ligações são muito curtas e ficam em torno de $0.95 \AA$, enquanto nas cadeias de $P_{2} V_{1}$ e $P_{4} V_{3}$ estas ligações são até $13 \%$ mais longas.

Partimos agora para análise dos ângulos de torção das cadeias de $P_{4} V_{3}$ ainda em comparação 


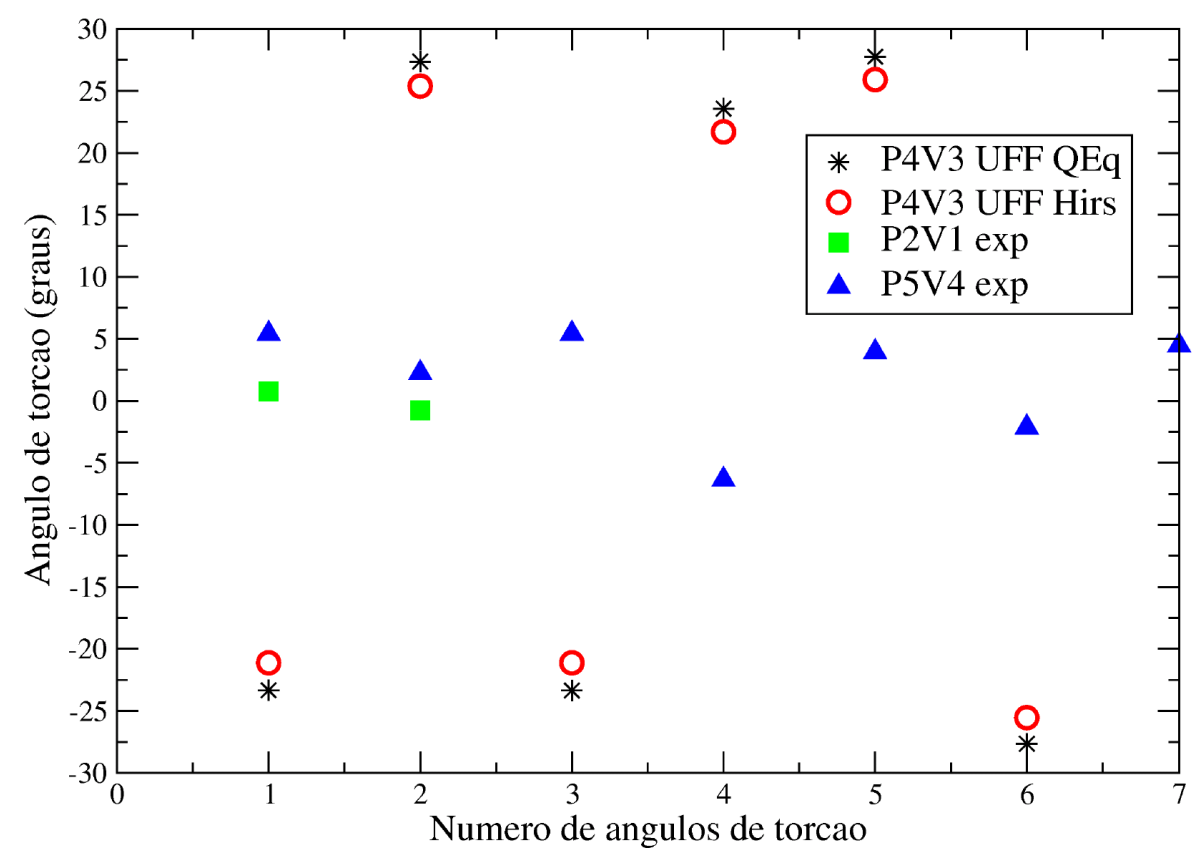

Figura 3.2: Ângulos de torção calculados para cadeias isoladas de $P_{4} V_{3}$ usando os campos UFFQEq e UFF-Hirs comparativamente aos valores observados para cadeias de cristais de $P_{2} V_{1}$ e $P_{5} V_{4}$. As moléculas de $P_{2} V_{1}$ são praticamente planares, o $P_{5} V_{4}$ apresenta torções de até $6^{\circ}$ enquanto as cadeias de $P_{4} V_{3}$ são bastante torcidas com ângulos diedrais de até $27^{\circ}$.

aos observados em cristais de $P_{2} V_{1}$ e $P_{5} V_{4}$, segundo mostra a figura 3.2. Nossos resultados apontam para cadeias com ângulos de torção que variam de 21 a $25^{\circ}$ quando usamos o campo UFF-Hirs e cadeias mais torcidas quando usamos o campo UFF-QEq com variações para torção de $23-27^{\circ}$. Os valores observados mostram que o $P_{2} V_{1}$ é aproximadamente planar enquanto o $P_{5} V_{4}$ mostra uma pequena torção de até $6^{\circ}$.

Calculamos também a barreira de torção para as moléculas isoladas de $P_{4} V_{3}$, girando os dois anéis mais internos e mantendo os demais ângulos diedrais planares. O gráfico da Figura 3.3 mostra a barreira de torção usando os campos UFF-QEq e UFF-Hirs. As curvas são semelhantes com diferença no mínimo de energia total: O campo UFF-QEq fornece o mínimo em torno de $15^{\circ}$ enquanto o campo UFF-Hirs fornece o mínimo de cadeia planar.

A seguir, verificamos a descrição dos parâmetros em cristais de cadeias infinitas de PPV segundo o campo UFF com efeito de cargas atômicas fixas. Para cada cristal calculamos as isosuperfícies de Energia total $\left(E_{T}\right)$ e as contribuições de interações de van der Waals $\left(E_{v W}\right)$ 


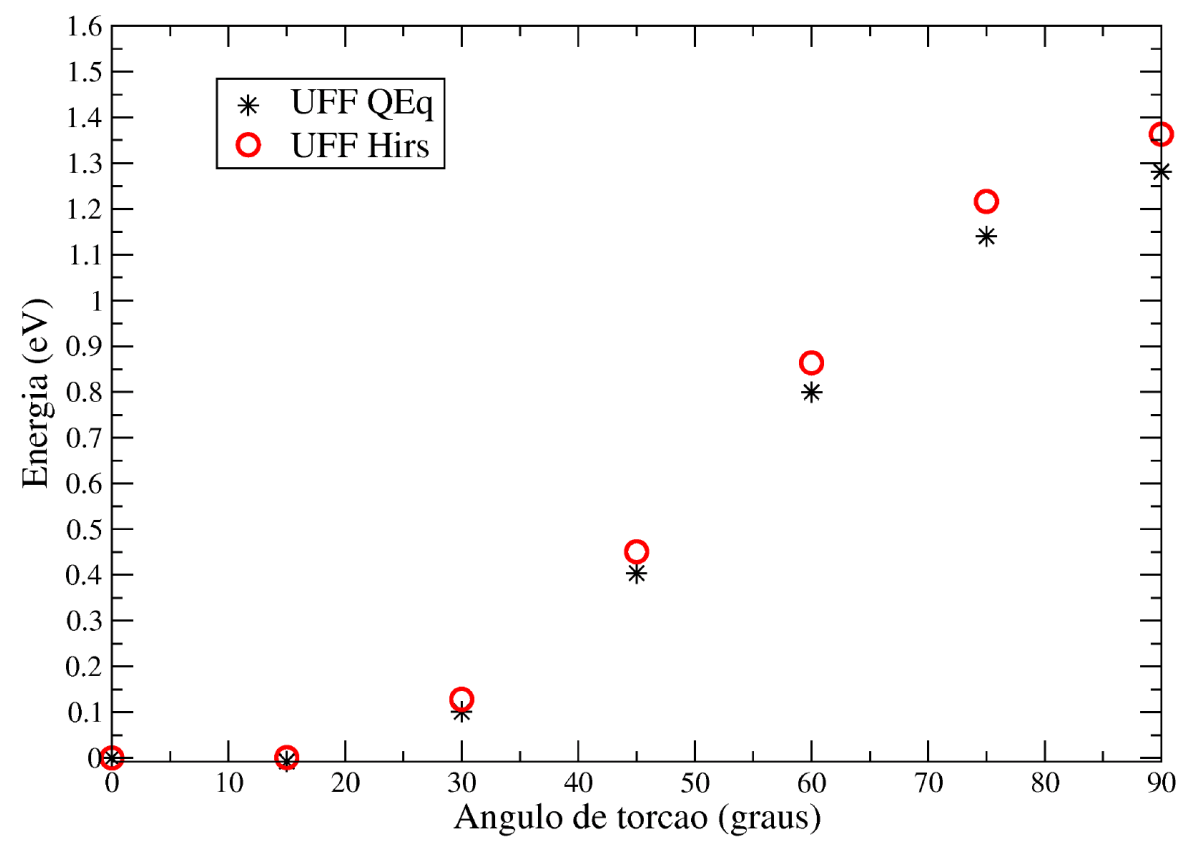

Figura 3.3: Barreira de torção para cadeias isoladas de $P_{4} V_{3}$ otimizadas com os campos UFFQEq e UFF-Hirs, com mínimos respectivamente em $15^{\circ}$ e $0^{\circ}$.

e Coulomb $\left(E_{C}\right)$ e quando necessário, calculamos também as contribuições de energia ligada $\left(E_{L}\right)$ correspondente a soma das energias de torção, ligação, inversão e ângulos.

Dessa forma, estudaremos cristais de PPV em deslocamento $\pi$-stack e com simetria herringbone. O objetivo neste caso, é investigar se o campo de forças Universal UFF consegue descrever de forma satisfatória os cristais estudados.

\subsection{Cristal de PPV $\pi$-stack}

Uma das propriedades estruturais mais importantes para o transporte por "hopping" entre duas cadeias orgânicas está relacionada à distância entre os eixos das cadeias $(d)$ e o ângulo intermolecular $(\alpha)$. No chamado deslocamento $\pi$-stack $(\pi S)$ as cadeias estão alinhadas ao longo da direção ortogonal aos seus planos, de forma que o fenil de uma cadeia esteja acima do segmento vinil da cadeia imagem, deslocado ao longo da direção da cadeia (eixo $c$ ) por metade da célula unitária [64] conforme mostra a figura 3.4.

Experimentalmente o $\pi S$ pode ser observado para os diferentes derivados do PPV, como 


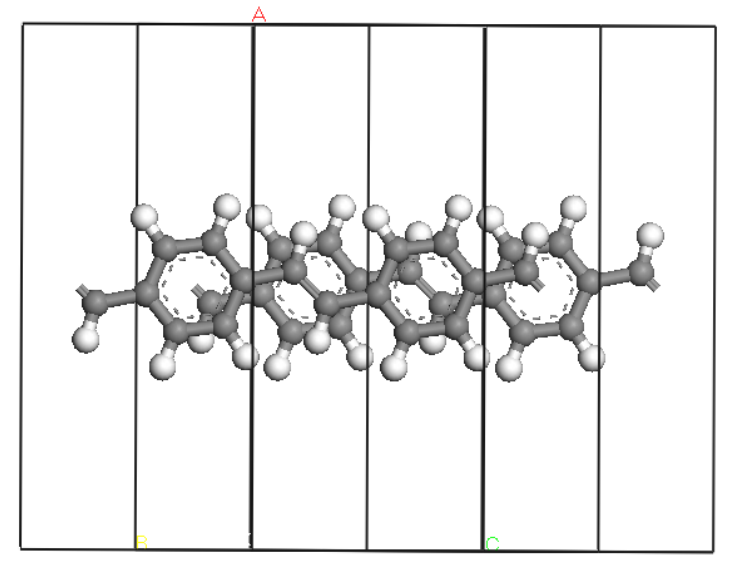

Figura 3.4: Cadeia infinita de PPV na disposição $\pi$-stack $(\pi S)$, com parâmetros $a=15 \AA$, $c=6.611 \AA$ (Otimizado UFF), $\beta=\gamma=90^{\circ}$. Os parâmetros $b$ e $\alpha$ estão relacionados com a distância $d$ entre os planos de cadeias vizinhas $(d=$ bsen $\alpha)$, cuja distância de referência [65] vale $d=3.56 \AA$.

o MEH-PPV [65] e o DO-PPV [66] cujas distâncias $d$ perpendiculares entre cadeias vizinhas são bem estabelecidas, $d=3.56 \AA$ para o MEH-PPV e $d=4.1 \AA$ para o DO-PPV. No caso do PPV a distância entre os planos das cadeias não é exatamente conhecida, mas sabe-se que [67] a introdução de cadeias laterais em cristais de PPV resulta no afastamento entre os planos moleculares.

Para o PPV $\pi$-stack variamos a distância $d$ entre cadeias vizinhas com incrementos de $\pm 0.05 \AA$ em torno do valor de stack obtido para o MEH-PPV, $d=3.56 \AA$. Para cada valor $d$, usando a relação $d=b \operatorname{sen} \alpha$, variamos o ângulo $\alpha$ a cada $1^{\circ}$, coletamos o respectivo valor de $b$ e calculamos a energia total de cada configuração com $a=15 \AA$ (pilhas lateralmente isoladas) considerando $c(\mathrm{UFF} / \mathrm{QEq})=6.609 \AA$. Como veremos na tabela 3.2, calculamos os módulos das cargas atômicas para a cadeia de $P_{4} V 3$ isolada usando a partição de Hirshfeld [57] com os métodos ab initio HF, MP2, DFT/GGA e DFT/LDA com base 6-31G(d,p) e para a cadeia infinita de PPV usando o método QEq.

O valor das cargas fixas de cada átomo é obtido fazendo uma média das cargas de referência sempre com o cuidado de manter o sistema com carga total nula. A tabela 3.3 mostra os rótulos atribuídos para os diferentes cálculos. 
Tabela 3.2: Cargas de Hirshfeld para o $P_{4} V_{3}$ planar obtidas com os métodos HF, MP2, GGA e LDA com a base 6-31G(d,p) e para uma cadeia infinita de PPV obtidas com o método QEq.

\begin{tabular}{c|c|c|c|c|c}
\hline Átomos & $\mathrm{HF}$ & $\mathrm{MP} 2$ & $\mathrm{GGA}$ & $\mathrm{LDA}$ & $\mathrm{QEq}$ \\
\hline$C_{1}$ & -0.0401 & -0.0391 & -0.0454 & -0.0514 & - \\
$C_{2}$ & -0.0387 & -0.0411 & -0.0460 & -0.0522 & - \\
$C_{3}$ & -0.0405 & -0.0387 & -0.0437 & -0.0492 & - \\
$C_{4}$ & -0.0021 & -0.0040 & -0.0055 & -0.0082 & - \\
$C_{5}$ & -0.0375 & -0.0368 & -0.0415 & -0.0467 & - \\
$C_{6}, C_{8}$ & -0.0375 & -0.0399 & -0.0448 & -0.0508 & - \\
$C_{7}$ & -0.0363 & -0.0373 & -0.0435 & -0.0488 & - \\
$C_{1}^{\prime}, C_{4}^{\prime}$ & -0.0024 & -0.0027 & -0.0053 & -0.0078 & +0.0398 \\
$C_{2}^{\prime}, C_{5}^{\prime}$ & -0.0369 & -0.0379 & -0.0421 & -0.0472 & -0.1107 \\
$C_{3}^{\prime}, C_{6}^{\prime}$ & -0.0386 & -0.0383 & -0.0427 & -0.0479 & -0.0954 \\
$C_{7}^{\prime}$ & -0.0368 & -0.0380 & -0.0441 & -0.0494 & -0.1324 \\
$H_{1}$ & 0.0405 & 0.0420 & 0.0475 & 0.0543 & - \\
$H_{2}$ & 0.0412 & 0.0419 & 0.0478 & 0.0546 & - \\
$H_{3}$ & 0.0376 & 0.0390 & 0.0444 & 0.0507 & - \\
$H_{5}$ & 0.0387 & 0.0396 & 0.0450 & 0.0508 & - \\
$H_{6}$ & 0.0408 & 0.0415 & 0.0475 & 0.0543 & - \\
$H_{7}, H_{8}$ & 0.0359 & 0.0364 & 0.0418 & 0.0472 & - \\
$H_{2}^{\prime}, H_{5}^{\prime}$ & 0.0399 & 0.0403 & 0.0460 & 0.0519 & 0.0943 \\
$H_{3}^{\prime}, H_{6}^{\prime}$ & 0.0384 & 0.0394 & 0.0451 & 0.0516 & 0.0943 \\
$H_{7}^{\prime}$ & 0.0361 & 0.0366 & 0.0420 & 0.0474 & 0.1100 \\
\hline
\end{tabular}

Dessa forma, partindo do cálculo de cargas atômicas de Hirshfeld, obtidas do cálculo ab initio MP2 com o conjunto de base $6-31 \mathrm{G}(\mathrm{d}, \mathrm{p})$ para o oligômero $P_{4} V_{3}\left(P_{4} V_{3} / \mathrm{MP} 2 / 6\right.$ $31 \mathrm{G}(\mathrm{d}, \mathrm{p}) /$ Hirshfeld $)$, descritas na tabela 3.2, obtemos o conjunto de cargas fixas que chamaremos de $Q_{1}$. Da mesma forma, o conjunto de cargas fixas vindas do método $P_{4} V_{3} / \mathrm{LDA} / 6$ $31 \mathrm{G}(\mathrm{d}, \mathrm{p}) /$ Hirshfeld chamaremos de $Q_{2}$ e as cargas atômicas fixas vindas do cálculo QEq para 
Tabela 3.3: Rótulos atribuídos aos conjuntos de cargas fixas obtidos com diferentes métodos.

\begin{tabular}{c|c}
\hline Método de obtenção de Carga & Rótulo de Carga Fixa \\
\hline$P_{4} V_{3} / \mathrm{MP} 2 / 6-31 \mathrm{G}(\mathrm{d}, \mathrm{p}) /$ Hirshfeld & $Q_{1}$ \\
$P_{4} V_{3} / \mathrm{LDA} / 6-31 \mathrm{G}(\mathrm{d}, \mathrm{p}) /$ Hirshfeld & $Q_{2}$ \\
Cadeia infinita/QEq & $Q_{3}$ \\
\hline
\end{tabular}

Tabela 3.4: Tipos atômicos para o UFF e valores de cargas fixas vindas dos cálculos ab initio MP2 $\left(Q_{1}\right)$ e LDA $\left(Q_{2}\right)$ ambos com a base $6-31 \mathrm{G}(\mathrm{d}, \mathrm{p})$ para o oligômero $P_{4} V_{3}$ (cargas de Hirshfeld), além das cargas fixas vindas do QEq $\left(Q_{3}\right)$ para uma cadeia infinita e isolada de PPV.

\begin{tabular}{c|c|c|c|c|c|c}
\hline Carga fixa & $C_{A}$ & $C_{B}$ & $C_{C}$ & $C_{R}$ & $H$ & $H_{1}$ \\
\hline$Q_{1}$ & -0.0398 & -0.0030 & -0.0381 & -0.0370 & +0.0366 & +0.0398 \\
$Q_{2}$ & -0.0525 & -0.0080 & -0.0475 & -0.0494 & +0.0474 & +0.0525 \\
$Q_{3}$ & -0.0943 & +0.0398 & -0.1030 & -0.1324 & +0.1100 & +0.0943 \\
\hline
\end{tabular}

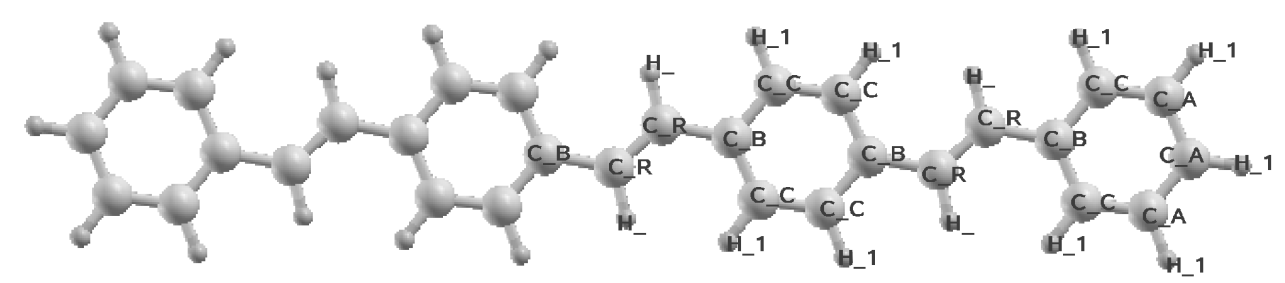

Figura 3.5: Tipos atômicos atribuídos ao Campo UFF com o propósito de manter fixas as cargas atômicas.

uma cadeia infinita e isolada de PPV chamaremos de $Q_{3}$. As cargas atômicas fixas no UFF estão descritas na tabela 3.4. O procedimento de fixar cargas no UFF, implica em utilizar átomos já existentes e "criar" outros quando necessário. No nosso caso temos os átomos $C_{A}, C_{B}, C_{C}, C_{R}, H_{1}, H$ como representados na figura 3.5. A partir de então, consideramos o efeito de diferentes cargas atômicas fixas para os cristais de PPV $\pi S$. A figura 3.6a mostra as superfícies de energia total na situação em que o UFF possui cargas fixas $Q_{1}$ cujos valores estão descritos na tabela 3.4. A distância interplanar de menor energia abrange os valores $d$ $=(3.46-3.47) \AA$ com $\alpha=(133-135)^{\circ}$. Novamente o empilhamento geométrico é bem descrito. 


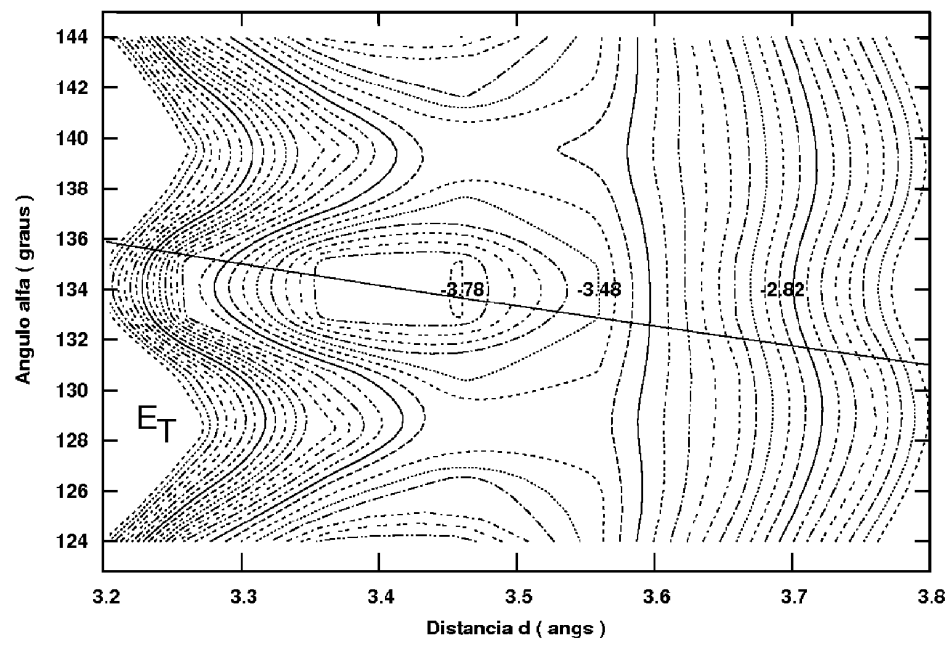

(a)

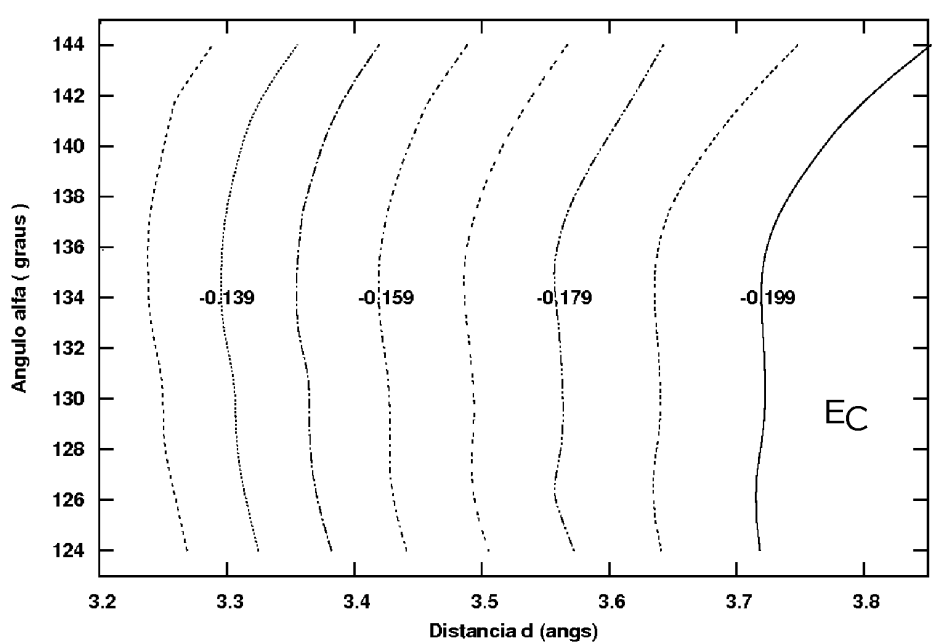

(b)

Figura 3.6: Em (a) temos a Isosuperfície de energia Total $E_{T}$ e em (b) a Isosuperfície de energia de Coulomb $\left(E_{C}\right)$, ambas em $(\mathrm{kcal} / \mathrm{mol})$, para o cristal de PPV em disposição $\pi S$ com cargas atômicas fixas $Q_{1}$. Os parâmetros de menor energia total são: $a=15 \AA, c=6.611 \AA$ (Otimizado $\mathrm{UFF}), \beta=\gamma=90^{\circ}$ (mantidos fixos), $d=(3.46-3.47) \AA \operatorname{com} \alpha=(133-135)^{\circ}$. A reta representa a curva de $\pi$-stacking geométrico para o PPV obtido da relação $\alpha=\arctan (2 d / c)$.

Neste caso a energia não-ligada de Coulomb $\left(E_{C}\right)$ representada na figura 3.6b, mostra energias mais baixas apontando para valores crescente da distância interplanar d.

No passo seguinte repetimos o procedimento descrito anteriormente, agora considerando o campo UFF com cargas atômicas não nulas fixas $Q_{2}$ e $Q_{3}$. As isosuperfícies (não mostradas aqui) são qualitavimente equivalentes àquelas mostradas na figura 3.6 e mesmo as configurações de menor energia apresentam praticamente a mesma estrutura, conforme podemos notar na tabela 
Tabela 3.5: Parâmetros do cristal de PPV $\pi$-stack. Comparação entre os resultados calculados com o UFF e cargas fixas $Q_{1}, Q_{2}$ e $Q_{3}$. Em todos os casos $\alpha=(133-135)^{\circ}$. O ângulo $\alpha$ obtido do stack geométrico em cada situação também é mostrada. Como referência temos que o stack experimental do MEH-PPV [65] é descrito por $\alpha=134.1^{\circ}$ e $d=3.56 \AA$.

\begin{tabular}{c|c|c|c}
\hline Parâmetro & $Q_{1}$ & $Q_{2}$ & $Q_{3}$ \\
\hline $\mathrm{d}(\AA)$ & $(3.46-3.47)$ & 3.47 & 3.47 \\
$\alpha$ Geométrico $\left(^{\circ}\right)$ & $(133.68-133.57)$ & 133.57 & 133.57 \\
\hline
\end{tabular}

3.5 que compara os valores de $d$ e o correspondente ângulo $\alpha$ obtido da relação geométrica $\alpha=\arctan (2 d / c)$. Enfim, podemos concluir que o stacking geométrico para o PPV é bem descrito pelo campo UFF com inclusão da energia de Coulomb a partir de cargas fixas.

\subsection{Cristal de PPV Herringbone}

A estrutura de filmes de PPV orientados foi estudada através de difração de raio X, e a partir desta análise, verificou-se que o PPV cristalino apresenta duas cadeias por célula unitária, simetria monoclínica, espaço de grupo $P 2_{1 / C}$, com constantes de rede $a=8.07 \AA, b=6.05 \AA$, $c=6.54 \AA$, $\beta=123^{\circ}$, e ângulo de colocação $\phi_{s}$ (ângulo de colocação formado entre a cadeia e o parâmetro $a)=52^{\circ}[68]$.

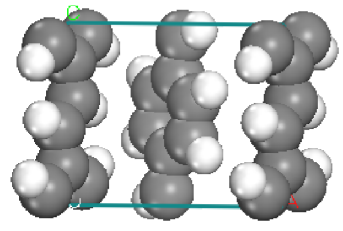

(a)

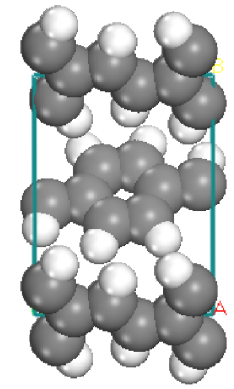

(b)

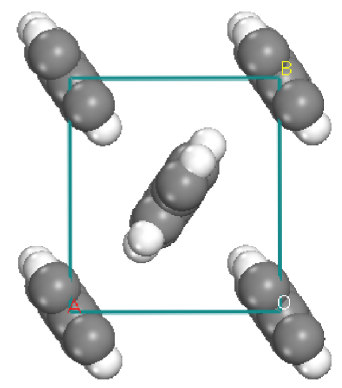

(c)

Figura 3.7: Célula unitária do PPV (empacotamento herringbone): Na figura (a) projeção no plano $a c$, em (b) no plano bc e na figura (c) no plano $a b$. 
Segundo Granier et al [30], os parâmetros para célula do PPV são: $a=7.9 \AA, b=6.05 \AA$, $c$ $=6.58 \AA, \alpha(\hat{b c})=123^{\circ}, \phi_{s}=(56-68)^{\circ}$ e densidade $\rho=1.283 \mathrm{~g} / \mathrm{cm}^{3}$. Assim, para descrição de célula unitária do PPV cristalino, precisamos minimizar pelo menos 5 diferentes parâmetros: $a$, $b, c, \alpha$ e $\phi_{s}$. Tomando como referência o cálculo de cadeia isolada obtido anteriormente, para o PPV usaremos os parâmetros $c(\mathrm{UFF})=6.611 \AA$, em bom acordo com os valores experimentais citados anteriormente.
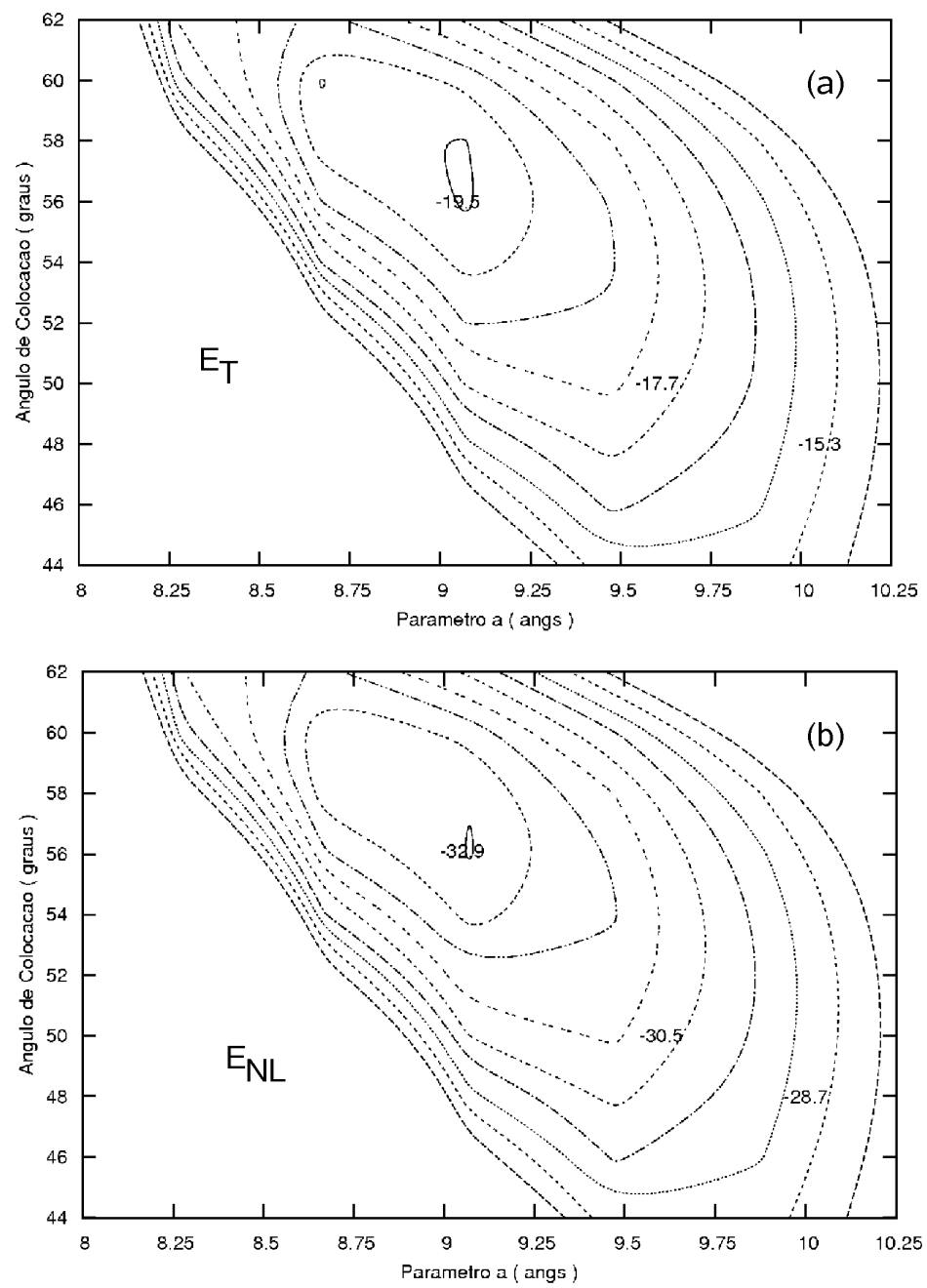

Figura 3.8: Isosuperfície de energia Total em (a) e de energia não-ligada em (b) para a célula cristalina do PPV herringbone com cargas atômicas fixas $Q_{1}$. Estrutura com menor energia total: $\alpha=133^{\circ}, b=6.05 \AA, c=6.611 \AA, a=9.10 \AA, \phi=(56-58)^{\circ}$ e $\rho=1.274 \mathrm{~g} / \mathrm{cm}^{3}$.

O passo seguinte então, é testar o Campo com cargas fixas não nulas. Assim, a figura 3.8a 
mostra as isosuperfícies de energia total usando o Campo Universal com cargas atômicas fixas $Q_{1}$, como descrito anteriormente na tabela 3.4.
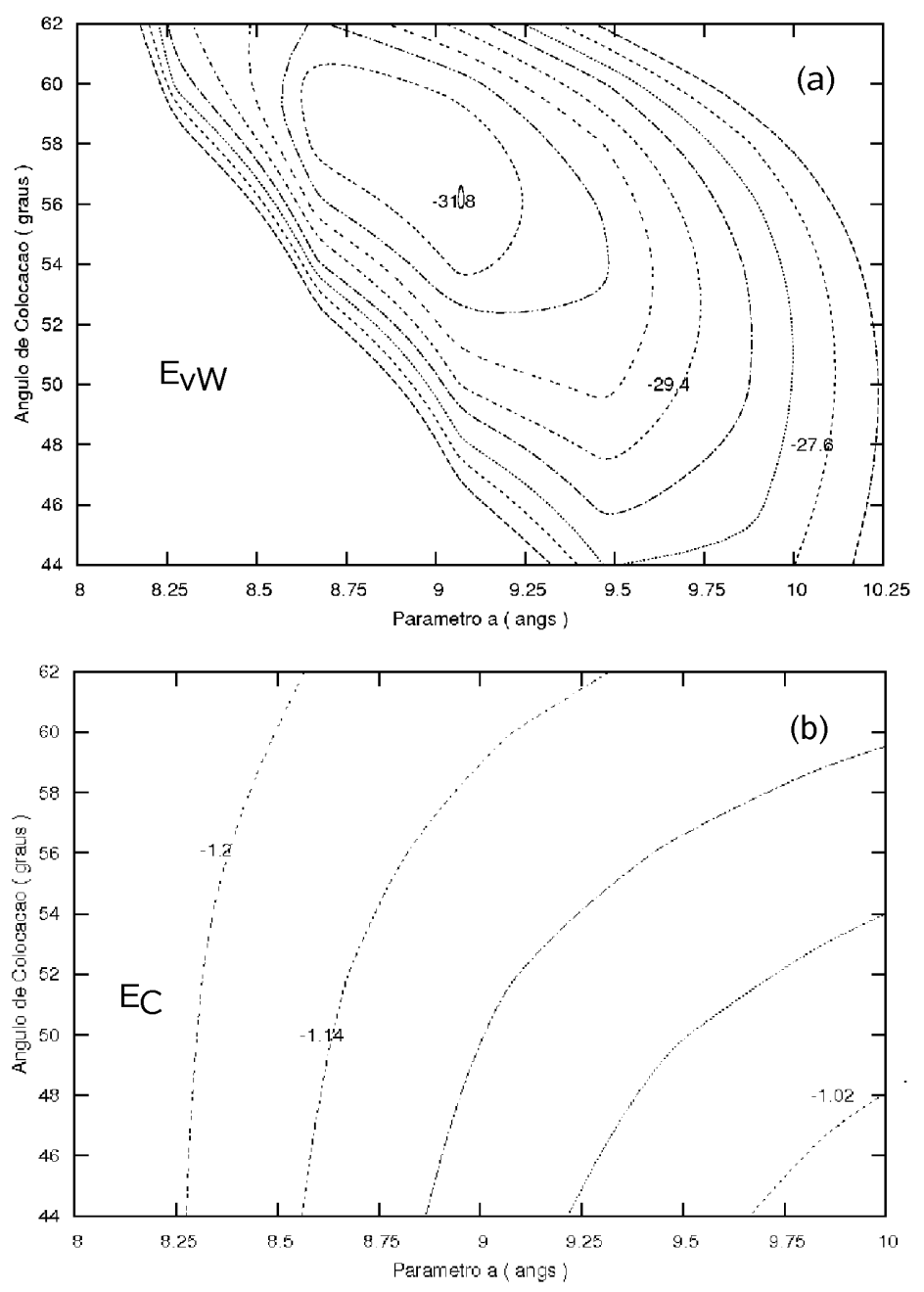

Figura 3.9: Isosuperfícies de energia de van der Waals em (a) e de energia de Coulomb em (b) para a célula cristalina do PPV herringbone com cargas atômicas fixas $Q_{1}$.

Neste caso, as situações de mínima energia total vistas na figura 3.8a estão nos intervalos: $\alpha=133^{\circ}, b=6.05 \AA, c=6.611 \AA, a=9.10 \AA, \phi=(56-58)^{\circ}$ e $\rho=1.274 \mathrm{~g} / \mathrm{cm}^{3}$. Novamente, o valor obtido para a densidade do cristal de PPV está em excelente acordo com o valor experimental $\rho_{\text {exp }}=1.28 \mathrm{~g} / \mathrm{cm}^{3}$. A influência da cargas fixas minimiza os erros dos parâmetros $\alpha$ e $a$, porém, mais uma vez os valores $\alpha=133^{\circ}$ e $a=9.10 \AA$ ficam bem acima dos valores experimentais $\left(\alpha_{\text {exp }}=123^{\circ}, a_{\text {exp }}=7.9 \AA\right)$, o que nos leva a pensar novamente que um erro corrige 
o outro para fornecer tão bom resultado para a densidade do cristal de PPV herringbone.

O mínimo de energia van de Waals (fig. 3.9a) coincide com o mínimo de energia total (fig. 3.8a). A figura 3.9b mostra que a energia de Coulomb, apresenta mínimos para menores valores de $a$, e valores de ângulo de colocação no intervalo $\phi=(56-58)^{\circ}$.

Entretanto, como o erro para $\alpha$ e $a$ em relação aos dados experimentais ainda continuam grandes partimos para outra situação, também de carga fixa. Agora fixamos as cargas $Q_{3}$ cujos módulos são, em geral, duas vezes maiores que aqueles da carga $Q_{1}$, conforme apresentado na tabela 3.4. As isosuperfícies calculadas segundo o $\mathrm{UFF}+Q_{3}$ para as energias total e não ligada, Coulomb + van der Waals, para o PPV herringbone, são similares as curvas apresentadas nas figuras 3.8 e 3.9 e por isso não serão mostradas aqui. Entretanto, o maior módulo de carga $Q_{3}$ resulta em uma estrutura de mínimo ligeiramente diferente: $\alpha=130^{\circ}, b=6.05 \AA$, $c=$ $6.609 \AA, a=8.25 \AA, \phi=54^{\circ}$ e densidade $\rho=1.342 \mathrm{~g} / \mathrm{cm}^{3}$ (densidade $4.86 \%$ acima do valor experimental [30]). Novamente, os parâmetros $\alpha\left(=130^{\circ}\right)$ e $a(=8.25 \AA)$ foram influenciados pelo efeito da carga fixa.

A tendência indica que o aumento do módulo das cargas atômicas reduz tanto o parâmetro $a$ quanto o ângulo $\alpha$. A comparação geral dos parâmetros da célula herringbone do PPV para as situações de cargas fixas $Q_{1}$ e $Q_{3}$ juntamente com os valores observados pode ser melhor visualizada na tabela 3.6 .

Tabela 3.6: Parâmetros do cristal de PPV herring-bone. Comparação entre os resultados calculados com o UFF e cargas fixas $Q_{1}$ e $Q_{3}$ descritas na tabela 3.4.

\begin{tabular}{c|c|c|c|c}
\hline Parâmetro & $Q_{1}$ & $Q_{3}$ & $\exp [68]$ & $\exp [30]$ \\
\hline$a(\AA)$ & 9.10 & 8.25 & 8.07 & 7.90 \\
$b(\AA)$ & 6.05 & 6.05 & 6.05 & 6.05 \\
$c(\AA)$ & 6.61 & 6.61 & 6.54 & 6.58 \\
$\alpha\left(^{\circ}\right)$ & 133 & 130 & 123 & 123 \\
$\phi\left(^{\circ}\right)$ & $(56-58)$ & 54 & 52 & $(56-58)$ \\
$\rho\left(g / \mathrm{cm}^{3}\right)$ & 1.274 & 1.342 & - & 1.28 \\
\hline
\end{tabular}




\subsection{Reparametrização das energias não ligadas do UFF a partir de cálculos ab initio}

Como verificamos na tabela 3.2, idealmente as cargas de Hirshfeld dos hidrogênios podem ser aproximadas por 0,05 e, os carbonos conectados aos hidrogênios apresentam carga em torno de -0,05e enquanto os demais carbonos têm carga praticamente nula. Apesar destes cálculos de carga terem sido realizados para pequenas cadeias, verificamos que estes valores podem ser tomados como padrão para sistemas baseados em fenil, vinil e fenil-vinil independentemente do tamanho da cadeia, de forma que podemos representar quaisquer destes diferentes grupos moleculares usando somente três tipos atômicos, um hidrogênio $(H)$, um carbono indicado por carbono $\alpha\left(C_{\alpha}\right)$ que representa qualquer carbono ligado a outros três átomos de carbono e mais um carbono $\beta\left(C_{\beta}\right)$ que indica qualquer átomo de carbono ligado a outros dois átomos de carbono e um átomo de hidrogênio.

Outro ponto importante a ser notado concerne o valor da carga atômica atribuída pelo método $Q E q$ aos átomos de carbono no anel fenil que conectam ao vinil $\left(C_{1}^{\prime}=C_{4}^{\prime}=C_{\alpha}\right)$. Como vemos, para o modelo empírico resulta carga positiva, ao contrário dos resultados quânticos em que temos todos os átomos de carbono são ligeiramente negativos. Essa diferença pode influenciar de forma significativa a simulação do empacotamento de cadeias pelo método de DMC.

Do exposto, adotamos o método de Hirshfeld para obtenção de cargas e correção da interação eletrostática, sendo necessárias ainda correções nos parâmetros do potencial de Lennard-Jones 6-12 que modela a repulsão de Pauli e a interação de van de Waals. Para isso, consideramos cálculos recentes da constante atrativa $C_{6}$ característica da interação de van der Waals e da separação inter-nuclear $r_{I J}[69,70]$. Podemos relacionar a confiabilidade de um campo a uma baixa margem de erros para os parâmetros cristalinos dos sistemas e ainda, à boa transferabilidade para um número suficiente de sistemas analisados. Assim, estendemos nossos estudos a diversos cristais orgânicos de fenileno, vinileno e fenileno-vinileno.

O carbono de carga nula pode ser estudado quando investigamos a grafite, sistema idealmente composto somente por carbonos do tipo $C_{\alpha}$. Usando o campo UFF verificamos uma distância interplanar de $3.38 \AA$, com erro abaixo de $1 \%$ em relação ao valor $3.4 \AA$ [71], o que 
nos levam a adimitir que nesse caso o campo padrão é já suficiente. Desta forma, após a escolha do método de obtenção de cargas, precisamos considerar uma nova busca dos parâmetros do potencial de Lennard-Jones 6-12 tomando como referência os valores de $C_{6}$ e $r_{i j}$ encontrados nos trabalhos $[69,70]$. A conversão para valores usuais de posição de mínimo em energia $r_{i j}$ em $\AA$ e profundidade de poço $D_{I J}$ em $\mathrm{kcal} / \mathrm{mol}$ podem ser vistos na tabela 3.7. A descrição do método de cálculo da constante $C_{6}$ e da distância entre núcleos $r_{i j}$ é dada a seguir.

Tabela 3.7: Constantes $C_{6}$ e $r_{i j}$ extraídas de $[69,70]$ e o valor de $D_{i j}$ calculadas usando a equação 3.25 .

\begin{tabular}{|c|c|c|c|}
\hline Átomo & $C_{6}\left(\mathrm{kcal} / \mathrm{mol} \AA^{6}\right)$ & $r_{I J}(\AA)$ & $D_{I J}(\mathrm{kcal} / \mathrm{mol})$ \\
\hline C (benzeno) & 417.5 & 3.535 & 0.107 \\
\hline C (grafeno) & 454.7 & - & - \\
\hline $\mathrm{H}$ & 33.4 & 2.783 & 0.036 \\
\hline
\end{tabular}

As relações entre as constantes atrativa $C_{6}$, repulsiva $C_{12}$, posição de menor energia $r_{I J}$ e profundidade de poço $D_{I J}$ podem ser obtidas a partir do potencial de Lennard-Jones 6-12 e são dadas por:

$$
D=\frac{C_{6}^{2}}{4 C_{12}} ; \quad r_{I J}=\left\{\frac{2 C_{12}}{C_{6}}\right\}^{1 / 6}
$$

Como já mencionado, a grafite composta somente por carbonos do tipo $C_{\alpha}$ é muito bem descrita pelo campo UFF. Assim, para o $C_{\alpha}$ fixamos o valor $r_{I J}=3.851 \AA$ do UFF, assumimos a constante atrativa para o grafeno $C_{6}=33.0$ Hartree. $(\text { Bohr })^{6}[69,70]\left(C_{6}=454.7 \mathrm{kcal} / \mathrm{mol}\right.$ $\AA^{6}$ ) e obtemos o valor do poço $D_{I J}$ usando as relações descritas anteriormente.

No caso geral, a constante $C_{6}$ pode entretanto apresentar diferenças para diferentes situações, por exemplo, para o carbono a variação é $C_{6}=\left[24.1\right.$ - 33.0]Hartree. $(\text { Bohr })^{6}[69]$ e, ainda, pode apresentar pequenas flutuações dependendo do sistema investigado. Assim, para o carbono $C_{\beta}$ realizamos pequenas perturbações em torno dos valores $C_{6}^{C s p^{2}}=30.3$ Hartree. $(\text { Bohr })^{6}\left(C_{6}=\right.$ $417.5 \mathrm{kcal} / \mathrm{mol} \AA^{6}$ ) e de $r_{I J}^{C s p^{2}}=3.535 \AA$ [70], e para o átomo de hidrogênio a variação é feita em torno de $C_{6}^{C s p^{2}}=2.42$ Hartree. $(B o h r)^{6}\left(C_{6}=33.4 \mathrm{kcal} / \mathrm{mol} \AA^{6}\right)$ e de $r_{I J}^{C s p^{2}}=2.780 \AA$. Dessa forma, temos sempre o par $C_{6}, C_{12}$ ou equivalentemente $r_{i j}, D_{i j}$ para ajuste do potencial 
de Lennard Jones 6-12.

A busca por novos parâmetros consiste em escoher um dado par $C_{6}, r_{i j}$ juntamente com cargas fixas vindas da partição de Hirshfeld, e para cada conjunto, realizamos uma completa otimização de geometria das cadeias e das células cristalinas com configurações inicialmente experimentais. Neste caso, extendemos nossa análise aos cristais de fenileno, bifenil [72], terfenil [73], quaterfenil [74] e poli-para-fenileno (PPP) [75, 76], além dos cristais de fenileno-vinileno, trans-estilbeno [77], $P_{5} V_{4}$ [78] e poli-para-fenileno-vinileno (PPV) [30, 68] e ainda, cristal de trans-poliacetileno (TPA) [79] cujas representações das células cristalinas podem ser vistas nas figuras 3.10 e 3.11 .

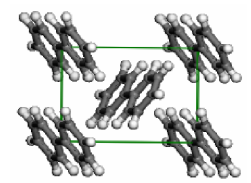

(a)

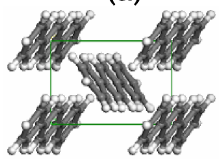

(d)

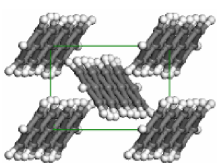

(g)

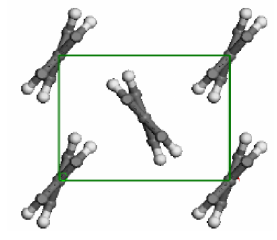

(j)

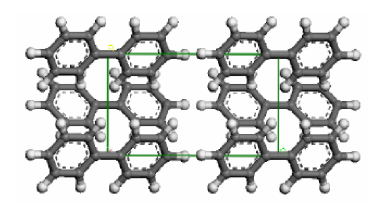

(b)

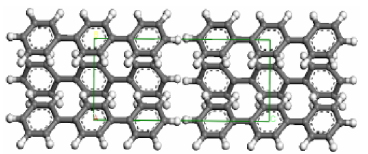

(e)

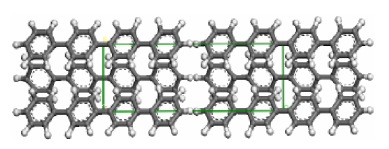

(h)

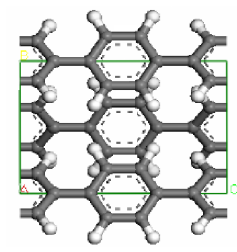

(k)

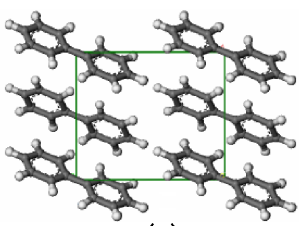

(c)

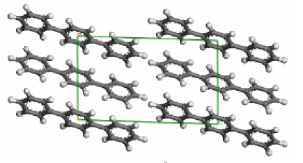

(f)

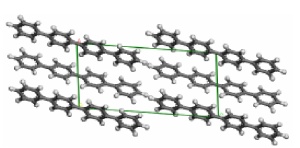

(i)

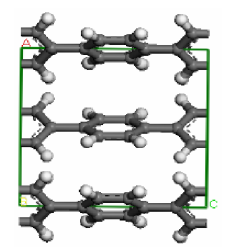

(l)

Figura 3.10: Projeções das células cristalinas nos planos ab, bc e ca para os cristais de bifenil em (a), (b) e (c); terfenil em (d), (e) e (f); quaterfenil em (g), (h) e (i) além do cristal de cadeia infinita PPP em (j), (k) e (l).

Usando a combinação dos diferentes valores de $C_{6}$ e $C_{12}$ para $C_{\beta}$ e $H$ geramos mais de 2500 conjuntos de força para teste em cada um dos cristais citados. Para escolher o melhor conjunto, 


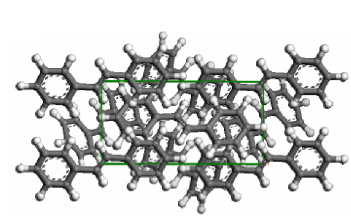

(a)

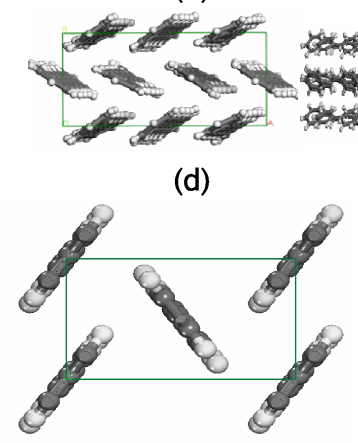

(g)

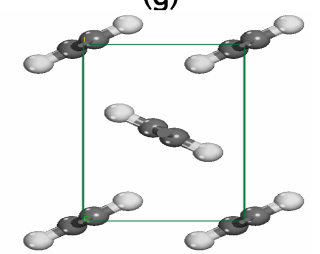

(j)

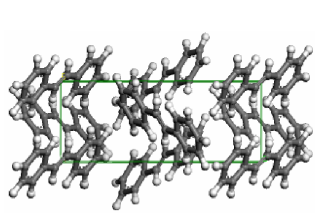

(b)

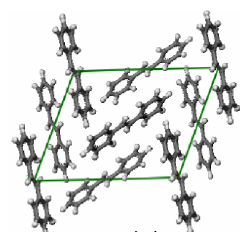

(c)

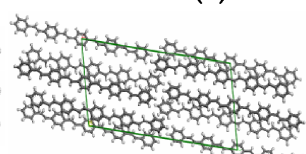

(f)

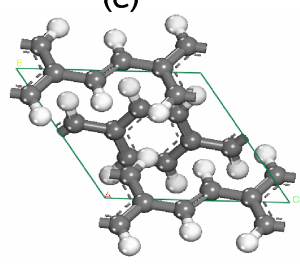

(h)

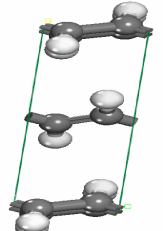

(k)

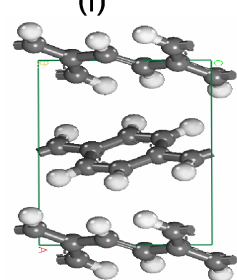

(i)

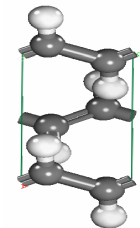

(I)

Figura 3.11: Projeções das células cristalinas nos planos ab, bc e ca para os cristais de transestilbeno $\left(P_{2} V_{1}\right)$ em (a), (b) e (c); cristal $P_{5} V_{4}$ em (d), (e) e (f); cristal de cadeia infinita de PPV em (g), (h) e (i) e cristal de cadeia infinita trans-poliacetileno em (j), (k) e (l).

calculamos o erro relativo aos parâmetros experimentais e coletamos o maior erro produzido por um conjunto em cada cristal. Em ordem decrescente este erro máximo nos permite obter o conjunto que melhor descreve os parâmetros estruturais dos cristais que analisamos. Como resultado, a tabela 3.8 mostra os parâmetros de Lennard-Jones 6-12 para nossa proposta de campo que chamaremos aqui de UFF-Nanomol (UFF-Nan).

Tabela 3.8: Parâmetros Lennard-Jones 6-12 para o campo UFF-Nanomol (UFF-Nan) resultante de otimização global sobre os sistemas considerados.

\begin{tabular}{c|c|c|c}
\hline Átomos & $C_{\alpha}$ & $C_{\beta}$ & $H$ \\
\hline$r_{I J}(\AA)$ & 3.851 & 3.820 & 2.900 \\
$D_{I J}(\mathrm{kcal} / \mathrm{mol})$ & 0.070 & 0.062 & 0.028 \\
\hline
\end{tabular}


Em seguida temos a tabela 3.9 com os erros percentuais para os cristais estudados usando os campos PCFF, UFF-carga-fixa-QEq e o UFF-Nan.

Os três campos conseguem descrever muito bem os parâmetros estruturais $a, b, c, \alpha, \beta, \gamma$, torção e colocação dos cristais de fenileno. Para o bifenil, o maior erro estrutural ocorre para o parâmetro a quando usamos o campo PCFF (4.3\%), enquanto para os campos UFF+QEq e UFF-Nan os erros maiores surgem para o parâmetro $\beta$ e valem $4.6 \%$ e $3.8 \%$ nesta ordem.

Passamos assim a analisar a propriedade elástica $B o$ que representa o módulo de volume e como dissemos é importante para simulação de filmes mais complexos. Neste caso, vemos que nenhum campo consegue uma descrição acurada de $B o$ para o bifenil, mas comparativamente ao UFF conseguimos excelentes resultados.

Já o cristal de terfenil apresenta a melhor descrição estrutural quando otimizado com PCFF. Os resultados UFF+QEq e UFF-Nan são equivalentes para este cristal, entretanto, novamente conseguir melhorar de forma muito significativa o módulo de volume quando usamos o UFFNanomol com erro percentual para Bo de $23.3 \%$.

O cristal de quaterfenil apresenta nosso (UFF-Nanomol) maior erro estrutural relativamente a descrição dos demais campos (UFF+QEq, PCFF). Este erro ocorre para o parâmetro $a$ e fica em torno de 6.1\% (UFF-Nanomol), 5.5\% (UFF+QEq) e 0.1\% (PCFF). Nosso erro percentual para o módulo de volume é intermediário ao valores dos demais campos, $69 \%$ (UFF-Nanomol), $206.3 \%$ (UFF+QEq) e 50.6\%(PCFF), mas é importante ressaltar novamente a grande correção do campo Nanomol em relação ao UFF padrão para este parâmetro.

A estrutura da célula do PPP também é bem descrita. Para este cristal, dentre os campos de força estudados, o UFF-Nanomol apresenta maior erro para o parâmetro a (6.1\%). Entretanto, conseguimos a melhor descrição tanto quanto à torção quanto ao ângulo de colocação da cadeia na célula. O PCFF, por exemplo, planariza o PPP.

Vamos passar agora aos cristais de fenileno e fenileno-vinileno. Na tabela 3.10, temos os erros relativos aos observáveis para os cristais de $P_{2} V_{1}, P_{5} V_{4}, P P V$ e TPA. Como ocorrido na situação dos fenilenos, aqui também temos uma descrição razoável para os parâmetros cristalinos para os campos PCFF, UFF padrão e UFF-Nanomol.

Para o cristal de trans-estilbeno $P_{2} V_{1}$, o maior erro percentual ocorre para o ângulo de torção quando usamos o campo PCFF (11.9\%). O cristal de $P_{5} V_{4}$ é melhor descrito pelo UFF- 
Tabela 3.9: Erro relativo aos valores experimentais para os parâmetros cristalinos do Bifenil, Terfenil, Quaterfenil, PPP. As cadeias e as células foram otimizadas considerando os campos PCFF, UFF-carga-fixa-QEq e UFF-Nanomol.

\begin{tabular}{|c|c|c|c|c|c|c|c|c|c|c|}
\hline cristal & $\mathrm{a}(\AA)$ & $\mathrm{b}(\AA)$ & $c(\AA)$ & $\alpha(0)$ & $\beta(0)$ & $\gamma(0)$ & $\phi(0)$ & $\theta(\circ)$ & $B_{0}$ & \\
\hline \multirow{4}{*}{ Bifenil } & 7,82 & 5,58 & 9,44 & 90,0 & 94,62 & 90,0 & 0,1 & 56,76 & 5,90 & exp \\
\hline & $-2,40$ & 1,40 & $-0,60$ & 0,0 & $-3,80$ & 0,0 & 0,0 & 7,60 & 80,3 & UFF-Nan \\
\hline & $-1,90$ & $-0,60$ & $-0,80$ & 0,0 & $-4,60$ & 0,0 & $-0,1$ & 6,35 & 222,9 & UFF \\
\hline & 4,30 & $-1,40$ & $-1,70$ & 0,0 & $-4,60$ & 0,0 & 0,0 & 3,71 & 56,1 & PCFF \\
\hline \multirow{4}{*}{ Terfenil } & 8,10 & 5,61 & 13,61 & 90,0 & 92,10 & 90,0 & 1,8 & 56,27 & 7,20 & $\exp$ \\
\hline & $-5,50$ & 1,00 & $-0,80$ & 0,0 & 3,20 & 0,0 & 2,2 & 6,40 & $-23,2$ & UFF-Nan \\
\hline & $-5,30$ & $-1,40$ & $-0,40$ & 0,0 & 3,70 & 0,0 & $-0,5$ & 6,42 & 187,8 & UFF \\
\hline & 0,30 & $-2,00$ & $-1,40$ & 0,0 & 4,20 & 0,0 & $-0,2$ & 3,91 & 41,7 & PCFF \\
\hline \multirow{4}{*}{ Quaterfenil } & 8,11 & 5,61 & 17,91 & 90,0 & 95,80 & 90,0 & 0,8 & 56,30 & 7,2 & $\exp$ \\
\hline & $-6,10$ & 0,80 & $-0,80$ & 0,0 & 2,70 & 0,0 & 1,1 & 7,40 & 69,0 & UFF-Nan \\
\hline & $-5,50$ & $-1,50$ & $-0,40$ & 0,0 & 2,90 & 0,0 & 0,3 & 6,20 & 206,3 & UFF \\
\hline & 0,10 & $-2,20$ & $-1,40$ & 0,0 & 3,60 & 0,0 & 0,4 & 3,70 & 50,6 & PCFF \\
\hline \multirow{4}{*}{ PPP } & 7,78 & 5,52 & 8,54 & 90,0 & 90,0 & 90,0 & 20,0 & 35,72 & - & $\exp$ \\
\hline & 6,10 & 0,30 & $-0,40$ & 0,0 & 0,0 & 0,0 & 7,3 & 0,80 & - & UFF-Nan \\
\hline & 5,90 & 1,10 & $-0,30$ & 0,0 & 0,0 & 0,0 & 10,6 & $-2,10$ & - & UFF \\
\hline & $-1,80$ & $-1,10$ & 1,10 & 0,0 & 0,0 & 0,0 & $-19,9$ & 25,2 & - & PCFF \\
\hline
\end{tabular}

Nanomol e a pior descrição estrutural ocorre quando o cristal é otimizado com o campo PCFF para o ângulo de torção (8.7\%). A estrutura do PPV fica melhor descrita pelo UFF-nanomol com maior erro acontecendo para a torção das cadeias (9.0). Os demais campos apresentam cadeias de $P P V$ bem mais torcidas com erros de $13 \%$ para o UFF e $17.1 \%$ para o PCFF. Por fim, o cristal de trans-poliacetileno $(T P A)$ como regra geral apresenta boa concordância entre os valores observados e calculados com os diferentes campos. A maior discordância acontece para o ângulo de colocação das cadeias com erros de 8\% (UFF-Nanomol), $5.8 \%$ (UFF) e 7.4\% $(\mathrm{PCFF})$.

Assim, vemos que para os diferentes 8 cristais baseados em grupos fenileno e/ou vinileno 
Tabela 3.10: Erro relativo aos valores experimentais para os parâmetros cristalinos do $P_{2} V_{1}$, $P_{5} V_{4}, P P V$ e $T P A$. As cadeias e as células foram otimizadas considerando os campos PCFF, UFF-carga-fixa-QEq e UFF-Nanomol.

\begin{tabular}{c|c|c|c|c|c|c|c|c|c}
\hline \hline cristal & $\mathrm{a}(\AA)$ & $\mathrm{b}(\AA)$ & $\mathrm{c}(\AA)$ & $\alpha(\circ)$ & $\beta(\circ)$ & $\gamma(\circ)$ & $\phi(\circ)$ & $\theta(\circ)$ & \\
\hline \multirow{4}{*}{$P_{2} V_{1}$} & 12,29 & 5,66 & 15,47 & 90,0 & 112,03 & 90,0 & 0,7 & 59,58 & exp \\
& $-4,10$ & 0,90 & $-0,10$ & 0,0 & $-1,00$ & 0,0 & 0,0 & 6,30 & $\mathrm{UFF}-\mathrm{Nan}$ \\
& $-3,90$ & 1,90 & 5,00 & 0,0 & $-2,60$ & 0,0 & 2,2 & 2,90 & $\mathrm{UFF}$ \\
& $-4,00$ & $-1,20$ & 0,60 & 0,0 & $-1,3$ & 0,0 & 11,9 & 4,60 & $\mathrm{PCFF}$ \\
\hline \multirow{5}{*}{$P_{5} V_{4}$} & 16,07 & 7,54 & 32,91 & 90,0 & 103,35 & 90,0 & 5,74 & 34,59 & $\mathrm{exp}$ \\
& 1,30 & $-3,50$ & $-1,30$ & 0,0 & $-2,20$ & 0,0 & 3,9 & $-2,80$ & $\mathrm{UFF}-\mathrm{Nan}$ \\
& $-2,70$ & 1,00 & 0,70 & 0,0 & $-3,20$ & 0,0 & 5,3 & $-3,50$ & $\mathrm{UFF}$ \\
& $-0,50$ & $-3,10$ & $-1,30$ & 0,0 & $-1,20$ & 0,0 & 8,7 & $-2,20$ & $\mathrm{PCFF}$ \\
\hline \multirow{5}{*}{$P P V$} & 7,90 & 6,05 & 6,58 & 123,0 & 90,0 & 90,0 & 0,0 & 60,0 & $\mathrm{exp}$ \\
& $-3,70$ & $-3,30$ & $-0,20$ & $-2,2$ & 0,0 & 0,0 & 9,0 & 2,0 & $\mathrm{UFF}-\mathrm{Nan}$ \\
& $-2,00$ & $-3,10$ & 1,90 & $-1,4$ & 0,0 & 0,0 & 13,0 & 1,30 & $\mathrm{UFF}$ \\
& $-0,50$ & $-7,70$ & $-0,10$ & $-2,0$ & 0,0 & 0,0 & 17,1 & $-0,80$ & $\mathrm{PCFF}$ \\
\hline \hline \multirow{5}{*}{$T P A$} & 4,10 & 7,40 & 2,45 & 90,0 & 90,0 & 90,0 & 0,0 & 55,0 & exp \\
& $-4,20$ & 0,50 & $-1,90$ & 0,0 & $-3,3$ & 0,0 & 0,0 & $-8,0$ & $\mathrm{UFF}-\mathrm{Nan}$ \\
& $-3,00$ & $-0,90$ & $-2,00$ & 0,0 & $-2,0$ & 0,0 & 0,0 & $-5,8$ & $\mathrm{UFF}$ \\
& $-5,30$ & $-0,90$ & $-1,90$ & 0,0 & $-3,3$ & 0,0 & 0,0 & $-7,4$ & $\mathrm{PCFF}$ \\
\hline
\end{tabular}

conseguimos uma descrição estrutural em geral equivalente àquela obtida pelos campos já bem estabelecidos no meio acadêmico, UFF e PCFF, e conseguimos melhorar significativa do módulo de volume quando comparado ao UFF padrão. O principal ponto a ser notado é que, ao passar para filmes amorfos, um parâmetro de propriedade elástica como este tem interesse especial. 


\section{Capítulo 4}

\section{Resultados: transporte em sistemas de fenileno-vinileno}

Neste capítulo passamos à aplicação do modelo desenvolvido acima a sistemas de fenilenos de vinila. Como dissemos repetidas vezes, o bom entendimento do mecanismo de transporte de portadores, deve estar relacionado ao conhecimento das características morfológicas. Assim, investigamos três diferentes sistemas, comparando morfologias idealmente cristalinas, e filmes amorfos, com diferentes características de distribuição de energias de sítio.

\subsection{Sistema cristalino de $P_{5} V_{4}$}

Inicialmente, estudamos o transporte em um sistema cristalino de $P_{5} V_{4}$. Partindo da célula unitária, obtida do estudo cristalográfico de Hutten et al.[78], construímos uma supercélula $5 \times 4 \times 2$ representada na figura 4.1-(a), onde vemos o arranjo herring-bone. A estrutura regular do cristal faz com que hajam 6 canais de hopping entre as cadeias vizinhas apresentadas na figura 4.1-(b), de forma que a topologia da rede de conectividade também se mostra regular, como representada no diagrama da figura 4.1-(c). Como os oligômeros se encontram estendidos, não ocorrendo quebra de conjugação cada cadeia define um sítio. Além disso como as cadeias são todas iguais, também são iguais as energias de sítio $\Delta \epsilon_{i j}=0$. Dessa maneira, o termo $\Delta E_{i j}$ depende apenas do fator de campo $-e \mathbf{E} \cdot \mathbf{R}_{i j}$, sendo as taxas de movimento no sentido oposto ao campo reduzidas pelo fator exponencial. Como consequência no regime estacionário, 
em virtude da completa equivalência entre os sítios e por usarmos condições periódicas de contorno, as cadeias apresentam o mesmo valor da probabilidade de ocupação.

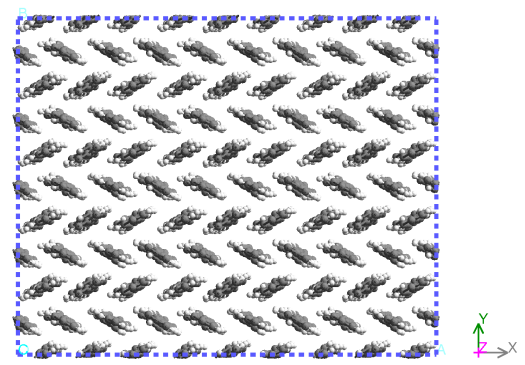

(a)

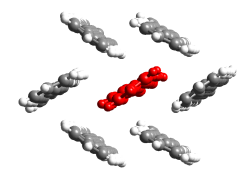

of

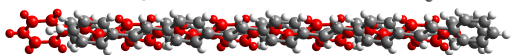

bot

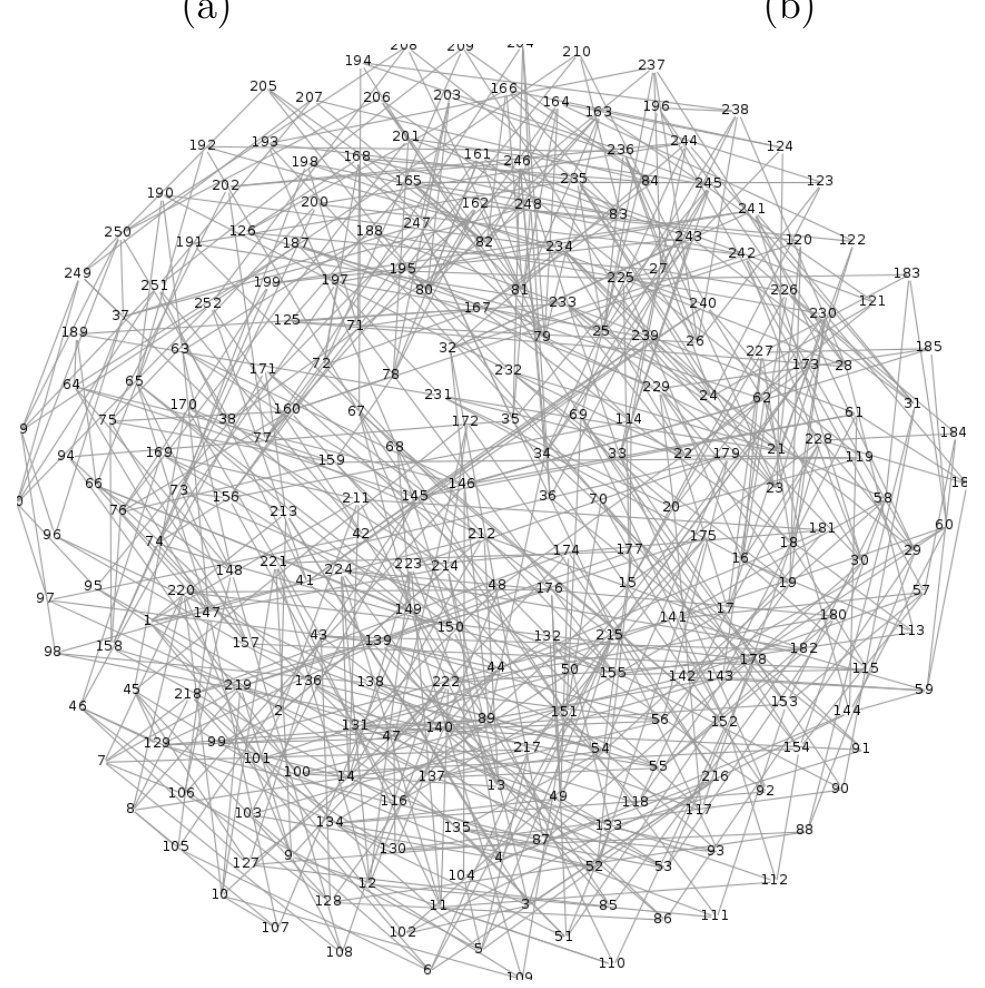

(c)

Figura 4.1: (a) Supercélula do cristal de $P_{5} V_{4}$; (b) cadeias conectadas à cadeia em destaque, tais que os valores de integral de hopping são maiores que $1 \mathrm{meV}$; (c) Rede topológica construída para a supercélula do cristal de $P_{5} V_{4}$. 
A curva de mobilidade apresentada no gráfico 4.2 foi calculada para uma concentração de portadores de $5 \times 10^{18} \mathrm{e} / \mathrm{cm}^{3}$ e temperatura de $300 \mathrm{~K}$. Dada a disposição das cadeias no cristal, altamente regular e anisotrópica, as mobilidades calculadas para campos aplicados em direção próxima aos eixos e na direção perpendicular a esta são bastante distintas. Os maiores valores para mobilidade com campo aplicado na direção $\hat{y}$ ocorrem devido à maior proximidade das cadeias nesta direção. Também nota-se o desvio da lei de Poole-Frenkel para esse sistema com a mobilidade caindo com o aumento do campo.

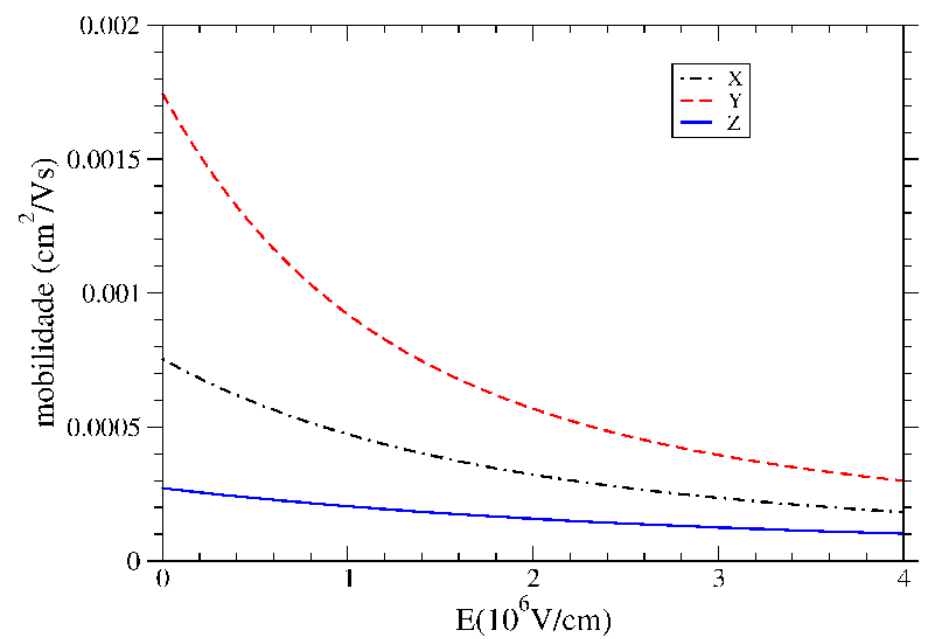

Figura 4.2: Curvas de mobilidade calculadas para a supercélula do cristal ideal de $P_{5} V_{4}$.

Esse comportamento da curva de mobilidade pode ser interpretado qualitativamente com a ajuda de um modelo analítico simplificado. Considerando uma rede cúbica de parâmetro de rede $R$, com sítios de mesmo comprimento de conjugação, sendo submetida a um campo $\mathbf{E}$ alinhado com uma das arestas da célula unitária. Pela simetria da rede, chamando o sítio $j$ de $j^{+}$tal que $\mathbf{R}_{i j^{+}}(i \rightarrow j+)$ está alinhado com o campo, teremos $w_{j^{+} i}=w_{0}$. Para a transição envolvendo o sítio oposto $\left(j^{-}\right)$, teremos $w_{j^{-} i}=w_{0} \exp (-\beta e E R)$. Os demais 4 sítios ortogonais ao campo não contribuem para a velocidade global. Assim,

$$
\begin{aligned}
& v(E)=\frac{1}{N} \sum_{i}^{N} \sum_{j} w_{j i} P_{i}\left(1-P_{j}\right)\left(\hat{E} \cdot R \hat{r}_{i j}\right) \\
& v(E)=\frac{1}{N} p(1-p) \sum_{i}^{N}\left[+R w_{j^{+} i}-R w_{j^{-i}}\right]
\end{aligned}
$$




$$
\begin{gathered}
v(E)=\frac{1}{N} w_{0} p(1-p) R \sum_{i}^{N}[1-\exp (-\beta e E R)] \\
v(E)=w_{0} p(1-p) R[1-\exp (-\beta e E R)]
\end{gathered}
$$

onde $w_{0}$ corresponde à constante de hopping para esse sistema-modelo, $p$ à probabilidade de ocupação de cada sítio, e $R$ à distância entre sítios. Todas essas quantidades são homogêneas em virtude de serem os sítios equivalentes.

Para este sistema regular com nenhum efeito de desordem, temos que a equação da velocidade e da mobilidade, dependem de $E$ conforme as equações 4.5 e 4.6.

$$
\begin{aligned}
& v(E) \sim 1-\exp (-\beta e E R) \\
& \mu(E) \sim \frac{1-\exp (-\beta e E R)}{E}
\end{aligned}
$$

Dessa maneira, com a saturação da velocidade temos a queda da mobilidade com $1 / E$ levando à perda do comportamento de Poole-Frenkel.

Em resumo, obtemos dois resultados importantes: em primeiro lugar uma forte anisotropia da mobilidade com relação à direção de aplicação do campo elétrico. Esse resultado á esperado, já que existe uma diferença direcional nas energias de transferência (termo não-diagonal na terminologia Bässler), enquanto as energias de sítio (termo diagonal) são todos idênticas. Além disso, não obtemos o crescimento de Poole-Frenkel de mobilidade com o campo, o que também pode ser associado às diferenças entre termos não-diagonais, sendo os termos diagonais iguais [13].

No laboratório em geral teríamos sistemas policristalinos, em que a orientação global seria perdida. Além disso, teríamos desvios substanciais de cristalinidade mesmo dentro de um único cristalito. Passamos assim a um sistema com desordem, primeiramente apenas não-diagonal. 


\subsection{Filme amorfo de $P_{3} V_{2}$}

Ainda como caso exemplar, investigamos o efeito de uma topologia obtida a partir de um filme desordenado mas com sítios de mesmo tamanho. Escolhemos um sistema de oligômeros curtos e admitimos que não ocorra a quebra de conjugação de modo a termos a mesma energia para todos os sítios. Assim, construímos um sistema amorfo de $P_{3} V_{2}$, equilibrado a $300 \mathrm{~K}$ por meio da DMC, inicialmente com o ensemble NPT a uma pressão de $1 \mathrm{~atm}$. Após nova etapa de equilibração, no ensemble NVT, geramos imagens do sistema separadas por intervalos de tempo de 1 ps. Na figura 4.3-(a) graficamos os valores das integrais de transferência obtidas ao longo da dinâmica. Para uma particular imagem do sistema, figura 4.3-(b), apresentamos a distribuição de conexões dos sítios na figura 4.3-(c). Como se vê temos aqui uma fonte de desordem apenas não-diagonal.

Na figura 4.4 apresentamos as curvas de mobilidade como função do campo elétrico para as diferentes direções de aplicação. As simulações foram realizadas para uma concentração de portadores de $6 \times 10^{18} \mathrm{e} / \mathrm{cm}^{3}$, e a Equação Mestre foi resolvida à mesma temperatura utilizada para gerar a morfologia, $300 \mathrm{~K}$. Observamos primeiramente um comportamento médio característico da mobilidade que não se altera signifitivamente entre uma direção e outra, revelando que o sistema é praticamente isotrópico.

Nos gráficos da figura 4.4 vemos também que a mobilidade cai com o aumento do campo elétrico externo, como foi observado para o sistema cristalino e agora os termos não-diagonais têm a desordem incorporada. Para estudar os detalhes do fenômeno selecionamos uma das imagens, com a curva de mobilidade próxima ao comportamento médio observado.

Na figura 4.5(a-c) apresentamos a rede topológica das conexões de hopping para essa particular imagem, e inserimos também o mapeamento dos sítios em termos do número de conexões. A carga final após a simulação da rede por meio da EME é mapeada por cores, para três valores de campo externo de $4 \times 10^{4} \mathrm{~V} / \mathrm{cm}(\sim 40 \mathrm{~V}), 10^{6} \mathrm{~V} / \mathrm{cm}(\sim 100 \mathrm{~V})$ e $4 \times 10^{6} \mathrm{~V} / \mathrm{cm}(\sim 400 \mathrm{~V})$, todos aplicados na direção $\hat{x}$. O gráfico da figura 4.5-(d) exprime quantitativamente as cargas após a convergência.

Da análise da figura 4.5 vemos que a distribuição de cargas se mantém para campos baixos aproximadamente uniforme, sem que a conectividade guarde correlação com a carga final. Isto 


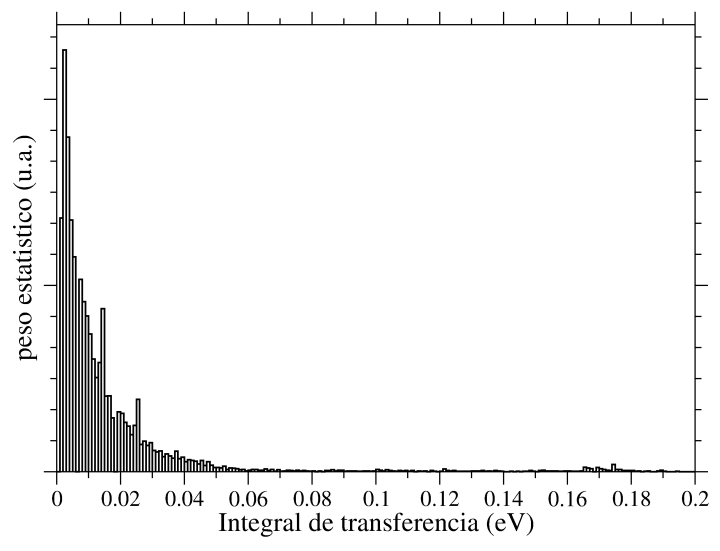

(a)

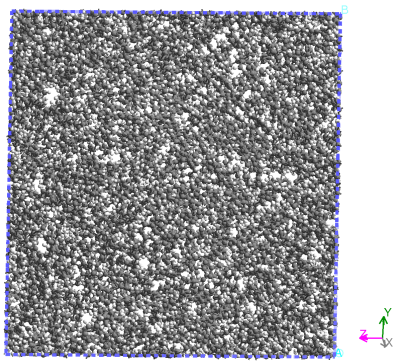

(b)

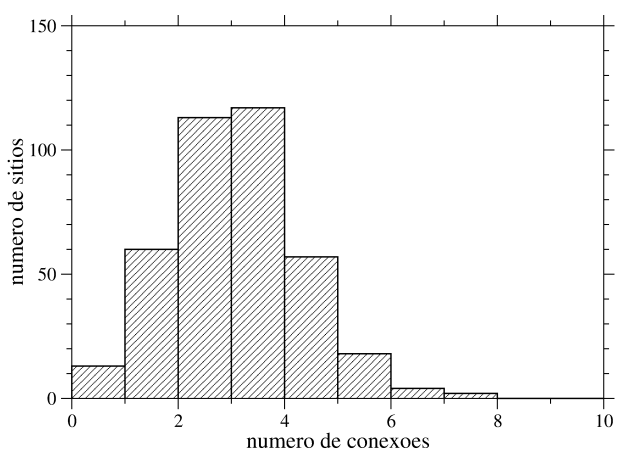

(c)

Figura 4.3: (a) Histograma das integrais de transferência ao longo da dinâmica; (b) Imagem particular do sistema amorfo de $P_{3} V_{2}$, equilibrada a $300 \mathrm{~K}$ e 1 atm; (c) Distribuição estatística da conectividade dos sítios na configuração mostrada em (b).

se deve ao fato de que para campo nulo (ou baixo) a taxa de saída $w_{i j}$ e de entrada $w_{j i}$ da carga em cada sítio $i$ ficam iguais (ou próximas), e não existe o desequilíbrio que implica na migração de carga de um sítio a outro.

Com o aumento do campo a carga se concentra progressivamente em alguns sítios específicos. Ao compararmos as cargas finais para campos aplicados na direção $\hat{y}$, vemos que ocorre o acúmulo de carga em sítios específicos diferentes daqueles obtidos para os campos aplicados na direção $\hat{x}$. Com isso podemos concluir que o efeito do acúmulo de carga neste sistema (que é homogêneo nas energias de sítios) está ligado fortemente à disposição espacial dos sítios e à orientação das conexões de hopping relativas ao campo, ou seja, é realçada a relevância da 


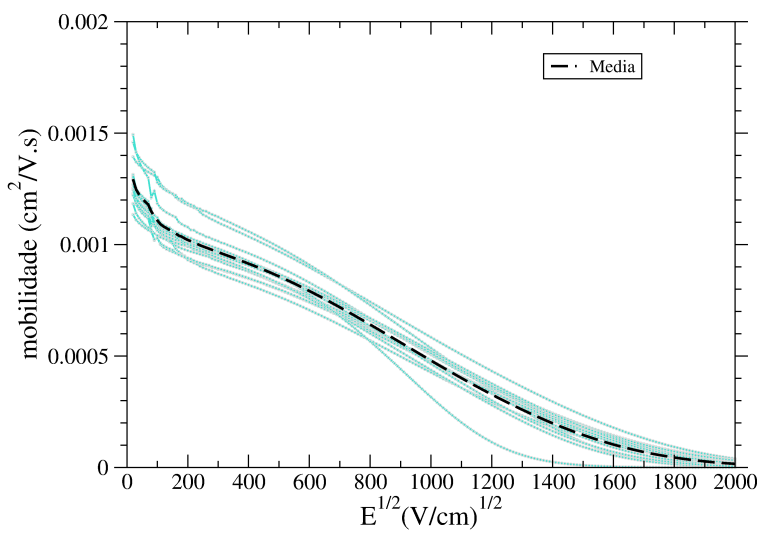

(a)

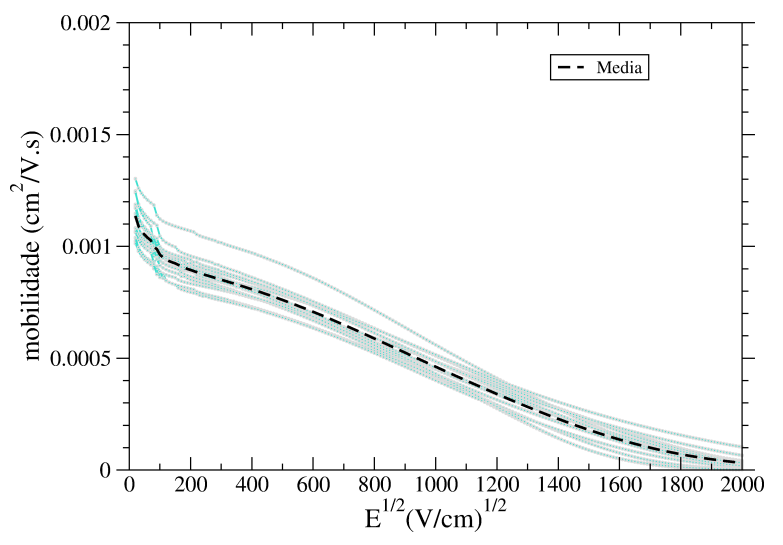

(b)

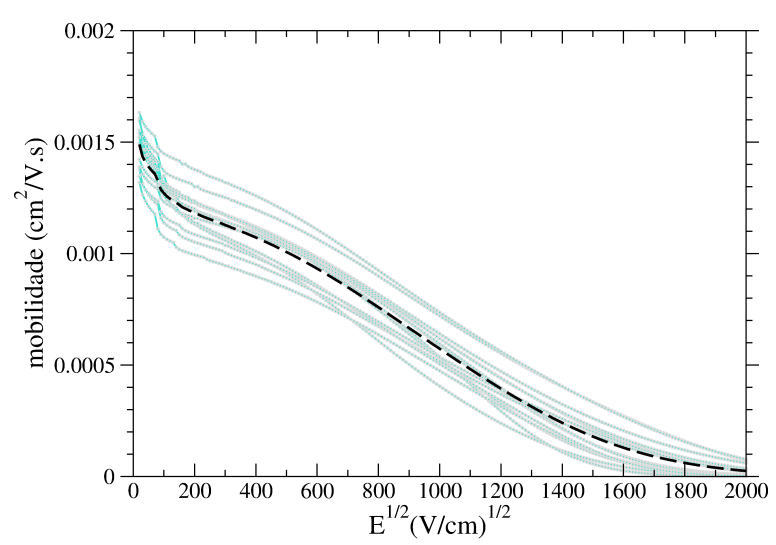

(c)

Figura 4.4: Mobilidades calculadas para a supercélula do cristal de P3V2, equilibrado a 300K, para campos elétricos aplicados nas direções: (a) $\hat{x} ;(\mathrm{b}) \hat{y}$; (c) $\hat{z}$. Imagens individuais e, na linha tracejada, a média para cada valor de campo.

morfologia.

Os múltiplos efeitos vindos de uma morfologia mais complexa, com a distribuição de diferentes valores para as energias de sítio, serão apresentados a seguir no estudo de sistemas amorfos com oligômeros mais longos, seção 4.3. Esses sistemas também tendem a exibir maior desordem na conectividade entre os sítios, ou seja na topologia da rede. 


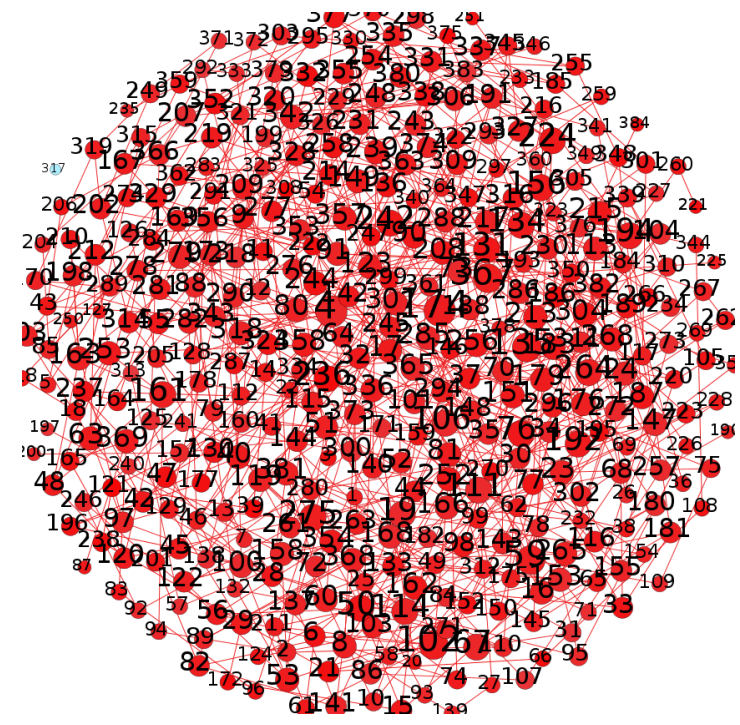

(a)

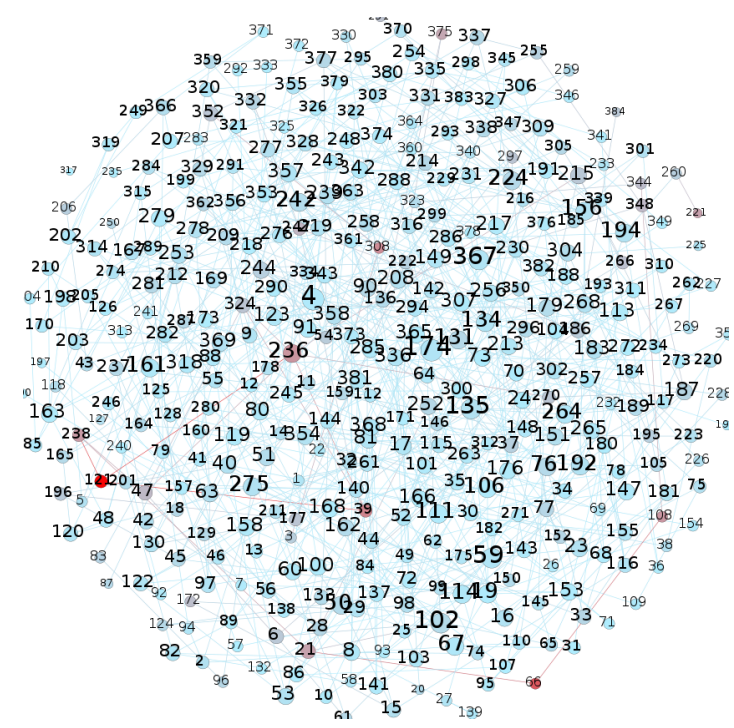

(b)

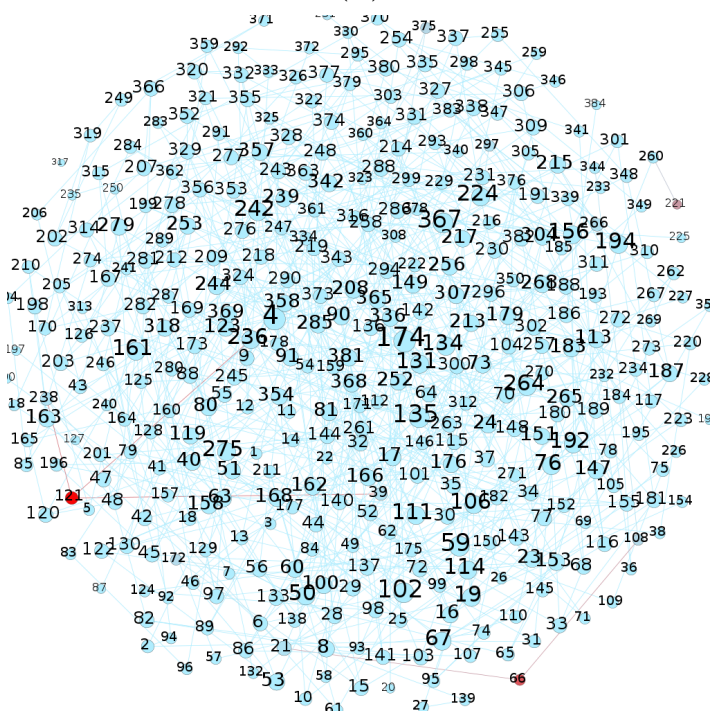

(c)

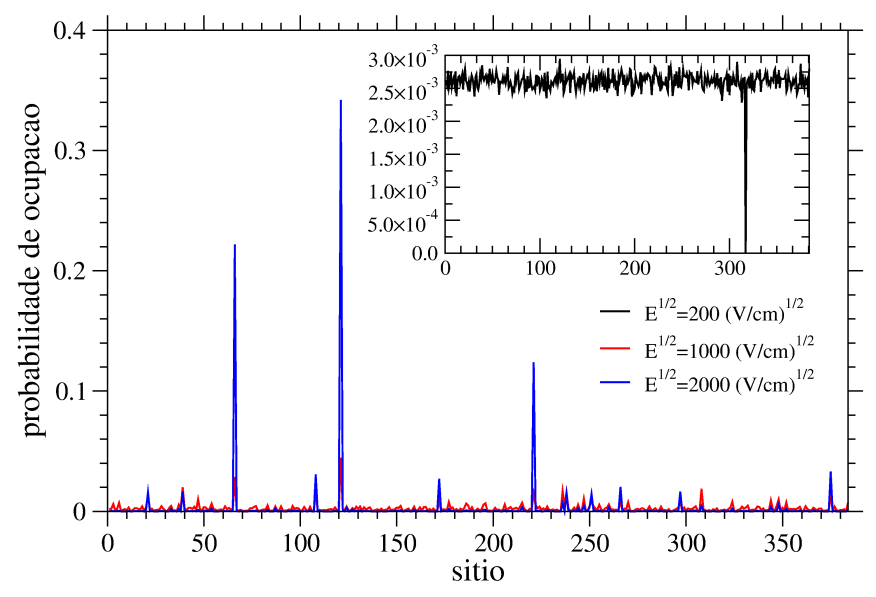

(d)

Figura 4.5: Rede topológica construída para uma imagem específica, com mapeamento do número de conexões (raio da circunferência) e da carga resultante da simulação através da EME (em cores, crescente de azul para vermelho) para diferentes valores de campo elétrico externo aplicado na direção $\hat{x}$ : (a) $4 \times 10^{4} \mathrm{~V} / \mathrm{cm}(\sim 40 \mathrm{~V})$; (b) $10^{6} \mathrm{~V} / \mathrm{cm}(\sim 100 \mathrm{~V})$; e (c) $4 \times 10^{6} \mathrm{~V} / \mathrm{cm}$ $(\sim 400 \mathrm{~V})$. Em $(\mathrm{d})$ temos as ocupações por sítio após a convergência. No detalhe as ocupações da rede para campo externo nulo. O sítio 317 é o único sítio que não está conectado a nenhum outro nesta imagem do sistema e, dessa forma, tem sempre carga nula. 


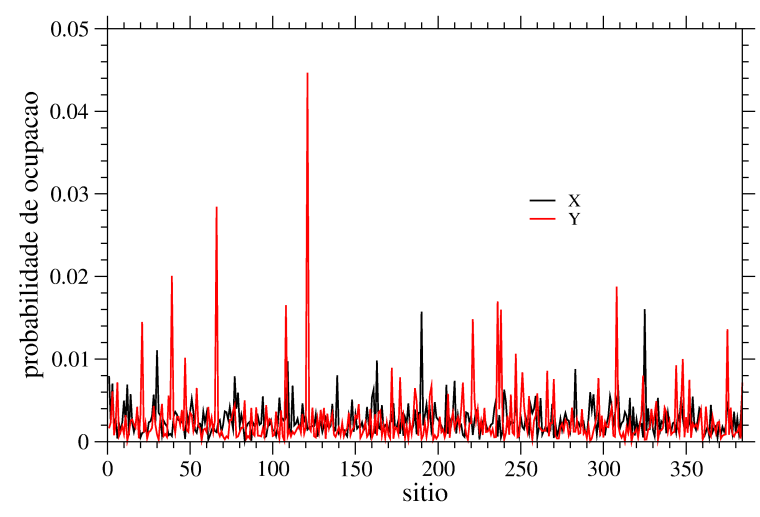

(b)

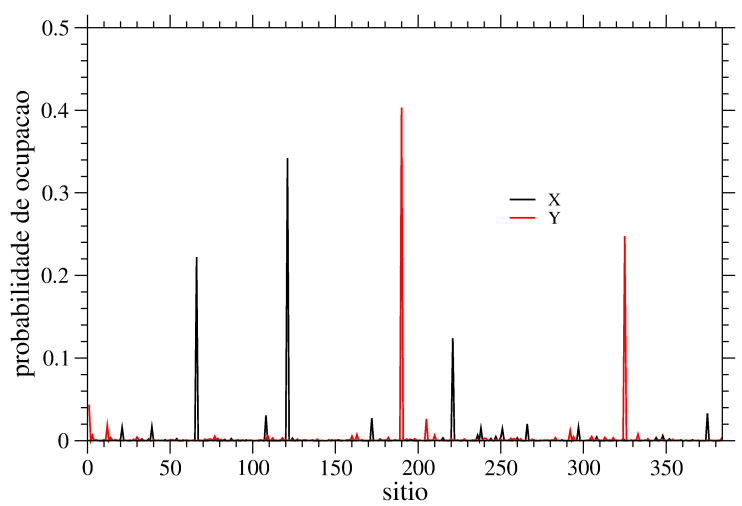

(c)

Figura 4.6: Ocupações por sítio após a convergência, comparada entre campo aplicado na direção $\hat{x}$ e $\hat{y}$ : (a) $E=10^{6} \mathrm{~V} / \mathrm{cm}(\sim 100 \mathrm{~V})$; (b) $E=4 \times 10^{6} \mathrm{~V} / \mathrm{cm}(\sim 400 \mathrm{~V})$.

\subsection{Sistema desordenado de $P_{26} V_{25}$}

O sistema estudado é construído a partir da disposição incialmente aleatória de 40 oligômeros de PPV com 26 anéis fenil (14480 átomos), perfeitamente estendidos e planares, em uma célula com baixa densidade. Após convergência em ensemble NPT, conforme exposto no capítulo de metodologia, em termos da densidade (valores de cerca $1.0 \mathrm{~g} / \mathrm{cm}^{3}$ ), temperatura $(300 \mathrm{~K})$ e pressão (1atm), obtivemos uma célula unitária triclínica, com vetores de rede $\mathbf{a}=(61,5 ; 0 ; 0)$, $\mathbf{b}=(-2,4 ; 62,4 ; 0)$ e $\mathbf{c}=(-1,3 ; 6.7 ; 63,4)$, cujo volume total é de $243.303 \AA^{3}$. A partir da estrutura convergida por meio do NPT, realizamos convergência (em termos da temperatura) no ensemble NVT, e a partir disto geramos um conjunto de 37 imagens do sistema em intervalos regulares de 0.5 ps.

As características morfológicas do ambiente molecular neste conjunto de imagens podem ser avaliadas por meio das distribuições apresentadas na Figura 4.7. A distribuição de distância entre anéis é apresentada na figura 4.7-(b) (o pico característico próximo a $6.5 \AA$ corresponde à distância entre anéis consecutivos em uma mesma cadeia), e a distribuição de ângulos entre anéis é apresentada na figura 4.7-(c), sendo notada uma baixa estatística para ângulos entre anéis de cadeias distintas em torno de $30^{\circ}$. Essa distribuição reflete a tendência a empacotamentos quase $\pi$-stack (ângulos próximos a zero) ou herring bone (ângulos próximos a $60^{\circ}$ ). Na figura 4.7-(c) é também representada a orientação relativa entre anéis pertencentes a uma mesma 
cadeia, sendo notado que anéis consecutivos tendem a se inclinar preferencialmente em ângulos entre $30^{\circ}$ e $75^{\circ}$. O ângulo entre anéis vizinhos tanto inter como intra cadeia apresenta baixa ocorrência de arranjos perpendiculares. A linearidade das cadeias, avaliada pela razão entre a distância entre os extremos da cadeia e o seu valor ideal, em geometria completamente plana e estendida, é apresentada na figura 4.7-(d). É visível que a totalidade das cadeias apresenta alguma curvatura, mas a maior parte mostra linearidade acima de 50\%, mostrando ser menor a ocorrência de arranjos de cadeia na forma de "U".

Na figura 4.8 apresentamos as distribuições estatísticas obtidas a partir de todas as 37 imagens para: comprimentos dos sítios; energias de sítio e diferenças de energia entre sítios conectados, $\Delta \epsilon_{i j}$; e integrais de transferência.

Em confronto aos modelos GDM para as energias de sítio, em nosso modelo atomístico vemos que os sítios longos são menos comuns que os sítios menores, figura 4.8-(a), mas a desordem não é gaussiana.

A distribuição de diferenças das energias de sítios conectados apresenta, conforme a figura 4.8-(b), um pico pronunciado em torno de zero, e picos menores em valores mais altos, característicos da conexão entre sítios longos e curtos. Ambas distribuições fogem do aspecto gaussiano, portanto.

A distribuição das integrais de transferência (ou taxas de hopping) nas diferentes imagens obtidas ao longo da DMC apresenta o comportamento da figura 4.8-(d), sendo mais comuns valores de integral de transferência abaixo de $50 \mathrm{meV}$ com um perfil de ocorrência estatística semelhante a uma exponencial (a menos de flutuações como visto no detalhe da figura).

A quantidade de conexões realizadas por cada sítio apresentam distribuição, mostrada na figura 4.8-(c), onde se nota ser mais provável a ocorrência de três conexões por sítio da rede, com progressiva menor incidência de maior conectividade, sendo muito rara a existência de sítios com conexão muito alta como 20, havendo ao longo de todas as 37 imagens uma única ocorrência de um sítio conectado a outros 30. Essas altas conectividades em geral ocorrem para sítios longos (acima de 20 unidades fenil), e se dão em virtude da existência de canais fracos (da ordem de $1 \mathrm{meV}$ ). O sítio que se conecta a outros 30 tem comprimento de conjugação (máxima) 26. Os sítios que estão isolados, não realizando conexões, em geral de baixo comprimento de conjugação (até duas unidades fenil), mostram-se aproximadamente tão comuns como aqueles 


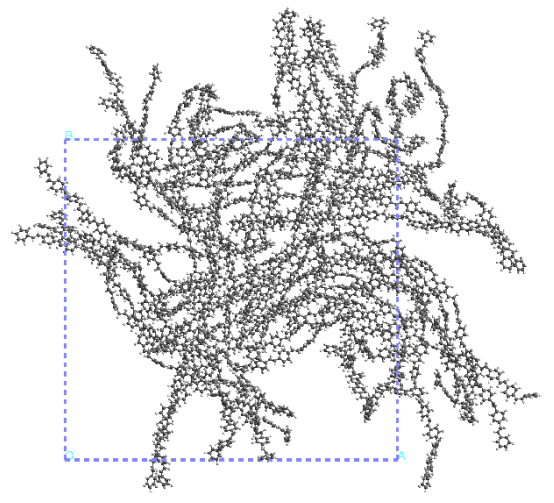

(a)

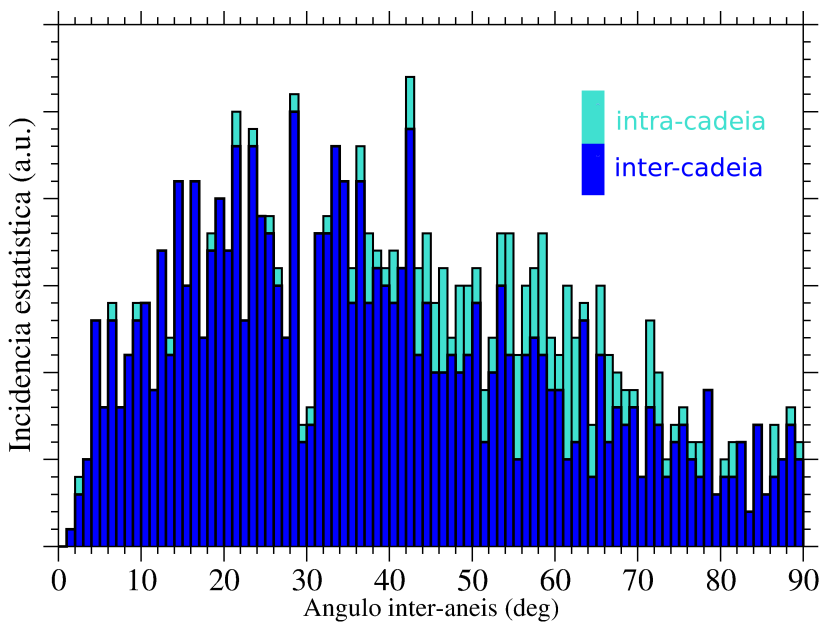

(c)

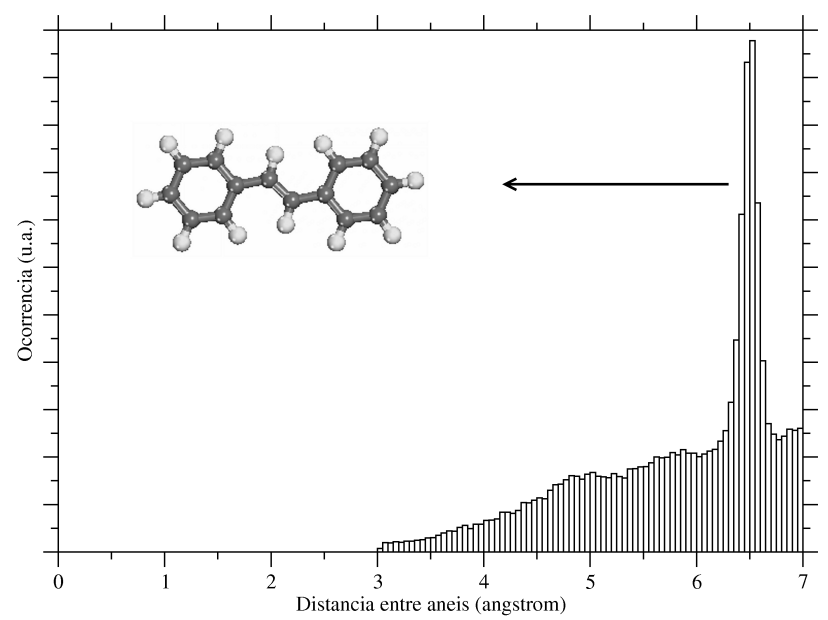

(b)

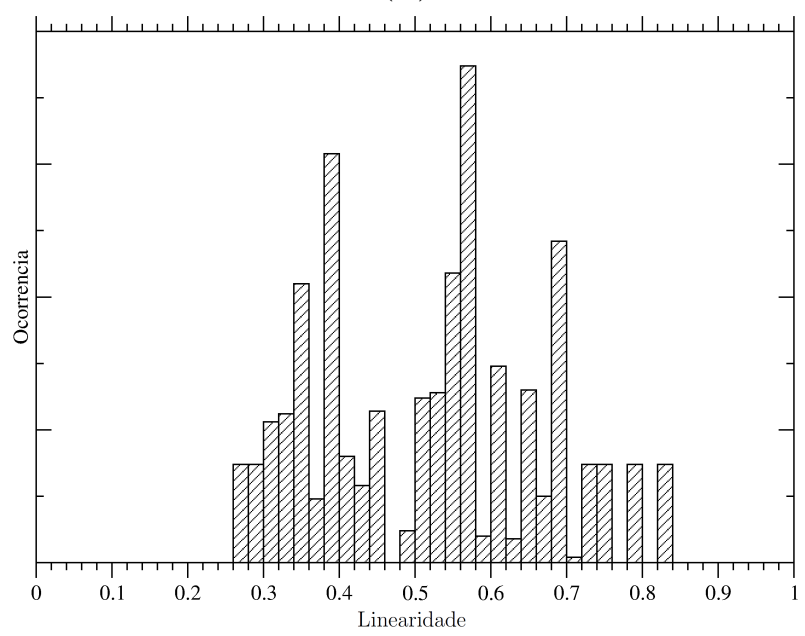

(d)

Figura 4.7: (a) Figura de uma configuração (imagem) do sistema analisado; Distribuições para todo o conjunto de imagens: (b) Distribuição radial da distância entre anéis, corte em $7.0 \AA$; (c) Ângulo entre normais dos anéis fenil em um raio de até 5.5, separadas as constribuições inter e intra-cadeia; (d) Linearidade (distância entre os anéis extremos da cadeia/comprimento ideal).

que realizam 10 conexões.

De fato, identifica-se uma correlação direta entre a conectividade de um sítio da rede e o correspondente tamanho do segmento conjugado como apresentamos na figura 4.9-(b). Em termos da linguagem da teoria de redes complexas estes sítios preservam característica de hubs, 


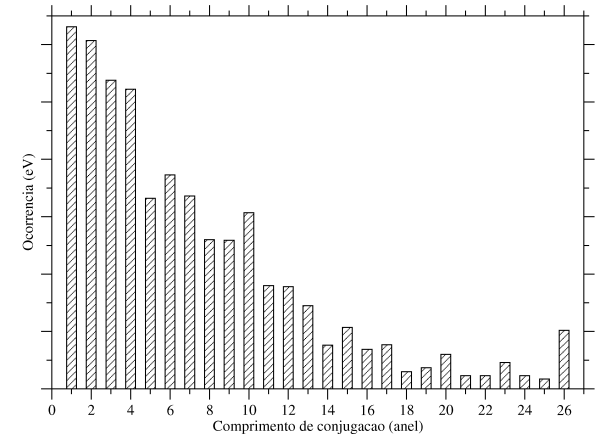

(a)

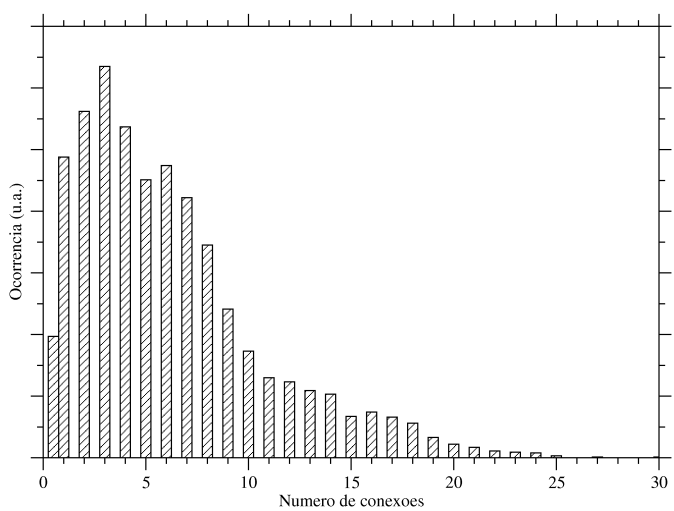

(c)
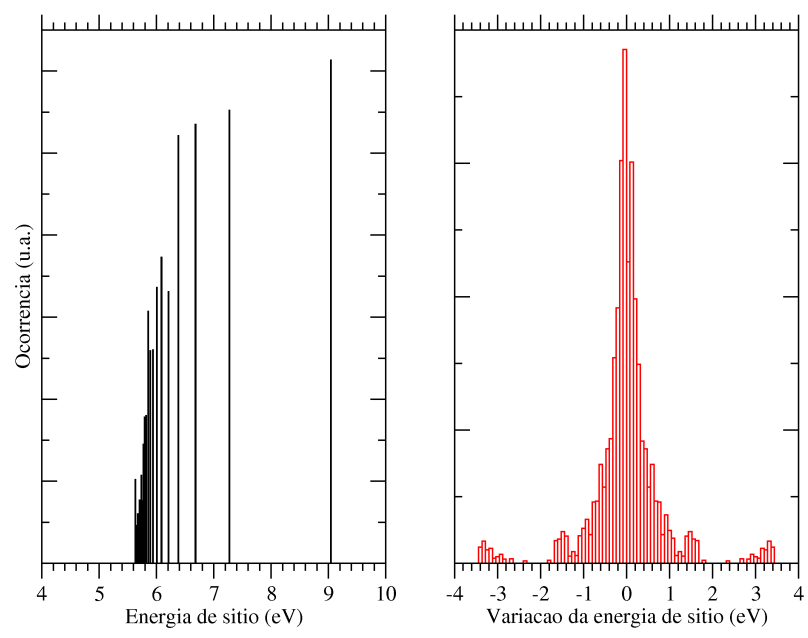

(b)

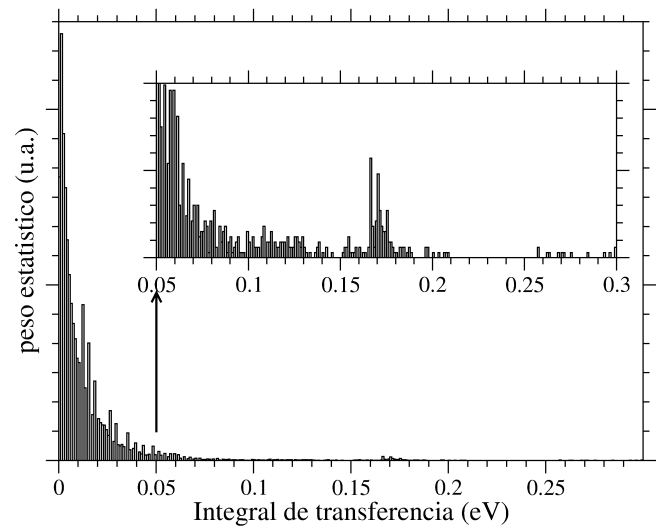

(d)

Figura 4.8: Distribuições estatísticas para as 37 imagens selecionadas da simulação do amorfo de $P_{26} V_{25}$. (a) Comprimento de conjugação dos sítios; (b) Energias de sítio $\epsilon_{i j}$ (à esquerda), e diferenças de energias de sítios conectados, $\Delta \epsilon_{i j}$ (à direita); (c) Número de conexões por sítio da rede topológica; (b) Integrais de transferência.

ou seja pontos da rede que realizam muitas conexões [80], sendo que, em geral, esses nós têm grande importância no comportamento global da rede.

A ocupação de sítios longos e de alta conectividade pode favorecer o aumento das velocidades dos portadores, na medida em que mais canais estariam disponíveis para migração de buracos, estando, entretanto, ainda dependentes das direcionalidades das conexões de hopping. Esses sítios, entretanto, apresentam baixa energia se comparada com sítios de baixa conjugação (2 


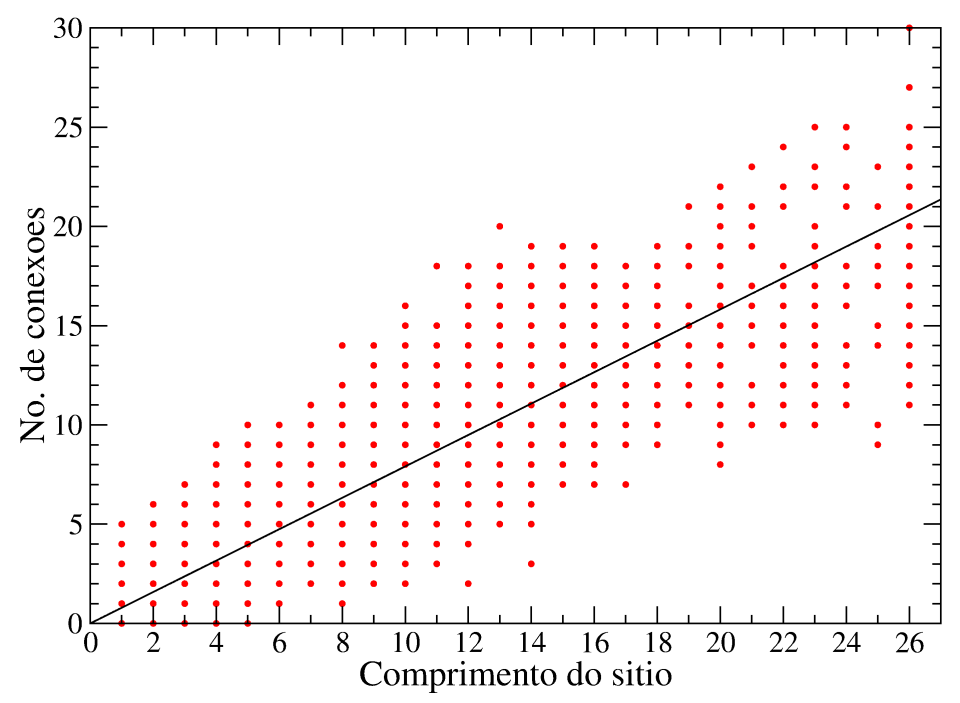

Figura 4.9: Gráfico da conectividade como função do comprimento de conjugação do sítio, calculado para todas as 37 imagens analisadas. Uma correlação linear é obtida, o coeficiente angular do ajuste linear é de 0.79 (erro no ajuste por mínimos quadrados de $0.4 \%$ ).

ou 1), e, portanto, concentram a carga para campos baixos, sendo a taxa de saída reduzida por conta da barreira energética.

A migração de portadores é fortemente dependente da intensidade do campo externo, conforme visto no sistema amorfo de $P_{3} V_{2}$, bem como de sua direção em sistemas não isotrópicos como o cristal de $P_{5} V_{4}$. Além de amorfos, esses sistemas de cadeias longas apresentam características morfológicas locais não uniformes, e, dessa forma, o surgimento de armadilhas de buracos torna-se possível.

No que segue abordamos a simulação das curvas de mobilidade utilizando uma ocupação de cerca de $4 \times 10^{18} \mathrm{e} / \mathrm{cm}^{3}$. Na figura 4.10, apresentamos a distribuição das ocupações para uma imagem particular em termos das energias de sítio para três valores de campo elétrico aplicado na direção $\hat{x}, 10^{4} \mathrm{~V} / \mathrm{cm}(\sim 10 \mathrm{~V}), 10^{6} \mathrm{~V} / \mathrm{cm}(\sim 100 \mathrm{~V})$ e $4 \times 10^{4} \mathrm{~V} / \mathrm{cm}(\sim 400 \mathrm{~V})$, e a campo nulo (reta contínua). Como se vê a campo nulo, e também campo baixo $\left(10^{4} \mathrm{~V} / \mathrm{cm}\right)$, as cargas se acumulam nos sítios de mais baixa energia (sítios longos). À medida em que o campo elétrico é elevado essa tendência é quebrada, e sítios de maior energia, dispostos em posição preferencial com ligações mais alinhadas ao campo, passam a ser ocupados, levando à concentração de portadores em sítios menos favoráveis do ponto de vista energético. 


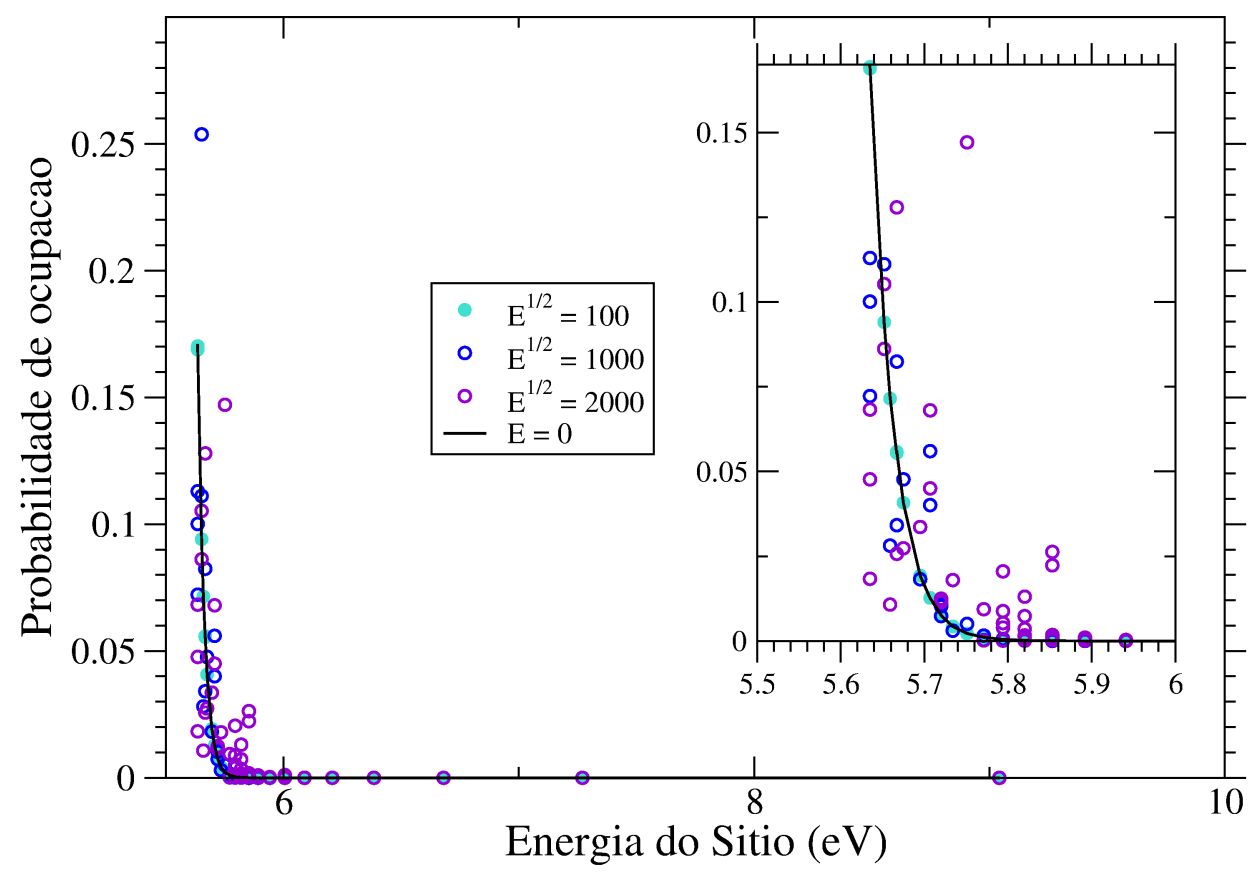

Figura 4.10: Distribuição das ocupações para uma imagem particular do sistema $P_{26} V_{25}$ em termos das energias de sítio para o campo elétrico aplicado na direção $\hat{x}, 10^{4} \mathrm{~V} / \mathrm{cm}, 10^{6} \mathrm{~V} / \mathrm{cm}$ e $4 \times 10^{4} \mathrm{~V} / \mathrm{cm}$. A linha contínua corresponde ao resultado obtido a campo nulo.

Dessa maneira, com a promoção de elétrons a sítios menores, que têm, em geral, menor conectividade, conforme demonstrado anteriormente, pode ocorrer potencial redução da velocidade de migração. Ou seja, o desequilíbrio da ocupação da rede causado pelo campo elétrico externo, pode levar a efeitos de limitação da corrente. Esse efeito é identificado nas curvas de mobilidade resultantes, apresentadas na figura 4.11, onde notamos ocorrer a saturação da mobilidade indicando que a velocidade efetiva de saída dos elétrons dos sítios ocupados cresce de forma aproximadamente linear com o campo $E$. A isotropia do sistema nas direções $\hat{y}$ e $\hat{z}$ revela-se na concordância global entre as curvas de mobilidade para campos externos aplicados nas diferentes direções.

Convém notar que no regime de campo elétrico muito baixo, temos a migração dos portadores guiada pela diferença entre energias de sítio, assim o fluxo de portadores pode se dar, dependendo do arranjo local dos sítios, até mesmo em oposição a direção do campo elétrico. Pela definição de velocidade que utilizamos as taxas de movimento em oposição ao campo assumem valores negativos, e, assim, é possível que o total dessas contribuições negativas seja 


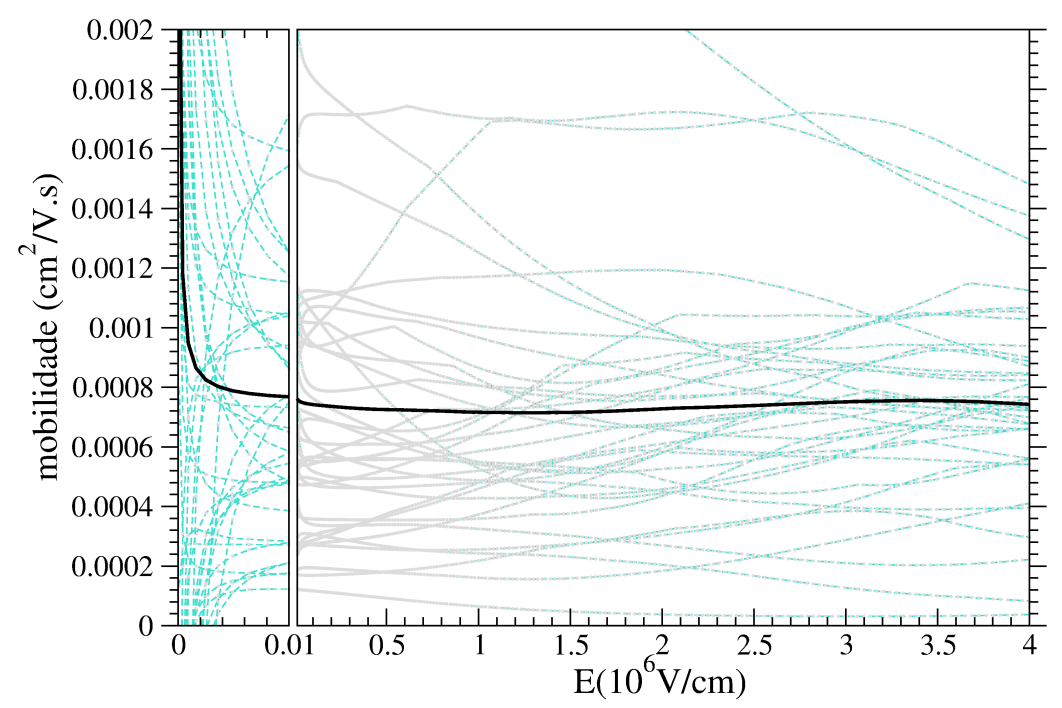

(a)

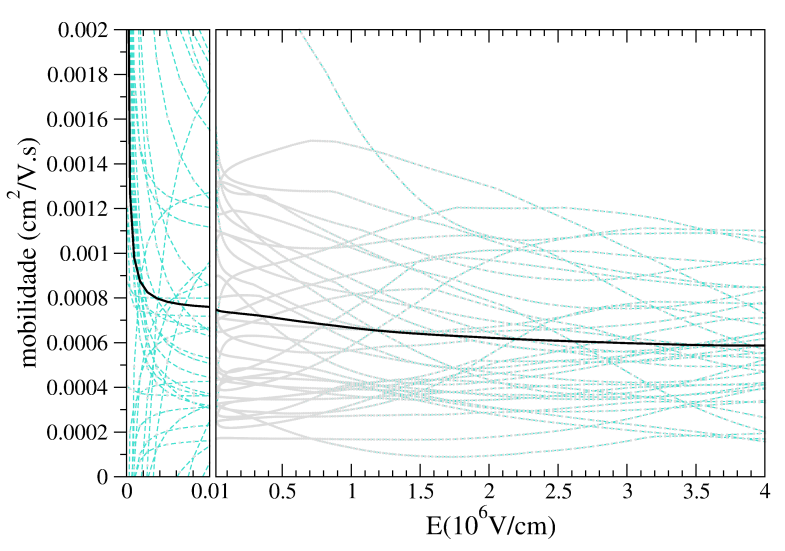

(b)

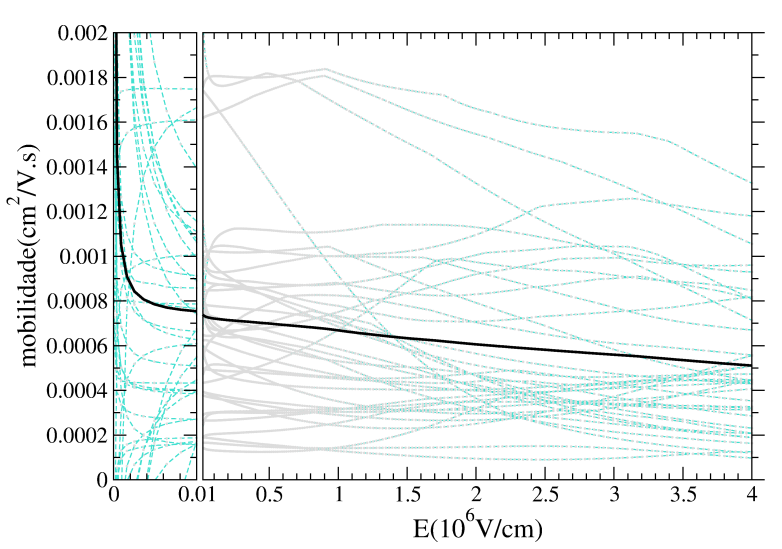

(c)

Figura 4.11: Curvas de mobilidade calculadas para 37 imagens do sistema amorfo de $P_{26} V_{25}$ a $300 \mathrm{~K}$, o intervalo entre duas imagens consecutivas é $0.5 \mathrm{ps}$. Estão representados os pontos definidos pelas simulações individuais e a curva média na linha contínua. Campo aplicado em: (a) direção $\hat{x}$; (b) direção $\hat{y}$; (c) direção $\hat{z}$.

superior às componentes positivas, o que se vê para curvas de imagens específicas. O crescimento de uma curva de mobilidade particular para campos baixos se deve ao fato de que ainda que a velocidade dos portadores decresça com o decréscimo do campo, esta queda se dá mais lentamente que a queda do campo levando ao comportamento observado.

O conjunto de curvas de mobilidade da figura 4.11 obtidas, entretanto, revela existir notável 
sensibilidade da curva de mobilidade com respeito às flutuações estruturais da rede ocorridas ao longo da dinâmica térmica. A possibilidade de criação de redes de conectividades completamente distintas pela indução natural das quebras de conjugação nas cadeias, dá origem a modificações instantâneas bastante pronunciadas.

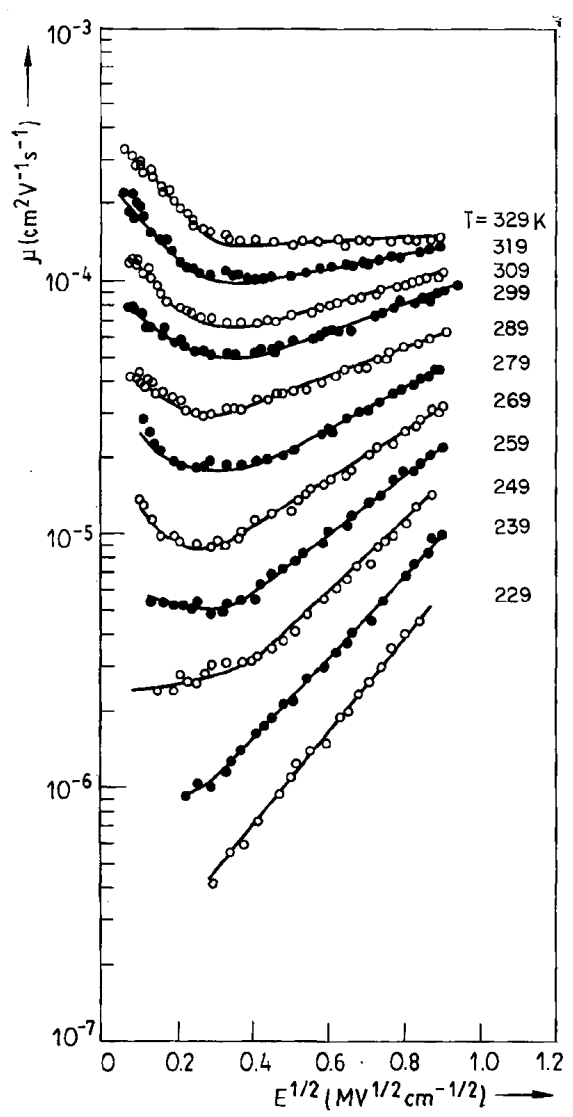

Figura 4.12: Mobilidade de buracos em TAPC/policarbonato versus $E^{1 / 2}$, paramétrico na temperatura $[13,81]$

Assim, fica claro em nosso trabalho a necessidade da inclusão dos efeitos de variação térmica da morfologia do sistema conjuntamente à modelagem do transporte dos portadores, algo que difere dos modelos usuais, quando a temperatura associada à cinética dos portadores é abordada como parâmetro independente da estrutura de níveis e da topologia da rede.

Focalizamos assim as curvas obtidas com a média das imagens, em que vemos o comportamento de queda inicial e posterior quase-constância de mobilidade com o campo; comparamos 
agora com o resultado experimental de Bässler [13] na figura 4.12. Vemos a mudança nítida do comportamento de Poole-Frenkel, a baixas temperaturas, para o comportamento muito semelhante ao por nós obtido no caso de temperaturas próximas à ambiente, o que mostra a adequação de nossa proposta.

A análise da variação da ocupação dos sítios com a presença do campo elétrico externo, como observado para o sistema de $P_{3} V_{2}$, apresenta grande sensibilidade com a direção do campo. O conjunto das ocupações da rede é bastante dependente da orientação dos canais de hopping relativamente ao campo elétrico externo, conforme mostra a figura 4.13, da rede de conectividades de uma particular imagem extraída do conjunto de imagens em caráter ilustrativo. Assim como no amorfo de $P_{3} V_{2}$, vê-se que a migração para sítios de menor conectividade, distintos para cada direção de campo externo, é bastante comum e também dependente da particular imagem selecionada, mostrando a sensibilidade com respeito às flutuações na conformação da cadeia, e que podem induzir mudanças bruscas na estrutura resultante de sítios em que o sistema será mapeado.

Em linhas gerais podemos, assim, concluir com base nessas simulações que os sítios de grande comprimento conjugado concentram as cargas no regime de equilíbrio a campo nulo; com o aumento do campo os portadores podem migrar para sítios menores, superando a barreira de energia. Sítios de menor coordenação, por sua vez, acabam atuando como armadilhas dos portadores, explicando a saturação da mobilidade verificada em nosso modelo.

Ao simularmos este mesmo conjunto de imagens do sistema amorfo de $P_{26} V_{25}$, porém reduzindo os ângulos de quebra de conjugação a 50 e assim gerando uma rede de sítios menores e, portanto de mais baixa conectividade, conforme as figuras 4.14-(b) e (c), obtivemos o efeito de redução apreciável da mobilidade dos portadores (valores de saturação de cerca de $2 \times 10^{-5} \mathrm{~cm}^{2} /$ V.s, conforme apresentado na figura 4.14-(a).

Como consequência desta relação de uma rede mais "granulada" (ou seja com mais sítios) e consequentemente com a distribuição de conectividade contraída para faixas mais baixas, podemos inferir que com o aumento da temperatura haverá a redução da mobilidade em concordância qualitativa com a literatura.

Por outro lado, agora com a mesma temperatura, mesmas imagens mas apenas reforçando o nível de desordem diagonal em relação à não-diagonal vemos em certa região de campo um 


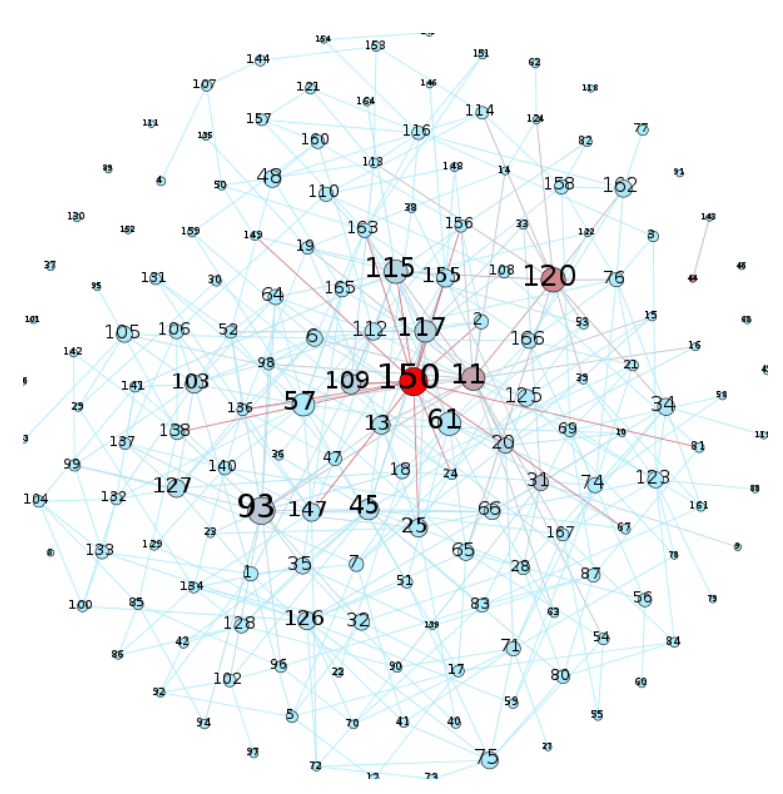

(a)

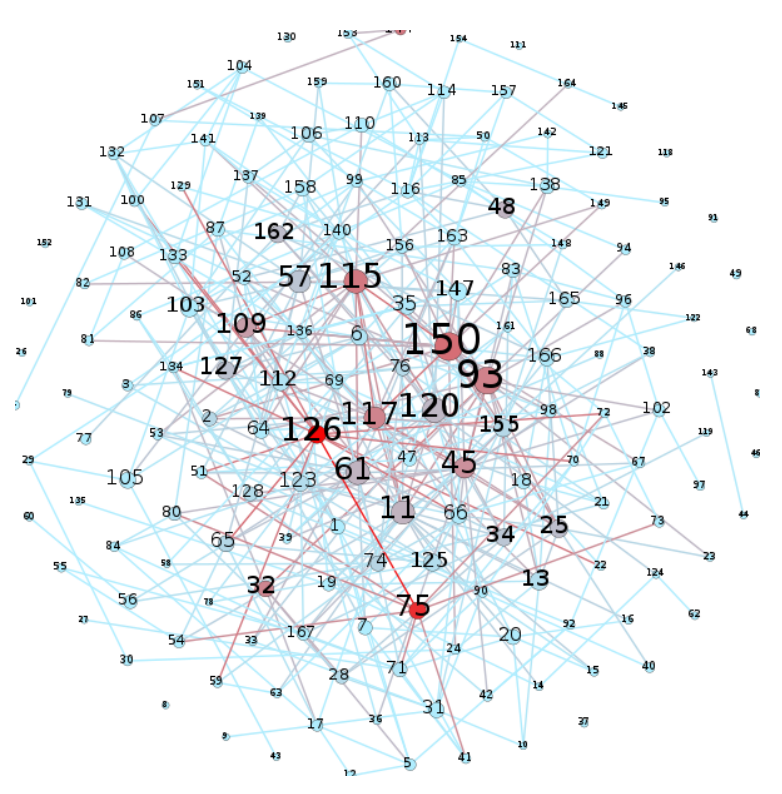

(b)

Figura 4.13: Redes topológicas do sistema amorfo analisado, 300K. A carga final obtida para um campo elétrico externo de intensidade de $4 \times 10^{6} \mathrm{~V} / \mathrm{cm}$ é mapeada em cores e o comprimento conjugado está representado em termos dos raios das circunferências correspondentes a cada sítio para: (a) campo aplicado na direção $\hat{y}$; (b) campo aplicado na direção $\hat{x}$.

comportamento crescente de moblidade, em acordo com a precisão de Bässler.

Por fim, para a aplicação do campo elétrico na direção - $\hat{x}$, modelamos o transporte utilizando diferentes valores de concentração de carga $q_{A}=4.11 \times 10^{17}, q_{B}=2.05 \times 10^{18}$, $q_{C}=4.11 \times 10^{18}, q_{D}=2.05 \times 10^{19}, q_{E}=4.11 \times 10^{19} \mathrm{e} / \mathrm{cm}^{3}$. O resultado das simulações e a curva média são apresentados no gráfico da figura 4.15.

Como resultado, vemos que o comportamento da curva de mobilidade do sistema com respeito a variação da concentração de portadores mantém acordo qualitativo com resultados vindos da aplicação usual da metodologia da Equação Mestre (com uso da desordem gaussiana), ou seja, em ambos os casos a mobilidade aumenta com o aumento da concentração.

Fica claro, por meio da análise da figura 4.15, que parte da saturação da mobilidade atingida é superada na medida em que se aumenta a concentração de buracos no sistema, mas, no geral, de nosso modelo resultam taxas menores de crescimento. Novamente encontra-se grande flutuação para as curvas de mobilidade calculadas a partir das múltiplas imagens. 
(a)
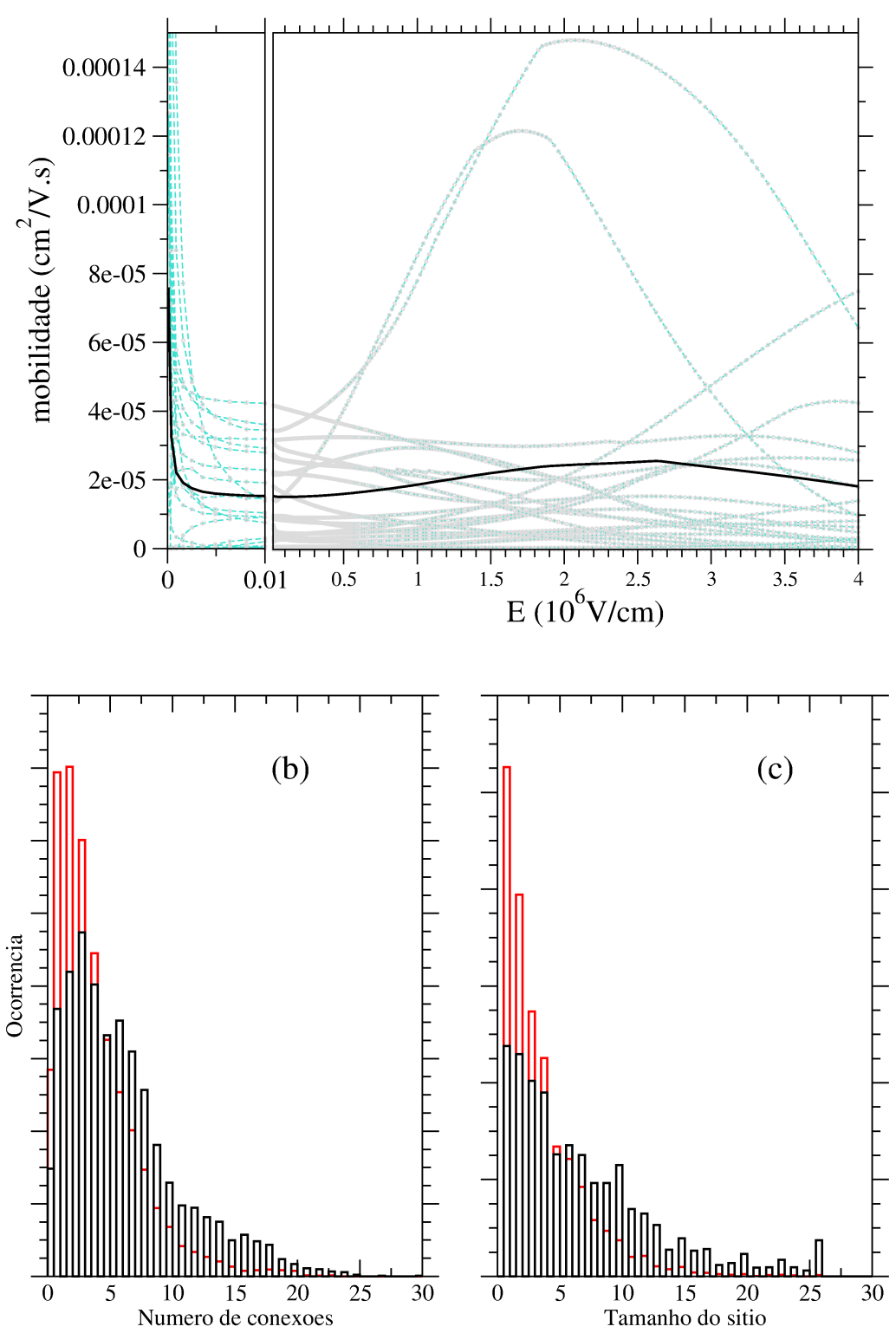

Figura 4.14: (a) Mobilidade como função do campo elétrico (aplicado na direção $\hat{x}$ ), obtido para o conjunto de imagens do sistema amorfo de $P_{26} V_{25}$ considerando a quebra de conjugação de $50^{\circ}$; na linha contínua a média para cada valor de campo. (b) Distribuição estatística do número de conexões dos sítios da imagem considerando o critério de quebra de conjugação em $50^{\circ}\left(60^{\circ}\right)$ em vermelho (preto); (c) Distribuição estatística do comprimento dos sítios da imagem considerando o critério de quebra de conjugação em $50^{\circ}\left(60^{\circ}\right)$ em vermelho (preto). 


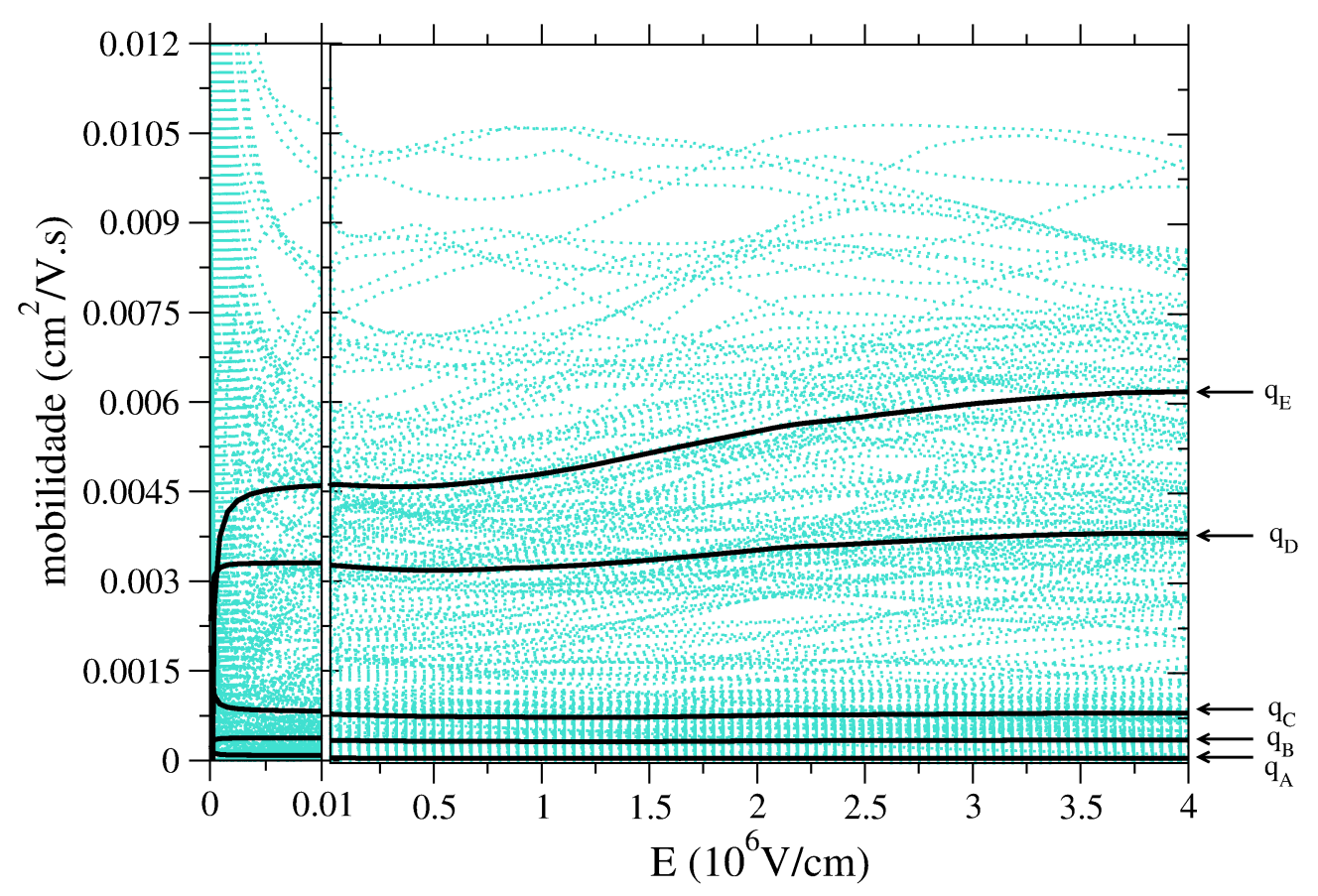

Figura 4.15: (a) Mobilidade como função do campo elétrico (aplicado na direção $\hat{x}$ ), obtido para o conjunto de imagens do sistema amorfo de $P_{26} V_{25}$ para diferentes valores de carga presentes na rede $q_{A}=4.11 \times 10^{17}, q_{B}=2.05 \times 10^{18}, q_{C}=4.11 \times 10^{18}, q_{D}=2.05 \times 10^{19}$, $q_{E}=4.11 \times 10^{19} \mathrm{e} / \mathrm{cm}^{3}$ (curvas médias indicadas no gráfico). O resultado das simulações individuais também são representados em azul.

Finalmente comparamos os resultados quantitativos para os valores de mobilidade obtidos por nós para esse filme modelado, e os valores experimentais de [82, 83], variando entre $10^{-5}$ $7,0 \times 10^{-4} \mathrm{~cm}^{2} / V s$ e medidas em temperatura ambiente.

Notamos a concordância bastante razoável, mesmo sendo nossos resultados referentes a um sistema-modelo de poucos oligômeros, de peso molecular muito baixo. Novamente, essa concordância mostra a adequação de nossa proposta. 


\section{Capítulo 5}

\section{Sumário e Conclusões}

Nesta tese de doutoramento abordamos o problema de transporte eletrônico em sistemas orgânicos conjugados a partir de um ponto de vista atomístico. Para tal foram empregadas diferentes metodologias teóricas: dinâmica molecular clássica (DMC) para simulação realista de filmes moleculares; dinâmica estocástica via Equação Mestre (EME) para simulação do transporte de buracos; e cálculos de primeiros princípios para obtenção de parâmetros tanto para a DMC, quanto para a EME. Nosso modelamento atomístico difere dos usualmente assumidos para tratamento da EME, como por exemplo o modelo de desordem gaussiana (GDM).

Após estudos com o campo de forças aberto Universal (Universal Force Field UFF), percebemos a necessidade de reparametrização de energias não ligadas (Coulomb e potencial de Lennard-Jones). Adotamos uma metodologia coerente para os dois termos, utilizando parâmetros calculados através da Teoria do Funcional da Densidade: as cargas atômicas foram calculadas pelo método de Hirshfeld e os coeficientes do potencial de Lennard-Jones $C_{6}$ e $C_{12}$ foram ajustados a partir do método de Tkatchenko e Scheffler. A adequação do campo foi baseada em parâmetros experimentais estruturais de cristais oligoméricos de fenilenos e fenilenos vinilenos, incluindo módulos de volume de forma que a boa descrição dos sistemas cristalinos permite que tratemos de sistemas mais complexos.

Para a modelagem pela EME também foram empregadas metodologias de primeiros princípios para obtenção dos parâmetros. O transporte eletrônico em tais sistemas ocorre via "hopping" e se dá pelo tunelamento entre estados moleculares localizados. O "sítio" localizado foi definido a partir das distorções estruturais das cadeias: torções frontais e laterais entre anéis 
adjacentes, que interrompem a deslocalização eletrônica do mais alto orbital ocupado (HOMO) e que, portanto, restrinjem o transporte de buracos ao longo da cadeia. Usamos o método Hartree-Fock para inferir valores limites para a quebra de conjugação em uma determinada cadeia, enquanto a energia de sítio foi parametrizada a partir resultados teóricos para o potencial de ionização de cadeias finitas curtas, obtidos através de teoria de perturbação de muitos corpos.

Finalmente, as taxas de hopping entre sítios foram parametrizadas em termos da posição e orientação relativa entre anéis de fenil, usando como base cálculos de estrutura eletrônica DFT que realizamos para cadeias de poli-para-fenileno-vinileno (PPV) em cristais com simetria herring-bone e $\pi$-stack ou seja, trazendo o efeito local do ambiente condensado. A partir do mapeamento de taxas, geramos uma rede de conectividade dos canais entre sítios onde pode ocorrer o salto dos portadores.

As características do procedimento desenvolvido foram testadas pela simulação de dois casos modelo admitindo todas as energias de sítio de um mesmo sistema iguais. No primeiro sistema temos a situação ideal da supercélula de uma supercélula cristalina de $P_{5} V_{4}$ e no segundo caso, acrescentamos desordem posicional gerando diversas imagens de um filme amorfo de $P_{3} V_{2}$. A prevalência da desordem não-diagonal traz os resultados esperados de redução de mobilidade com campo, até atingir um patamar constante. $\mathrm{No}_{3} \mathrm{~V}_{2}$ amorfo, que apresenta real desordem estrutural e portanto desordem na conectividade entre sítios, notamos que podemos associar esse comportamento ao armadilhamento de portadores em sítios específicos, sendo esses ditados pelo alinhamento característico dos canais de hopping com respeito ao campo externo.

Para o $\mathrm{P}_{26} \mathrm{~V}_{25}$ amorfo temos desordem associada a todos os parâmetros do modelo. É especialmente importante o resultado que concerne ao espectro de energias de sítio, que revelouse distinto do modelo GDM usualmente admitido. De origem totalmente estrutural, temos o efeito de correlação direta entre o comprimento de conjugação de um sítio e o número de conexões. Os sítios longos de menor energia são preferencialmente ocupados a baixos campos e a ocupação de sítios de maior energia se inicia com o aumento do campo elétrico, como previsto. Como, entretanto, os sítios de maior energia estão associados a menores comprimentos de conjugação, e, portanto, em média menor conectividade, como resultado tem-se a saturação da mobilidade, no nosso modelo calculada ser da ordem de $8 \times 10^{-4} \mathrm{~cm}^{2} / \mathrm{Vs}$. Um teste simulando 
redução de comprimentos de conjugação, para o mesmo filme, leva à redução concomitante da mobilidade para valores da ordem de $2 \times 10^{-5} \mathrm{~cm}^{2} / \mathrm{Vs}$, em virtude da consequente redução da conectividade média de cada sítio. Esse comportamento nos permite prever redução da mobilidade com o aumento da temperatura, já que as torções entre anéis devem ser maiores. Obtivemos finalmente crescimento da mobilidade com o aumento da concentração de portadores, devido ao preenchimento de armadilhas.

Concluindo, nosso modelo se comporta muito bem quanto aos testes para sistemas-modelo, a apresenta resultados para sistemas realísticos que permitem correlação clara com a estrutura morfológica do filme, além de mostrar concordância qualitativa e quantitativa com os resultados experimentais relevantes.

Como desenvolvimento futuro, prevemos o detalhamento da desordem energética, incorporando o efeito do ambiente condensado (além do comprimento de conjugação); e a possibilidade de simulação de sistemas com maior número de oligômeros, em tempos de simulação mais longos. 


\section{Apêndice A}

\section{Detalhes de Cálculos Quânticos}

Independentes do Hamiltoniano usado podemos sempre adotar um conjunto de bases, do tipo local ou expandidos em ondas planas. Da mesma forma o método de cálculo de cargas atômicas de Hirshfeld também pode ser obtido por meio de função de Onda ou da densidade eletrônica. Descrevemos a seguir alguns detalhes usados em nossos cálculos realcioandos aos tipos de base e carga adotados.

\section{A.1 Bases locais}

O orbital Molecular pode ser expandido como uma combinação Linear. Na situação em que a expansão é feita em termos de funções centradas no átomos temos uma combinação linear de orbitais atômicos (base local). Cada função de base pode ainda ser expandida em termos de funções gaussianas. Assim, se considerarmos a base 6-31G, cada função de base associada a uma função de caroço é expandido por 6 gaussianas primitivas. Os orbitais de valência são duplicados (double zeta), sendo um deles expandido em 3 gaussianas e o outro em 1 gaussiana. Existem ainda situações em que a distribuição de carga é ligeiramente deslocada da região central o que permite uma possível polarização do orbital atômico. O conjunto de base polarizado usa gaussianas primitivas com maiores valores de momento angular l. Assim o conjunto de bases de Polarização 6-31G(d,p) adiciona gaussianas primitivas do tipo $d$ a elementos pesados e um grupo de gaussianas primitivas do tipo $p$ para cada átomo de hidrogênio. Já o conjunto aug-cc- 
pVDZ (Correlation-Consistence polarized valence double zeta) desenvolvido por Dunning [43] consegue melhorar os resultados HF e MP2 corrigindo erros relacionados a energia de correlação. O prefixo aug implica que o conjunto cc-pVDZ é aumentado por uma série de funções difusas $s, p$ e $d$.

\section{A.2 Ondas Planas}

Para um sistema periódico, temos que a energia potencial tem a propriedade de carregar a periodicidade da rede e a função de onda pode ser representada pela soma:

$$
\psi_{k}=\sum_{\vec{G}} C_{\vec{k}+\vec{G}} e^{i(\vec{k}+\vec{G}) \cdot \vec{r}}
$$

Quando conjunto de base é expandido em Ondas Planas (PW) a equação de Schrödinger pode ser escrita em termos do vetor de onda $\vec{k}$ e do vetor de translação da rede recíproca $\vec{G}$ na forma matricial:

$$
\left[-\frac{\hbar}{2 m}(\vec{k}+\vec{G})^{2}+\epsilon\right] C_{\vec{k}+\vec{G}}-\sum_{\overrightarrow{G^{\prime}}} V_{G-G^{\prime}} C_{\vec{k}+\vec{G}^{\prime}}=0
$$

Em que $V_{G-G^{\prime}}$ é a componente de Fourrier do Potencial cristalino e $C_{\vec{k}+\vec{G}^{\prime}}$ representam os coeficientes da expansão. Em geral, a quantidade de ondas planas é limitada pelo valor da energia cinética $|\vec{G}|^{2}$ através de um raio de corte que limita o valor de $\vec{G}$ na expansão da Função de Onda $\psi_{k}$.

\section{A.3 Pseudopotencial}

Através do método de Pseudopotenciais conseguimos eliminar a necessidade de incluir os orbitais mais internos dos átomos (de caroço). Neste caso os elétrons de caroço são substituídos por uma função potencial conveniente, e somente os elétrons de valência são tratados explicitamente. Segundo Vanderbilt [52] a construção de um novo Pseudopotencial pode ser descrita em três estágios: 
1 - O autovalores obtidos para os estados de valência atômicos devem ser idênticos aos autovalores obtidos com os pseudopotencial. Alé disso, as autofunções obtidas com o pseudopotencial devem ser iguais as autofunções do cálulo "all electron" (AE) para $r>R_{C}$, em $R_{C}$ é o raio de corte. Uma autofunção $\mathrm{AE}$ de momento angular $l m$ definidos é solução da equação de Schrödinger.

2 - A derivada logartimica do pseudopotencial deve tender a função de onda AE, para $r>R_{C}$.

3 - As densidades de carga obtidas, de 0 até $r, r>R_{C}$, com o pseudopotencial devem ser idênticas as densidades de carga da solução AE. 


\section{Referências Bibliográficas}

[1] W. P. Su, J. R. Schrieffer and A. J. Heeger. Phys. Rev. Lett. 42, 1698 (1979).

[2] J. H. Burroughes, D. D. C. Bradley, A. R. Brown, R. N. Marks, K. Mackay, R. H. Friend, P. L. Burns and A. B. Holmes. Nature. 347, 539 (1990).

[3] M. Wang and X. Wang. Polymer. 49, 1587 (2008).

[4] R. H. Friend, R. W. Gymer, A. B. Holmes, J. H. Burroughes, R. N. Marks, C. Taliani, D. D. C. Bradley, D. A. Dos Santos, J. L. Bredas, M. Logdlund and, W. R. Salaneck. Nature. 397, 121 (1999).

[5] P. K. H. Ho, J. Kim, J. H. Burroughes, H. Becker, S. F. Y. Li, T. M. Brow, F.Cacialli and R. H. Friend. Nature. 404, 481 (2000).

[6] L. G. Wang, H. W. Zhang, X. L. Tang and C. H. Mu. Eur. Phys. J. B. 74, 1 (2010).

[7] W. Brutting. Physics of organics semiconductors. Wiley-VCH (2005).

[8] X. Feng, V. Marcon, W. Pisula, M. R. Hansen, J. Kirkpatrick, F. Grozema, D. Andrienko, K. Kremer and K. Mullen. Nature Materials. 8, 421 (2009).

[9] S. M. Rezende. Materiais e Dispositivos Eletrônicos. São Paulo, Editora Livraria da Física. $2^{\text {o }}$ Edição (2004).

[10] N. F. Mott and E. A. Davis. Electronic Processes in Non-Crystalline Materials. Clarendon, Oxford. Second Edition (1979).

[11] P. W. Anderson. Phys. Rev. 109, 1492 (1958). 
[12] L. M. M. Jorge and M. J. Caldas. Synth. Met. 159, 2222 (2009).

[13] H. Bässler. Phys. Stat. Sol. 175, 15 (1993).

[14] Z. G. Yu, D. L. Smith, A. Saxena, R. L. Martin and A. R. Bishop. Phys. Rev. B. 63, $085202(2001)$.

[15] Z. G. Yu, D. L. Smith, A. Saxena, R. L. Martin and A. R. Bishop. Phys. Rev. Lett. 84, $721(1999)$.

[16] J. C. Dyre and T. B. Schroder. Rev. Mod. Phys. 72, 873 (2000).

[17] J. Kirkpatrick, V. Marcon, J. Nelson, K. Kremer and D. Andrienko. Phys. Rev. Lett. 98, $227402(2007)$.

[18] J. Kirkpatrick, V. Marcon, K. Kremer, J. Nelson and D. Andrienko. J. Chem. Phys. 129, 094506 (2008).

[19] M. M. Garcia. Modelos para o transporte eletrônico em filmes orgânicos desordenados, IFUSP. Dissertação de Mestrado. (2006).

[20] J. M. Pinheiro Junior, M. J. Caldas, V. Blum, P. Rinke and M. Scheffler. a ser publicado $\mathrm{xx}, \mathrm{x}(\mathrm{xx})$.

[21] A. Ferretti, A. Ruini, E. Molinari and M. J. Caldas. Phys. Rev. Lett. 90, 0866401 (2003).

[22] A. Ferretti, A. Ruini, G. Bussi, E. Molinari and M. J. Caldas. Phys. Rev. B. 69, 205205 (2004).

[23] A. K. Rappé, C. J. Casewit, K. S. Colwell, W. A. Goddard III and W. M. Skiff. J. Am. Chem. Soc. 114, 10024 (1992).

[24] W. F. Pasveer, J. Cottaar, P. A. Bobbert and M. A. J. Michels. Synth. Met. 152, 157 (2005).

[25] W. F. Pasveer, J. Cottaar, C. Tanase, R. Coehoorn, P. A. Bobbert, P. W. M. Blom, D. M. de Leeuw and M. A. J. Michels. Phys. Rev. Lett. 94, 206601 (2005). 
[26] R. A. Marcus. Annu. Rev. Phys. Chem. 15, 155 (1964).

[27] A. Miller and E. Abrahams. Phys. Rev. 120, 745 (1960).

[28] S. Westenhoff, W. J. D. Beenken, A. Yartsev and N. C. Greenham. J. Chem. Phys. 125, $154903(2006)$.

[29] C. J. Finder, M. G. Newton and N. L. Allinger. Acta Cryst. B. 30, 411 (1974).

[30] T. Granier, E. L. Thomas, D. R. Gagnon, F. E. Karasz and R. W. Lenz. J. Pol. Sci. B: Pol. Phys. 24, 2793 (1986).

[31] D. Chen, M. J. Winokur, M. A. Masset and F. E. Karasz. Polymer. 33, 3116 (1992).

[32] S. P. Kwasniewski, L. Claes, J. P. François and M. S. Deleuze. J. Chem. Phys. 118, 7823 (2003).

[33] R. Giro, M. J. Caldas and D. S. Galvão. Int. J. Quantum Chem. 103, 588 (2005).

[34] L. Claes, S. Kwasniewski, J. P. François and M. S. Deleuze. J. Mol. Struct. (Theochem). 549, 63 (2001).

[35] G. Zheng, S. J. Clark, S. Brand and R. A. Abram. J. Phys.: Condens. Matter. 16, 8609 (2004).

[36] R. B. Capaz and M. J. Caldas. Phys. Rev. B. 67, 205205-1 (2003).

[37] R. B. Capaz and M. J. Caldas. J. Mol. Struct. (Theochem). 464, 31 (1999).

[38] W. J. Hehre, R. Ditchfield and J. A. Pople. J. Chem. Phys. 56, 2257 (1972).

[39] R. Ditchfield, W. J. Hehre and J. A. Pople. J. Chem. Phys. 54, 3902 (1971).

[40] M. J. S. Dewar et al. J. Am. Chem. Soc. 107, 3902 (1985).

[41] E. R. Davidson and D. Feller. Chem. Rev. 86, 681 (1986).

[42] T. H. Dunning Jr. J. Chem. Phys. 90, 1007 (1989).

[43] R. A. Kendall et al. J. Chem. Phys. 96, 6796 (1992). 
[44] M. Traetteberg, E. B. Frantsen and A. Hoekstra. J. Mol. Struct. 26, 57 (1975).

[45] A. Karpfen, C. H. Choi and M. Kertesz. J. Phys. Chem. 101, 7426 (1997).

[46] O. Lhost and J. L. Brédas. J. Chem. Phys. 96, 5279 (1991).

[47] P. Hohenberg and W. Kohn. Phys. Rev. 136, 864 (1964).

[48] W. Kohn and L. J. Sham. Phys. Rev. 140, A1133 (1965).

[49] J. P. Perdew and A. Zunger. Phys. Rev. B. 23, 5048 (1981).

[50] D. M. Ceperley and B. J. Alder. Phys. Rev. Lett. 45, 566 (1980).

[51] J. P. Perdew, K. Burke and M. Ernzerhof. Phys. Rev. Lett. 77, 3865 (1996).

[52] D. Vanderbilt. Phys. Rev. B. 41, 7892 (1990).

[53] P. Gianozzi et al. http://www.quantum-espresso.org. (1985).

[54] J. D. M. Viana, A. Fazzio and S. Canuto. Teoria Quântica de Móleculas e Sólidos: Simulação Computacional. Livraria da Física (2004).

[55] R. S. Mulliken. J. Chem. Phys. 23, 18 (1955).

[56] P. Löwdin. J. Chem. Phys. 18, 365 (1950).

[57] F. L. Hirshfeld. Theor. Chem. Acc. 44, 129 (1977).

[58] Cerius2. Accelrys Inc. (2001).

[59] A. K. Rappé and W. A. Goddard. J. Phys. Chem. 95, 3358 (1991).

[60] M. P. Allen and D. J. Tildesley. Ab Initio Computer Simulation of Liquids (1990).

[61] A. K. Rappé and C. J. Casewit. Molecular Mechanics across Chemistry. University Science Books. (1996).

[62] H. C. Andersen. J. Chem. Phys. 72, 2384 (1980). 
[63] H. J. C. Berendsen, J. P. M. Postma, W. F. Van Gunsteren, A. DiNola and J. R. Haak. J. Chem. Phys. 81, 3684 (1984).

[64] A. Ruini, A. Ferretti, G. Bussi, E. Molinari and M. J. Caldas. Semicond. Sci. Technol. 19, $362(2004)$.

[65] C. Y. Yang, F. Hide, M. A. Díaz-García, A. J. Heeger and Y. Cao. Polymer. 39, 2299 (1998).

[66] S. H. Chen, A. C. Su, S. R. Han, S. A.Chen and Y. Z. Lee. Macromolec. 37, 181 (2004).

[67] R. Resel, R. Kiebooms, D. Vanderzande and F. Stelzer. Am. Chem. Soc. 132, 433 (2001).

[68] D. Chen, M. J. Winokur, M. A. Masse and F. E. Karasz. Phys. Rev. B. 41, 6759 (1990).

[69] A. Tkatchenko and M. Scheffler. Phys. Rev. Lett. 102, 073005 (2009).

[70] O. A. V. Lilienfeld and A. Tkatchenko. unpublished $\mathrm{xx}(\mathrm{x}), \mathrm{xx}(\mathrm{xxx})$.

[71] M. J. Allen, V. C. Tung and R. B. Kaner. Chem. Rev. xxx, A (2009).

[72] G. Charbonneau and Y. Delugeard. Acta Cryst. B. 32, 1420 (1976).

[73] P. J. L. Baudour and H. Cailleau. Acta Cryst. B. 33, 1773 (1977).

[74] J. L. Baudour, Y. Delugeard and P. Rivet. Acta Cryst. B. 34, 526 (1978).

[75] C. Ambrosch-Draxl, J. A. Majewski, P. Vogl and Leising, G. Phys. Rev. B. 51, 9668 (1995).

[76] A. Mani, S. T. Selvan and K. L. Phani. J. Sol. St. Elec. 2, 242 (1998).

[77] A. Hoekstra, P. Meertens and A. Vos. Acta Cryst. B. 31, 2813 (1975).

[78] D. Hu, J. Yu, K. Wong, B. Bagchi, P. J. Rossky and P. F. Barbara. J. Am. Chem. Soc. 121, 5910 (1999).

[79] L. H. Spangler, R. V. Zee and T. S. Zwier. Phys. Rev. B. 32, 4060 (1985).

[80] Jon M. Kleinberg. Journal of ACM 42, 604 (1999). 
[81] P. M. Borsenberger, L. Pautmeier and H. Bässler. J. Chem. Phys. 94, 5447 (1991).

[82] E. Lebedev, Th. Dittrich, V. Petrova-Koch, S. Karg and W. Brütting. Appl. Phys. Lett. 71, 2686 (1997).

[83] H. M. Lee, D. K. Oh, C. H. Lee, C. E. Lee, D. W. Lee and J. Jin. Synth. Met. 119, 473 (2001). 